University of Louisville

ThinkIR: The University of Louisville's Institutional Repository

$12-2014$

\title{
An evaluation of a brief, theatre-based intervention for the prevention of adolescent cyberbulllying and suicide.
}

Kathryn Laurel Hopkins

University of Louisville

Follow this and additional works at: https://ir.library.louisville.edu/etd

Part of the Student Counseling and Personnel Services Commons

\section{Recommended Citation}

Hopkins, Kathryn Laurel, "An evaluation of a brief, theatre-based intervention for the prevention of adolescent cyberbulllying and suicide." (2014). Electronic Theses and Dissertations. Paper 1747.

https://doi.org/10.18297/etd/1747

This Doctoral Dissertation is brought to you for free and open access by ThinkIR: The University of Louisville's Institutional Repository. It has been accepted for inclusion in Electronic Theses and Dissertations by an authorized administrator of ThinkIR: The University of Louisville's Institutional Repository. This title appears here courtesy of the author, who has retained all other copyrights. For more information, please contact thinkir@louisville.edu. 


\title{
AN EVALUATION OF A BRIEF, THEATRE-BASED INTERVENTION FOR THE PREVENTION OF ADOLESCENT CYBERBULLLYING AND SUICIDE
}

\author{
By \\ Kathryn Laurel Hopkins \\ B.F.A. New York University, 2004 \\ M.Ed. University of Louisville, 2013

\begin{abstract}
A Dissertation
Submitted to the Faculty of the

College of Education and Human Development of the University of Louisville in Partial Fulfillment of the Requirements

for the Degree of
\end{abstract}

Doctor of Philosophy

Department of Counseling Psychology, Counseling, and College Student Personnel

University of Louisville

Louisville, Kentucky

December 2014 
Copyright 2014 by Kathryn Hopkins

All rights reserved 



\title{
AN EVALUATION OF A BRIEF, THEATRE-BASED INTERVENTION FOR THE PREVENTION OF ADOLESCENT CYBERBULLLYING AND SUICIDE
}

\author{
By \\ Kathryn Laurel Hopkins \\ B.F.A. New York University, 2004 \\ M.Ed. University of Louisville, 2013
}

A Dissertation Approved on

September 23, 2014

by the following Dissertation Committee:

Dr. Patrick Pössel

Dr. Jason Osborne

Dr. Eileen Estes

Dr. Marco Munoz 


\section{DEDICATION}

This Dissertation is dedicated to my children, June Apple and Wilder Max, both

born during this process. They serve as constant reminders of what is important and for whom all this work was for. 


\section{ACKNOWLEDGEMENTS}

This dissertation is made possible by the incredible support of my co-chairs, Drs. Patrick Pössel and Jason Osborne, along with my other committee members, Drs. Eileen Estes and Marco Munoz. I am eternally grateful for the help of my coders- Sara Keebler, Megan Manthos, Anne Taylor Wilson, and Johanna Strokoff. I also want to acknowledge the additional support I received from Drs. Nancy Cunningham and Patrick Hardesty, who helped to lay a foundation for this project, for which I am deeply thankful.

I also am indebted to my mentor and mother, Dr. Karen Graves, whose own passion for the lives of children inspired the same in me. Her support and encouragement throughout this process, from babysitting to reading and editing endless drafts of this dissertation made its completion possible.

Finally, I want to thank my husband, Amos Hopkins, who supported me on this journey from the start, and whose question, "When are you going to get your PhD?" over 8 years ago started this whole adventure. To say that I am grateful for him does not suffice. 


\begin{abstract}
AN EVALUATION OF A BRIEF, THEATRE-BASED INTERVENTION FOR THE PREVENTION OF ADOLESCENT CYBERBULLLYING AND SUICIDE
\end{abstract}

Kathryn Hopkins

September 23, 2014

Quality program evaluation investigates both the process and the outcomes of an intervention in order to accurately determine its effectiveness and impact. In the present study, the effectiveness of CHOICES, a brief, applied-theatre intervention that addresses cyberbullying and suicide was evaluated. The fidelity of implementation of the intervention was assessed to determine whether the delivery of CHOICES was consistent with the original goals of the program, as well as consistent across multiple deliveries. Investigation of the fidelity of implementation revealed that CHOICES was not implemented with high levels of fidelity. The study also determined whether exposure to CHOICES led to significant gains in students' knowledge of effective strategies to address cyberbullying and the warning signs of suicide, as well significant increases in students' ability to correctly identify the warning signs of suicide. This study also determined if exposure to the program led to significant increases in student willingness and confidence in their ability to apply 
newly acquired knowledge about cyberbullying and suicide. The analyses of the outcomes found no significant changes in student knowledge of effective strategies that address cyberbullying and suicide. No significant change was found in student confidence or willingness to intervene on behalf of a peer in a cyberbullying situation. No significant change was found in student confidence or willingness to intervene on behalf of a peer exhibiting the warning signs of suicide. 
TABLE OF CONTENTS

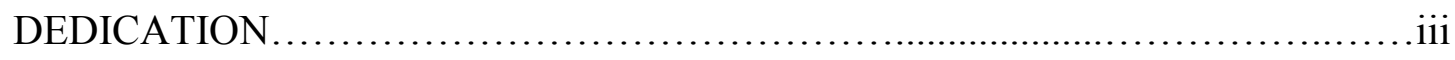

ACKNOWLEDGEMENTS ......................................................

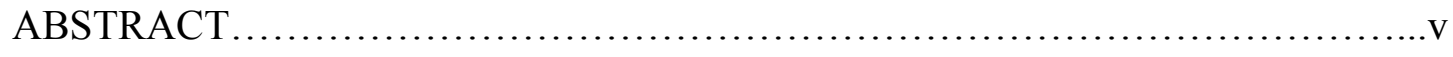

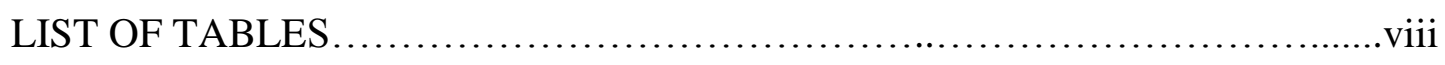

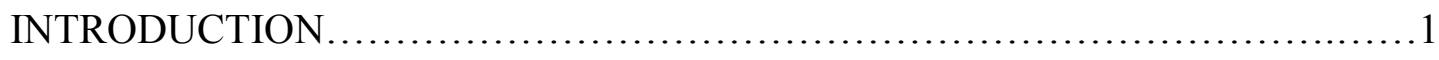

LITERATURE REVIEW .....................................................

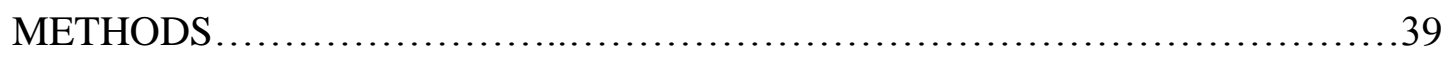

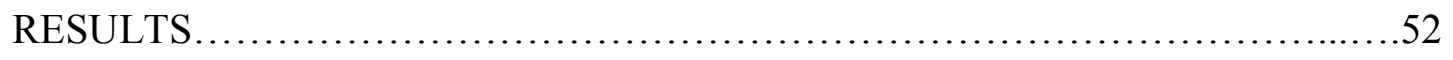

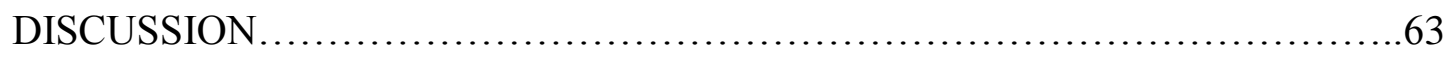

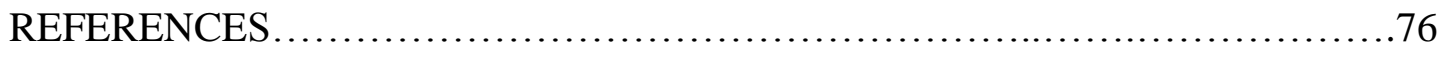

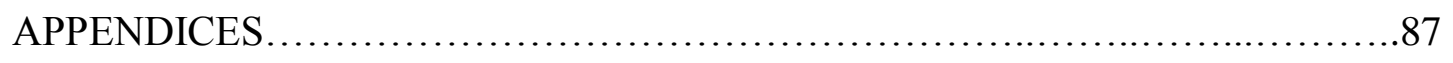

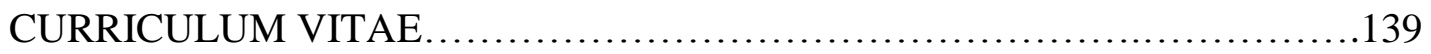




\section{LIST OF TABLES}

TABLE $\quad$ PAGE

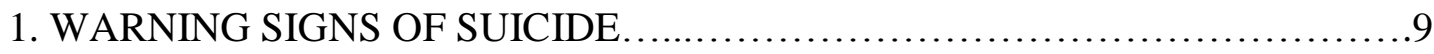

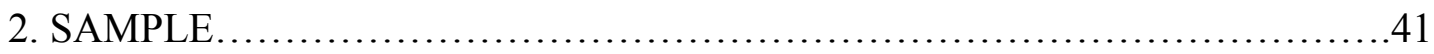

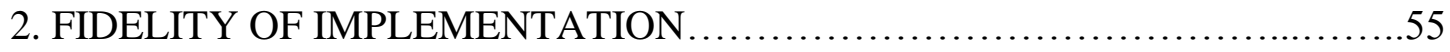

3. ADHERENCE, QUALITY, AND RESPONSIVENESS .......................56

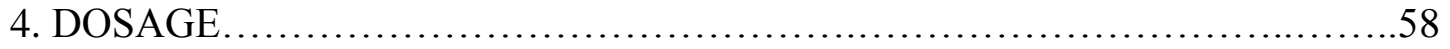

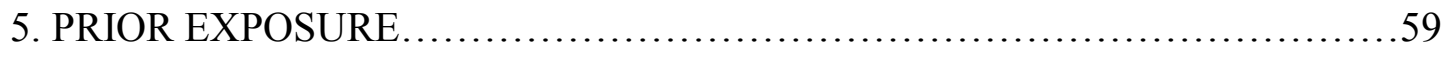

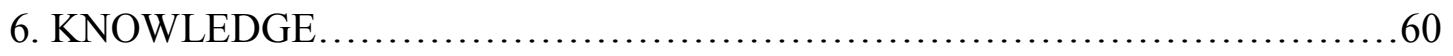

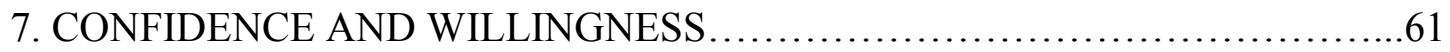




\section{CHAPTER I}

\section{INTRODUCTION}

The purpose of this study was to evaluate the effectiveness of a brief, schoolbased theatre intervention, CHOICES, developed to increase knowledge of effective strategies to address cyberbullying and suicide.

CHOICES was delivered in a large urban school district in a middle southern state. State laws mandate that school districts must provide all middle and high schools students with cyberbullying and online safety education, as well as suicide

prevention awareness information (Stanton, 2012). Cyberbullying and suicide remain significant health problems for children and adolescents aged 10-17 (CDC, 2012). Victims of cyberbullying are more likely to experience psychological disorders, such as depression and anxiety, than students who are not victims (Mishna et al., 2011). Adolescents with psychological disorders are nine times more at risk of suicide than adolescents without the presence of such distress (Bridge et al., 2006). Considering this, it is important that the most effective cyberbullying and suicide prevention programs be implemented in schools. In addition, it is essential that they be implemented with the highest level of fidelity, as varying levels of implementation can lead to varying levels of effectiveness (Orsini et al., 2012; O’Donnell, 2008; Mowbray et al., 2003). 
The cyberbullying strategies provided to participants in CHOICES include the Stop-Block-Tell approach, which encourages students who are experiencing cyberbullying to stop interacting and/or responding to the bully electronically or otherwise; block the bully using site specific blocking mechanisms, or software designed to block certain sites and users and; report the cyberbullying activity to a trusted adult, and if necessary an internet/cell phone provider and law enforcement. In a systematic review of prevention and intervention efforts that address cyberbullying, Mishna et al. (2011) found evidence that some Internet safety programs, including those using the Stop-Block-Tell approach, did show significant increases in students' knowledge of Internet safety. While the Stop-Block-Tell approach is commonly found in cyberbullying prevention materials provided to students (Lorenz \& Laanpere, 2012; Mishna et al., 2011; Hinduja \& Patchin, 2009; Diamandouros et al., 2008), the research on its efficacy is only beginning to emerge. School-based efforts to prevent suicide in adolescents have produced mixed results (Cross et al., 2011; Portzky \& van Heeringen, 2006; Shaffer \& Craft, 1999). The suicide prevention content provided in CHOICES is modeled after the Gatekeeper model of suicide prevention. Gatekeeper programs focus on the recognition of suicide warning signs and the referral to appropriate help (Brown et al., 2007). This model is increasingly used as a suicide prevention approach across settings, including schools (Isaac et al., 2009; Brown et al., 2007). Gatekeeper programs have been shown to significantly increase participant's perceived preparedness, self-evaluated knowledge, and lead to greater access to help for suicidal students (Wyman et al., 2008). Gatekeeper programs have also been shown to 
significantly increase participant's skills and attitudes towards suicide prevention (Cross et al., 2011; Freedenthal, 2010; Isaac et al., 2009). Shaffer and Craft found that the most beneficial intervention at the school level was directly screening students for predictors of suicide and referring them for help, if needed (1999). Although the popularity and support for screening approaches in schools are on the rise, psychoeducational, assembly-style programs, like the one involved in this study, continue to be the most common suicide prevention effort employed (Katz et al., 2013; Portzky \& van Heeringen, 2006).

CHOICES uses applied theatre techniques to engage students through roleplay and generation of possible strategies to address cyberbullying and suicide. Applied theatre interventions have been shown to be an effective method to involve students in the process of devising strategies to deal with peer aggression and bullying (Gourd \& Gourd, 2011; Burton, 2009; Baer \& Glasgow, 2008; Graves, Frabutt, \& Vigliano, 2007; Kiseal et al., 2006; Gervais, 2006; Belliveau, 2005). Couvillon and Ilieva (2011) point to the advantages of engaging students actively in the process of identifying effective strategies to address cyberbullying. Brief intervention and assembly-style programs (e.g 1hour- 1 day in length) in schools generally only involve students, and largely leave teachers and administrators out. These programs have demonstrated little effectiveness in increasing knowledge or changing behaviors (Freedenthal, 2010; Joronen et al., 2008). Despite this, schools often seek out brief programming in the interest of cost and time effectiveness (Wills \& Sabo, 2010). Although Nation et al. (2013) suggest a comprehensive approach 
when designing school-based prevention programming, these designs are rarely used in reality.

\section{Intervention}

CHOICES was developed and is facilitated by the theatre company's Artistic and Community Outreach Directors. Both the Artistic Director and the Community Outreach Director hold masters degrees in Educational Theatre from New York University and have extensive training and experience in applied theatre, Theatre of the Oppressed and Forum Theatre principles and techniques.

The main components of CHOICES consist of a brief performance (20 minutes) by professional actors for an audience of students (20-80 students, on average), followed by an interactive discussion between the actors and the students, which includes student role-plays of cyberbullying situations introduced in the performance. More specifically, students in the audience are encouraged to suggest, and subsequently role-play with the actors, possible alternative solutions to those presented in the play. During the course of these interactive discussions and roleplays, the facilitators teach key strategies that address cyberbullying and suicide.

CHOICES was designed to be 90 minutes in length. The basic structure of CHOICES occurs in five distinct sections. In the Section 1, the intervention is introduced as an interactive program aimed at addressing cyberbullying and suicide. The facilitator introduces herself, along with two professional actors who will perform a short play. The facilitator provides background on the theatre company and explains the structure of the intervention to the student participants. 
Section 2 consists of a 20-minute multi-media play, which includes live performance, recorded music, and projected slides of text. The play depicts a teenage girl, Hannah, experiencing cyberbullying online and via cell phone text messages, while at home and school. Hannah also displays warning signs of suicide. See Appendix 1 for a full script of the play.

Section 3 of the intervention occurs after the play ends. The facilitator describes the Forum Theatre technique by explaining that they (students and facilitator, together) will come up with possible strategies to address the cyberbullying that occurs in the play. She informs them that they will be given the opportunity to come up and role-play these possible strategies. The facilitator then guides the student participants in the audience in a discussion. The students are asked to describe Hannah at the beginning of the play, and talk about her transition that results in the outcome at the end of the play. Next, students are asked to brainstorm and share ideas of what Hannah might have done differently to address the cyberbullying. At this point, the facilitator formally defines cyberbullying. The facilitator then reminds the students that they will be given the opportunity to roleplay their suggestions. As the facilitator explains, the play will be performed again, beginning at the point in the action when the cyberbullying begins. The students are invited to halt the action at any point, and come up and role-play their solution, by taking the place of the actress playing Hannah. They may also choose to explain their solutions to the actress playing Hannah, in order to have her perform it. This method of actively brainstorming and rehearsing possible solutions are at the heart of the Forum Theatre technique. 
In Section 4, the facilitator leads the student participants and actors through the performance several times. Students are allowed to stop the performance at any time to suggest and role-play strategies to address the cyberbullying from Hannah's perspective. The students role-play their suggestions themselves, or the actors roleplay the suggestion the student provides. The Stop-Block-Tell strategies to address cyberbullying are explicitly taught and rehearsed, to insure that the student participants learn and experience how these strategies are effective in dealing with cyberbullying. These role-plays are followed by a discussion about why or why not the strategies role-played worked. The facilitators explain to the students why certain strategies are effective or ineffective.

In Section 5, the facilitator leads a discussion about the warning signs of suicide, as shown in the original performance. The specific warning signs including withdrawing from family, friends and activities; hopelessness; a drastic change in mood; and finding lethal means/making a plan are taught. Specific examples, which exemplify these signs from the play, are used. There is a guided discussion regarding what to do if a peer is displaying these warning signs. The facilitator then asks all the student participants to come up with the names of three trusted adults, who they can go to for help, if they see a peer exhibiting these signs of suicide. The facilitator shares facts about adolescent suicide, including that suicide is the second leading cause of adolescent death. The intervention ends with a reiteration of the core content items- the Stop-Block-Tell cyberbullying strategies; the warning signs of suicide; and the strategy of coming up with the names of three trusted adults to who the students can go to for help. 
In CHOICES, the core content related to cyberbullying includes the Stop, Block, and Tell strategies. When experiencing cyberbullying, a student should stop the interaction between him/herself and the cyberbully (Stop); block the bully's electronic messages (Block) and; report the cyberbullying to a trusted adult, such as a parent or teacher (Tell). These strategies are supported in literature as approaches students should use to address cyberbullying (Lorenz \& Laanpere, 2012; Robinson, 2012; Mishna et al., 2011, Hinduja \& Patchin, 2011; Feinberg \& Robey, 2009).

\section{Current Evaluation}

Quality program evaluation investigates both the process and the outcomes of an intervention in order to accurately determine its effectiveness and impact. Thorough evaluation also determines the reliability of the intervention, as well as identifies areas for change and growth (Wall, 2009). As formal evaluations of prevention programs become the standard, results from these evaluations indicate that anecdotal beliefs of program success have proven false (Nation et al., 2003). Informal feedback from schools and student participants have suggested that CHOICES "works" and is well received by school faculty and students. However, what "works" about the intervention has not been defined. Until this point, CHOICES has not been formally evaluated, hence the purpose of this study. Feedback from this evaluation will provide useful information to the program developers to help improve the intervention and increase its effectiveness for future deliveries. This study will evaluate whether or not CHOICES was delivered with fidelity of implementation, and if it succeeded in producing the intended outcomes. 
Tracking fidelity of implementation is an essential part of program evaluation (Durlak \& DuPre, 2008; Fagen et al., 2008; Dusenbury et al., 2003). Fidelity refers to the extent to which the program is implemented in accordance with the guidelines and delivery methods specified by the developers (Fagen et al., 2008; Dusenbury et al., 2003; Dane \& Schneider, 1998). In this study, the fidelity of implementation of the intervention was assessed to determine whether the delivery of CHOICES was consistent with the original goals of the program, as well as consistent across multiple deliveries.

The study also determined whether exposure to CHOICES led to significant gains in students' knowledge of effective strategies to address cyberbullying and the warning signs of suicide, as well significant increases in students' ability to correctly identify the warning signs of suicide. This study also determined if exposure to the program led to significant increases in student willingness and confidence in their ability to apply newly acquired knowledge about cyberbullying and suicide.

Given what is known about effective prevention programming, I proposed that the effectiveness of CHOICES is related to the level of fidelity of its deliveries, as well as how well the intervention produces the intended outcomes related to cyberbullying and suicide. Therefore, the research questions addressed by this evaluation are as follows:

(1) Was the intervention delivered with fidelity?

(2) Did the intervention produce changes in student knowledge and attitudes related to effective strategies that address cyberbullying and suicide? 


\section{CHAPTER II \\ LITERATURE REVIEW}

\section{Fidelity of Implementation}

Fidelity of implementation refers to the level at which a program or intervention is implemented as the developers' intended (O'Donnell, 2008; Dusenbury et al., 2003; Dane \& Schneider, 1998). High levels of fidelity speak to an intervention's consistency, not only in terms of the stated goals of the program, but also across deliveries. According to Dusenbury and colleagues (2003), if a program is not presented with high levels of fidelity, then the program has low feasibility. Concurrently, if programs are implemented with high degrees of fidelity but produce poor outcomes, then the program may need to be restructured (Dusenbury et al., 2003). Measuring the fidelity of implementation is important in order to be able to accurately interpret a program's outcomes. Without consideration of how, and to what degree, the intervention was delivered, one might incorrectly attribute negative or ambiguous outcomes to an ineffective program, when it is possible it was due to a failure in implementation (O’Donnell, 2008; Dusenbury et al., 2003; Dane \& Schneider, 1998).

\section{Measuring Fidelity of Implementation}

Dane and Schneider (1998) outline five types of program fidelity of implementation necessary to comprehensively measure and capture what is actually 
delivered in a certain setting. These include; (1) program adherence: the extent to which the implementation of the intervention corresponds with the originally intended program; (2) dosage: how much of the original program has been delivered (in terms of strength, as well as number, frequency and length of sessions); (3) the quality of the implementation which describes how well (i.e. with clarity, accuracy and enthusiasm) the different components of the intervention were delivered; (4) participant responsiveness: to the degree to which the participants involved in the program are engaged or involved in the intervention; and (5) program differentiation the extent to which the program's theoretical and methodological components can be distinguished from other programs (Dane \& Schneider, 1998). Other researchers have found that these five types of fidelity of implementation are the most commonly used measures of fidelity of implementation within and across vast numbers of social programs (Durlak \& Dupre, 2008; Gottfredson \& Gottfredson, 2008; O’Donnell, 2008; Dusenbury et al., 2003). In this study, fidelity of implementation will be measured across all five types of fidelity- adherence, dosage, quality of delivery, participant responsiveness, and program differentiation.

Adherence refers to the level at which the delivery of the program is consistent with the original design of the program, which includes the predetermined essential components (Dane \& Schneider, 1998). In order to accurately assess fidelity of implementation, it is therefore first necessary to define the essential elements or components of the intervention. These components are comprised of specified content and specified delivery strategies (Ennett et al., 2011). The components can then be used to evaluate the adherence to the planned intervention (Dusenbury et al., 2003). 
Adherence can be measured in several ways, including facilitator self-reports, which reflect their own delivery of the program. Dusenbury et al., warn that using this method alone may not be as valid as having an outside observer complete a fidelity measure (2003). A more sound approach includes both observer and self-report data measuring levels of adherence (Dusenbury et al., 2003). O'Donnell (2008) suggests that the best approach is to use multiple methods of measurement, including video and audio recording, live observations, self-report surveys and facilitator interviews, thus allowing for the most accurate assessment of the level of adherence of the intervention.

Using more than one observer to track and code adherence is also advised (O’Donnell, 2008; Borelli et al., 2005; Lombard et al., 2002). While researchers do not define an ideal number of observers/coders, Lombard and colleagues suggest that using two or more coders is a necessary step in validating the coding system (2002). Lombard et al. (2002) suggest using both percent agreement and Cohen's kappa to determine the inter-rater agreement. Percent agreement is a commonly used index, although tends to be liberal, therefore using the additional Cohen's kappa index, is more likely to capture agreement that happens by chance (Lombard et al., 2002). Lombard and colleagues also suggest that for the measure to be deemed reliable, Cohen's kappa should be .70 or higher and, if this is not the case, percent agreement should be .90 or higher (Lombard et al., 2002).

Dosage refers to the amount of program content delivered to the participants through the intervention (Dusenbury et al., 2003). It can be described in terms of number, length, and frequency of sessions (Fagen et al., 2008). Dosage can also refer 
to the amount of content presented per session (Dusenbury et al., 2003). Dosage is commonly measured using facilitator logs and checklists.

The quality of the implementation describes how well the different components of the intervention were delivered. Many school-based prevention programs rely on interactive elements to disseminate knowledge to their participants, with facilitators guiding students in order to gain skills or develop specific attitudes or beliefs (Dusenbury et al., 2003). Therefore, the quality of the interaction needs to be measured (Dusenbury et al., 2003). Quality of implementation is commonly measured through both self-report and observations (Ennett et al., 2011; Dusenbury et al., 2003).

Participant responsiveness refers to the extent to which participants were engaged by and involved in the activities and content of the intervention (Dusenbury et al., 2003). According to Ennett et al., participants' response and level of enthusiasm towards an intervention may be an indication of the facilitator's skill in implementing the intervention as intended (2011). Consequently, the degree of participant's active engagement in the intervention influences its potential outcomes (Ennett et al., 2011). Participant responsiveness is also measured with the total number of participants attending the intervention (Dusenbury et al., 2003). Ennett et al. (2011) and Fagen et al. (2008) reported on the importance of also measuring participant responsiveness by documenting common implementation problems encountered (i.e. student misbehavior, lack of student responsiveness).

Program differentiation refers to the absence of contamination from another 
program that might account for a program's outcomes (Ennett et al., 2011). Ennett et al. (2011) measured implementation across the five fidelity types in a subset of nearly 400 respondents from a national random sample of middle schools. Respondents taught one of ten evidence-based substance abuse prevention programs during the 2004-2005 school year. Of all of programs evaluated for implementation across all five of the fidelity types, program differentiation was the type least likely to achieve fidelity, with close to $85 \%$ of the programs evaluated using other similar prevention programming simultaneously. This suggests the likelihood that other programs may have contaminated these programs' effects (Ennett et al., 2011). Overall, program differentiation has received little attention in fidelity of implementation research (Durlak \& DuPre, 2008; Dusenbury et al., 2003).

\section{Aspects of Program Implementation}

In Dusenbury et al.'s (2003) review of 25 years' worth of research involving fidelity of implementation, the authors recommend that researchers develop and use reliable measures to track fidelity, which parallel the five aspects of program implementation as described by Dane and Schneider (1998). Dusenbury and colleagues report that it is not clear that all five types of fidelity must be present for a program to reach its goals (2003). Across all of the drug abuse prevention evaluation literature reviewed, the authors did not find any measures of program differentiation (Dusenbury et al., 2003). The authors also report that, as of 2003, no single published study of drug abuse prevention included all of them (Dusenbury et al., 2003). However, Dane and Schneider (1998) strongly recommend measuring across all five types of fidelity in order to gain a comprehensive picture of program quality. 
Although fidelity is closely linked to outcomes, literature on fidelity of implementation is limited in social science research (Dusenbury et al., 2003). In a meta-analysis of primary and secondary prevention literature from 1980 to 1994 , Dane and Schneider found that only $24 \%$ of the 162 studies evaluating the effectiveness of academic, behavioral, and social problems assessed implementation of fidelity. The authors also reported that of those $24 \%$, only one third considered the impact of fidelity on the outcomes of the program or intervention (Dane \& Schneider, 1998). Durlak and DuPre suggest that evaluations, which do not attend to the fidelity of implementation, are "flawed and incomplete" (2008, p. 340). The authors contend that without implementation data, researchers and evaluators cannot accurately describe what exactly the program or intervention does, or how outcomes should be interpreted (Durlak \& DuPre, 2008).

The available research shows that in many school-based prevention programs high levels of implementation are positively correlated with program effectiveness (Gottfredson \& Gottfredson, 2008; Fagen et al., 2008; Durlak \& DuPre, 2008; Dusenbury et al., 2003; Dane \& Schneider, 1998). Furthermore, the research demonstrates that many of these programs are not implemented with high levels of fidelity (Gottfredson \& Gottfredson, 2008; Fagen et al., 2008; Durlak \& DuPre, 2008; Dusenbury et al., 2003). Durlak and DuPre reviewed data from close to 500 promotion and prevention studies, evaluated in 5 meta-analyses, and reported that mean effect sizes were 2-3 times higher in programs that were carefully implemented than programs that showed low levels of fidelity (2008). 
Correct interpretations of the outcomes rely on knowing what aspects of the intervention were implemented, along with how well they were delivered (Durlak \& DuPre, 2008). Although researchers agree that fidelity of implementation is important in comprehensively evaluating the effects of a program or intervention, many studies do not include it (Durlak \& DuPre, 2008; Dusenbury et al., 2003; Dane \& Schneider, 1998). In their review of prevention literature spanning 1980-1994, Dane and Schneider (1998) found that only 39 of the 162 mental health prevention studies analyzed contained any measure of fidelity of implementation. Further, of those 39, only 13 connected the fidelity of implementation to outcomes (Dane \& Schneider, 1998). As Dane and Schneider (1998) assert, a comprehensive evaluation of an intervention's outcomes must include measures of fidelity.

\section{Outcome Evaluation}

A program evaluation involves collecting and analyzing information and data to make decisions about the program (McNamara, 2006). McNamara (2006) describes three major types of evaluation- goals-based, process-based, and outcomebased. Goals-based evaluations determine whether a program is meeting its established goals. Process-based evaluations assess how the program works and how it is being delivered in order to achieve its outcomes. Measuring the fidelity of implementation of a program is a part of process-based evaluations. Outcome-based evaluations determine the impact of the intervention on its participants. Outcomes can be measured in terms of knowledge and skills acquired, as well as attitude and behavior change (McNamara, 2006). 
Outcome evaluation systematically documents the impact or results of a program or intervention (Wall, 2000; McNamara, 2006; Orsini et al., 2012). Results are viewed in terms of the relationship between the predetermined goals of the program and what was actually achieved. Thus, it allows program developers to decide whether the chosen activities or components in the intervention actually produce the desired outcomes (McNamara, 2006).

Information on the effectiveness of a program, in terms of its impact on its participants, can provide powerful and useful feedback to the program developers (Plantz et al., 2006). Programs must clearly define their intended outcomes in order to evaluate them, which in itself can provide a tremendous amount of focus to efforts of the program (Plantz et al., 2006). Outcome evaluation is also important because it can lead to programmatic changes and improvements that need to be made in order to affect future outcomes of the intervention (Wall, 2000; McNamara, 2006; Plantz et al., 2006, Hendricks et al., 2008; Orsini et al., 2012). Outcome information can also serve as an excellent motivator for program developers, staff, and facilitators, who can measure the progress they are making with participants in a consistent and concrete manner (Plantz et al., 2006).

Nonprofit organizations, as well as other organizations (such as schools) that seek public and private funding, are often required to measure and document a variety of performance-related aspects, including inputs, activities, outputs, financial accountability, quality assurance and participant or client related measures (Hendricks et al., 2008). Funding agencies often require that organizations provide evidence of their programs' impact on their participants (McNamara, 2006; Hendricks et al., 
2008). In addition to maintaining funding, organizations can use the findings of outcome evaluations when initially seeking funding by demonstrating the positive effects of the program and the need for further implementation (McNamara, 2006). The evaluation and measurement of outcomes shifts the focus from activities to results, allowing programs to not only understand their process, but their product as well.

The United Way of America (UWA; http://www.unitedway.org/outcomes/), the largest philanthropic institution in the United States, aims to improve communities by partnering with local organizations to address local problems, as well as the issues that underlie these problems. The UWA requires agencies who receive its funding to systematically track their outcomes (Hendricks et al., 2008). The UWA provides an excellent model for implementing outcome-based evaluations (McNamara, 2006; Hendricks et al., 2008). The UWA recommends that a successful evaluation begins with identifying the major outcomes the evaluation will assess. For each outcome, observable measures must be determined, in order to verify that the major outcomes are being achieved. Additionally, a target goal or criteria must be defined in order to determine that the outcomes were successfully met. Next, the information needed to demonstrate these measures must be identified, along with a plan as to how that information can be collected. Examples of major methods for information collection include pre and post assessments, surveys, program documentation, and observations (McNamara, 2006). Pre and post assessments and surveys can provide valuable information about the participant's level of knowledge and skills before and after an intervention (Hendricks et al., 2008). Documentation 
review allows for the assessment of how the program was developed, the key components of the program, along with the intended implementation of the program. Observation of the program provides an opportunity to capture how the program was actually implemented, and to what extent program fidelity was maintained (McNamara, 2006; Dusenbury et al., 2003). Following the collection of the implementation and outcome information from the sources outlined above, findings can then be analyzed and reported (McNamara, 2006).

Outcomes are usually demonstrated in terms of benefits or changes in participants' knowledge, skills, behavior, attitudes, values, condition or status (Plantz, Greenway \& Hendricks, 2006). Plantz et al. (2006) provide an excellent description of how to approach outcome measurement through the lens of a program's goals, using If-Then statements in a hierarchal manner. Using one of the goals of CHOICES, “Increase students' knowledge of how to recognize and address the presence of warning signs of suicide in a peer." as an example: If the intervention provides information on suicide to adolescents, then the adolescents have increased knowledge of how to identify and address warning signs of suicide in a peer. If the adolescents have increased knowledge of how to identify warning signs of suicide in a peer, then this leads to changed behavior: the adolescents recognize the signs and report them to a trusted adult. If the adolescent follows these steps, then a suicidal adolescent can receive the help they need. The hierarchy of If-Then statements describes the theory behind how the program benefits its participants. As Plantz et al. state, this hierarchy "also describes a chain of influences, with program inputs (resources) leading to activities, which leads to outputs, which leads to a series of 
outcomes.” (2006, p.4). This series of outcomes includes immediate outcomes, intermediate outcomes, and longer-term outcomes. Immediate outcomes are more easily attributable directly to program factors than longer-term outcomes. Longerterm outcomes may be achieved due to a variety of influential mediating factors, thus making it more difficult to attribute it directly to the program (Plantz et al., 2006). Using the example provided earlier, the program could directly influence the immediate outcome of the adolescents' knowledge of how to recognize and address the presence of warning signs of suicide in a peer. In contrast, the adolescents disposition, past experience with suicide, and other exposure to suicide awareness materials outside of the program, not to mention the 'trusted' adults willingness to actually intervene- all of which the program cannot control- may have as much influence as the program on the longer-term outcome of a suicidal adolescent getting the help they need. When determining what level of outcome to measure, it is important to decide how far a program should reach in selecting its outcome. Therefore, selecting the outcome to be measured must be far enough to capture the full scope of the program's impact, while not too far-reaching that other mediating factors obscure the program's effects (Plantz et al., 2006).

The statistical power of an intervention's outcomes can decrease when it moves from a laboratory setting to the real world (O'Donnell, 2008; Dusenbury et al., 2003). Therefore, there is a need to assess the fidelity of implementation in both efficacy and effectiveness studies, in order to determine the relationship between the intervention's degree of fidelity and its outcomes. This is especially true when researchers want to know whether to attribute poor outcomes to low levels of fidelity 
or a poorly designed intervention (O’Donnell, 2008). Efficacy studies are those done in a laboratory setting, with tightly controlled conditions, and are equivalent to randomized controlled trials. The purpose of these studies is to determine the true outcomes, as linked to the program's goals. Failure in outcomes, under such controlled conditions, could not therefore be attributed to a failure of implementation (O’Donnell, 2008). Effectiveness studies, on the other hand, evaluate the impact of an intervention in actual practice, where it is more likely that mediating and moderating factors are present. Efficacy studies address the internal validity of an intervention and effectiveness studies address an intervention's external validity (O'Donnell, 2008).

The current study's evaluation was concerned with the effectiveness of CHOICES. Effectiveness, in this context, refers to the ability of the intervention to produce the desired outcomes in real-world settings (O'Donnell, 2008). While an efficacy study might attempt to monitor and control levels of fidelity in the intervention, this study sought to measure possible variations in fidelity and link them to outcomes. If results indicated that CHOICES did not achieve its desired outcomes, than the author might ask if certain programmatic features were not delivered in a manner close to what the developers had originally intended (O’Donnell, 2008).

\section{Cyberbullying}

Bullying continues to be an important issue affecting school-aged children, academically, socially, and psychologically (Espelage \& Holt, 2012; Vieno et al., 2011; Solberg, Olweus \& Endreson, 2007; Nansel et al., 2001). Olweus has provided a working definition of traditional bullying as follows, "A student is being bullied or 
victimized when he or she is exposed, repeatedly and overtime, to negative actions on the part of one or more students" (Olweus, 1993, p. 9). In a bullying situation, there is a real or perceived imbalance in power, between the perpetrator(s) and the victim. This imbalance can be related to physical, mental or social factors, or strength in numbers, with multiple perpetrators harassing a single individual (Solberg, Olweus \& Endreson, 2007).

Bullying is commonly categorized into six major types in the literature: physical bullying, verbal bullying, relational bullying (Espelage \& Holt, 2012; Vieno et al., 2011; Turner et al., 2011; Wang et al., 2009), sexual bullying (Vieno et al., 2011) also labeled sexual harassment (Espelage \& Holt, 2012; Turner et al., 2011), and cyberbullying (Espelage \& Holt, 2012; Vieno et al., 2011; Turner et al., 2011; Wang et al., 2009). Cyberbullying is a form of bullying in which bullies use electronic means, such as the Internet and cell-phones to harass, humiliate, and deliberately hurt others (Espelage \& Holt, 2012; Jose et al., 2011; Ybarra \& Mitchell, 2004).

Hinduja and Patchin (2008) found that approximately 30 percent of 1,378 adolescent Internet users surveyed online reported cyberbullying victimization, while 11 percent of respondents admitted to cyberbullying others. Kowalski and Limber (2007), polled 3,767 middle school students, 18 percent of whom reported being a victim of cyberbullying in recent months and 11 percent reported cyberbullying others. Mishna et al. (2012) surveyed a large and diverse sample of over 2,000 middle and high schools students, who completed an in-class, self-report measure of their involvement in cyberbullying. The authors found that over 30 percent of the 
students participating in the study reported involvement in cyberbullying, as either a victim or a perpetrator. Of those involved, 25 percent reported having been involved in cyberbullying as both victim and perpetrator. The 2011 Youth Risk Behavior Surveillance, published by the Centers for Disease Control and Prevention (CDC), surveyed over 15,000 students in grades 9-12. Of those students surveyed, $16 \%$ percent reported being cyberbullied in the 12 months prior to the survey (CDC, 2012). As children and adolescents' use of technology increases, bullying prevention programing have begun to include cyberbullying prevention (Espelage \& Holt, 2012; Mishna et al., 2011; Chibnall et al., 2006; Crombie \& Trinneer, 2003; Salvatore, 2006). However, there remains a paucity of cyberbullying prevention and intervention programs found to be effective (Espelage \& Holt, 2012; Mishna et al., 2011).

Common modes of cyberbullying include; telephone calls, text messages, pictures and video clips sent electronically, emails, Internet instant messaging, Internet chat rooms, and messages posted on social networking sites (Smith et al., 2008; Beale \& Hall, 2007). Smith et al. (2008) conducted a study identifying the specific forms cyberbullying takes, using several surveys administered to 615 students, ages 11-16 years. Adolescents most frequently reported being cyberbullied via cell phone calls/texts, as well as Internet instant messaging. Although not as frequent, respondents reported the highest levels of distress when cyberbullying occurred via pictures/video clips (Smith et al., 2008).

Ybarra, Deiner-West, and Leaf (2007) used a national cross-sectional online survey with 1,588 youth, ages 10-15. The main measures were Internet harassment and school functioning. Results of the survey indicated that $36 \%$ of those reporting 
cyberbullying did also report being bullied at school. Youth who reported cyberbullying were twice as likely to report receiving two or more detentions or suspensions and skipping school in the past year. Youth who reported being a victim of cyberbullying were 8 times more likely than all other youth to report carrying a weapon to school in the past 30 days (Ybarra, Deiner-West \& Leaf, 2007). The impact of cyberbullying on school functioning combined with direct access to cyberbullies and victims, positions schools well to provide direct interventions aimed at preventing cyberbullying.

Adolescent victims of cyberbullying are significantly more likely to experience psychological distress, such as depression, anxiety, difficulty concentrating, and fear (Devine \& Lloyd, 2012; Mishna et al., 2011; Sourander et al., 2010; Mitchell, Ybarra, \& Finkelhor, 2007; Ybarra et al., 2007; Ybarra \& Mitchell, 2004). Using data from Ireland's 2009 Kids' Life and Times Survey of 3,657 ten and eleven year-olds, Devine and Lloyd (2012) reported that $12.5 \%$ of children who reported being cyberbullied, also reported significantly lower rates of personal wellbeing than children who had not been cyberbullied. Ybarra and Mitchell (2004) conducted a telephone survey of 1,501 regular Internet users between the ages of 10 and 17. Nineteen percent of those surveyed were involved in cyberbullying and reported higher rates of major depressive-like symptomology and a lower commitment to school (Ybarra \& Mitchell, 2004) than those not involved in cyberbullying. Sourander et al. (2010) reported that one in four students who reported being cyberbullied were scared for their safety. These students were more likely to experience fear when they were cyberbullied by an adult, an unknown 
person, or a group of people. The authors suggest that this is most likely due to a greater imbalance of power compared with peer bullying (Sourander et al., 2010). Ybarra, Diener-West and Leaf (2007) also reported that victims of cyberbullying were more likely to experience higher levels of fear at home and school than those not victimized. Adolescents who are involved in cyberbullying, either as a victim or as an offender, have significantly lower levels of self-esteem than those not involved Patchin \& Hinduja, 2010).

Mitchell et al. (2007) surveyed nationally 1,501 youth, ages 10-17, who use the Internet. The authors looked specifically at the relationship between online and traditional forms of harassment with symptoms of depression, delinquency and substance use (Mitchell et al., 2007). Of those surveyed, 57\% reported being bullied or harassed interpersonally and $23 \%$ percent reported being victimized online. Seventy-three percent of those bullied online also reported being bullied offline. The authors found that all types of victimization were independently related to depressive symptoms, delinquency, and substance use. The authors suggest that these types of victimizations are likely characterized by common underlying characteristics of the youth, such as risky behavior or need for social acceptance. It is not yet clear which comes first however, the tendency to engage in these behaviors or the victimization (Mitchell et al., 2007).

Demographic variables have also been linked to cyberbullying involvement. Research has shown that involvement in cyberbullying, as in traditional bullying, peaks during the middle school years (Beale \& Hall, 2007). The literature also shows 
that girls bully others for their physical appearance, while boys are more likely to make remarks that are sexually explicit in nature (Beale \& Hall, 2007; Mason, 2008).

\section{Adolescent Suicide}

According to the Centers for Disease Control (CDC, 2012), suicide is the third leading cause of death for people ages 10-24, resulting in 4600 deaths each year. The rates of attempted suicide are even higher, with 157,000 youth receiving medical care each year as a result of self-inflicted injuries. According to the CDC's Youth Risk Behavior Survey of students in grades 9-12, nearly $16 \%$ reported seriously considering suicide, $13 \%$ reported devising a plan, and $8 \%$ reported attempting to take their own life in the 12 months preceding the survey (CDC, 2012).

\section{Warning Signs of Suicide}

While identification of long-term risk factors is important in identifying youth who may be predisposed to suicide, the identification of more immediate factors, signaling a current suicidal crisis, is also important. These factors serve as precipitating conditions that put youth at an acute level of risk, thus demanding immediate intervention (van Orden et al., 2006). van Orden et al. (2006) make a key distinction between the symptoms and signs that indicate a risk of suicide. Symptoms are indicators described by the individual to others, whereas signs are behavioral manifestations of symptoms, as observed by others. Thus, warning signs of adolescent suicide serve as observable indicators of an acute crisis.

Researchers with the American Association of Suicidology (AAS) reviewed the empirical literature and developed a comprehensive list of warning signs for 
suicide (Rudd et al., 2006). They are detailed in Table 1. Van Roden et al. (2006) suggested that efforts, which emphasize the recognition of warning signs of suicide and taking immediate steps to intervene are essential tools to help people predict and therefore prevent suicide.

\section{Table 1}

Warning Signs of Suicide

- Someone threatening to hurt or kill themselves

- Someone seeking means to kill themselves; seeking access to pills, weapons or other means

- Someone talking or writing about death dying or suicide

- Hopelessness

- Rage, anger, seeking revenge

- Acting restless or engaging in risky activities, seemingly without thinking

- Feeling trapped- like there's no way out

- Increasing alcohol or drug use

- Withdrawing from friends, families, or society

- Anxiety, agitation, unable to sleep or sleeping all the time

- Drastic changes in mood

- No reason for living; no sense of purpose in life

\section{Cyberbullying and Suicide}

Research on the relationship between cyberbullying and suicide is only beginning to emerge (van Geel et al., 2014; Hinduja \& Patchin, 2010). Victims of cyberbullying are more likely to have suicidal thoughts than those not victimized (Hinduja \& Patchin, 2010). Ybarra, Deiner-West, and Leaf (2007) reported that victims of cyberbullying were one and a half times more likely to have attempted suicide than those who were neither a victim nor a perpetrator of cyberbullying. Accounting for the risk factors associated with both suicide (Bridge, Goldstein, \& 
Brent, 2007; Cheng et al., 2000; Eggert et al., 1995) and cyberbullying victimization (Mitchell et al., 2007; Ybarra, Deiner-West, and Leaf, 2007), identifying effective prevention strategies that address both issues is important.

\section{School-based Cyberbullying Prevention and Intervention}

In Smith et al.'s (2008) survey of 615 students, ages 11-16 years, respondents reported coping strategies that were most effective in addressing cyberbullying, including blocking/avoiding messages, and telling someone. However, many cybervictims had not reported the abuse. The authors suggest that researchers, practitioners, and adults who engage with children and adolescents should be careful to consider the multi-dimensionality of cyberbullying. Schools should explicitly define cyberbullying in school bullying policies. Parents should work to educate themselves on the potential uses of the Internet and cell phones and learn how to contact Internet and cell phone service providers and the legal rights in these arenas (Smith et al., 2008). Beale and Hall also advise promoting a school climate in which students feel comfortable and encouraged to report incidences of cyberbullying to a responsible adult. This also includes the establishment of school policies, which specifically prohibit cyberbullying of a student, with the school reserving the right to discipline a student for actions off of school grounds if these actions have negative repercussions on a student's safety and wellbeing while in school (2010). Further, students should be educated on the safest and most appropriate way to navigate digital communication, including how to block and report inappropriate messages (Couvillon \& Ilieva, 2011). 
Effective interventions aimed at educating students on Internet safety, along with ways to address and report cyberbullying, are a vital component of effective school anti-bullying efforts (Couvillon \& Ilieva, 2011; Smith et al., 2008; Ybarra, West, \& Leaf, 2007; Beale \& Hall, 2007). In a systematic review of prevention and intervention efforts that address cyberbullying, Mishna et al., (2011) found significant results between pre and post test scores related to knowledge of Internet safety, although increase in knowledge was not linked to significant changes in risky Internet behavior. The literature reveals a need for effective programming, which not only lead to increases in knowledge about addressing cyberbullying, but also leads to changes in behavior.

\section{Stop-Block-Tell}

iSafe (iSafe, Inc., 1998, 2009) employs what are referred to in the literature as 'Stop-Block-Tell' strategies when educating students on Internet safety (Snakenborg et al., 2011; Kraft \& Wang, 2009; Diamanduros et al., 2008; Saini et al., 2007). StopBlock-Tell describes common effective strategies advocated in cyberbullying prevention research (Lorenz \& Laanpere, 2012; Robinson, 2012; Mishna et al., 2011; Hinduja \& Patchin, 2011; Feinberg \& Robey, 2009). Lorenz and Laanpere (2012) reported on common Internet safety strategies taught to students, in particular the Stop-Block-Tell approach, which encourages students who are experiencing cyberbullying to stop interacting and/or responding to the bully electronically or otherwise; block the bully using site specific blocking mechanisms or software designed to block certain sites and users and; report the cyber bullying activity to a trusted adult, and if necessary an internet/cell phone provider and law enforcement. 
Stopbullying.gov is a website maintained by the US Department of Health and Human Services whose aim is to provide empirically-based resources that address bullying, including cyberbullying (www.stopbullying.gov). The website suggests immediate steps to take when cyberbullying occurs, including the Stop-Block-Tell strategies. According to the website, students should not respond or forward the harassing messages and should block the person who is the cyberbully. The website gives guidelines regarding how to report the incident to online service providers, law enforcement and schools. Hinduja and Patchin (2011) suggested that schools develop an anonymous reporting system, as many students may be reluctant to report. Snakenborg et al. (2011) reviewed commonly used cyberbullying prevention and intervention efforts at community, school and family levels. The authors reported that the most basic steps for addressing cyberbullying include the Stop-Block-Tell strategies. The authors suggest that students should be taught to refrain from continuing to communicate with the cyberbully, as further engagement or retaliation might only exacerbate the situation. While many students report knowing the steps to block particular individuals online, students appear more apprehensive to report such behavior. For this reason, Snakenborg et al., stress that teaching students the skills to block messages is not enough. The authors also encourage schools and parents to create an open and trusting environment that encourages reporting and discussing issues related to cyberbullying (2011). In promoting the Stop-Block-Tell strategies, Feinberg and Robey (2009), from the National Association of School Psychologists, also warn against the possibility of retaliation if the cyberbully victim responds to the harassment, suggesting stopping and blocking all further messages. The authors also 
warn that continued communication may make it more difficult for authorities to determine the original instigator of the bullying. Thus students should be taught to report the behavior as soon as it happens (2009).

\section{School-based Suicide Prevention}

Owens et al., reported that as many as $75 \%$ of individuals who committed suicide were not in contact with a mental health professional at the time of their death (2003). Therefore, other individuals (i.e., parents, teachers, peers) who are likely to have more frequent contact with a suicidal individual would benefit from knowledge of the warning signs of suicide, as well as how to help (van Orden et al., 2006).

School-based programming to prevent adolescent suicide has produced mixed results (King, Strunk, \& Sorter, 2010; Portzky \& Heeringen, 2006; Shaffer \& Craft, 1999). Shaffer and Craft (1999) reviewed a number of studies on adolescent suicide prevention efforts. The authors categorized school-based suicide prevention programs into three distinct types: psycho-educational programs aimed at reducing stigma and promoting self-referral; education of others (i.e., parents, teacher and peers) of the warning signs and how to refer a suicidal adolescent for help; and direct screening of students.

\section{Gatekeeper Communication Model}

The Gatekeeper Communication Model focuses on the recognition of suicide warning signs and referral of those exhibiting these signs to appropriate help (Brown et al., 2007). Gatekeeper programs are increasingly used as a suicide prevention approach in schools and are targeted toward school staff, teachers, and students who 
are in a position to observe warning signs and provide assistance to suicidal adolescents (Issac et al., 2009; Wyman et al., 2008; Brown et al., 2007). In a review of studies investigating the efficacy of gatekeeper programs, Isaac et al. (2009) report numerous studies show an increase of knowledge and skills from gatekeeper programs used with youth. In a randomized trial of a gatekeeper program used with high school staff in 32 schools, Wyman et al. (2008) reported significant increases in staff members' self-evaluated knowledge (Cohen's $d=0.41$ ) and appraisals of efficacy (Cohen's $d=1.22$ ). Quinnet's (1995) Question-Persuade-Respond program is a standardized community gatekeeper suicide prevention program developed for youth. The QPR program is relatively brief, lasting about an hour, consisting of a lecture, a short introductory video, distribution of booklets and referral cards, along with a question and answer period (Quinnet, 1995). Cross et al. (2011) reported on the effects of the Question-Persuade-Respond program used in conjunction with behavior rehearsal, via role-plays. The authors compared the program plus role-play model to the standard QPR program and found that both conditions produced significant increases in knowledge between pre and post assessment $(F(2,156)=$ 17.73, $p<.001$ ), with no main effects difference between conditions. However, the program with role-plays resulted in higher total gatekeeper skill scores after training $(F(1,127)=6.25, p<.05)$, and at 3 -month follow-up $(F(1,127)=11.18, p<.001 ;$ Cross et al., 2011).

The key strategies highlighted in relation to suicide in CHOICES are a form of a gatekeeper program (Quinnett, 2011; Brown et al., 2007) and include helping students recognize important warning signs of suicide in peers and coming up with 
the names of three trusted adults the students can report their concerns about a peer's suicidal behavior. Research shows that using a gatekeeper model can be effective, which supports its use in the intervention involved in this study. Furthermore, Cross et al. suggest that programs, which employ active learning strategies, such as the roleplays used in CHOICES, combined with the QPR model, may produce greater knowledge and skill acquisition than treatment using the QPR model alone (2011).

\section{Applied Theatre in Schools}

CHOICES uses principles of applied theatre, with specific techniques derived from the Theatre of the Oppressed framework. Applied theatre is created to address a specific social issue, with the primary goal being promoting social change (Stuttaford et al., 2006). The use of applied theatre and role-plays has been shown to be a useful approach in the dissemination of knowledge (Cheadle et al., 2013; Robinson \& Meyer, 2012; Ponzetti et al., 2009; Marsella, Johnson, \& LaBore, 2003). In a study of 2,915 elementary students in 47 schools involved in an applied theatre program, Cheadle et al. (2013) reported significant increases in students' knowledge related to healthy eating and active living immediately following the intervention, as well as 3 weeks later. Children's knowledge of four healthful behaviors was measured using a brief survey before and immediately after performances, followed by another survey three weeks later. The authors reported statistically significant increases in knowledge pre/post for individual topics $(p<.01)$. The percentage of children who answered correctly all four healthy behavior questions increased from 17\% to 63\% immediately after the performances $\quad(p<.01)$. Knowledge was retained over the short term; the proportion had declined only slightly three weeks later with $54 \%$ of students 
answering all four questions correctly (Cheadle et al., 2013).

Roberts et al. (2007) evaluated the effects of an applied theatre program, which aimed at educating high school and college students on early psychosis. The program was used with 2500 students in 52 schools and colleges. Significant gains $(p<.0001)$ were reported with respect to an increase in self-reported knowledge and understanding of early psychosis (a reduction in the stigma surrounding mental illness, and an improvement in awareness of ways to get help) one week following the intervention, as well as at six-month follow-up (Roberts et al., 2007).

Applied theatre can also effect behavior change (Howard, 2004; Harvey, Stewart, and Swan, 2000). Harvey, Stuart, and Swan (2000) conducted an extensive study involving a randomized community intervention trial in South Africa, with over 1,000 secondary students, using an applied theatre intervention focusing on AIDS awareness and condom-use promotion. The study found that the students' mean percentage scores on knowledge about HIV and AIDS, increased from 50.0 to 51.8 (statistical significance not reported). In terms of behavioral change, students' mean percentage scores on self-reported condom use, increased significantly from 38.2 to 55.0 ( $p<.01$; Harvey, Stewart, \& Swan, 2000). Kisiel et al. (2006) investigated the effects on behavior change in a study of 140 fourth graders in eight classrooms involved in an applied theatre- based youth violence prevention program in Boston schools. The authors reported significant multilevel multivariate effect for teachers' reports of prosocial behaviors $(F(1,351)=5.23, p=.023)$. Follow-up multilevel univariate analyses indicated significant effects for teachers' report of youth cooperative behaviors $(F(1,111)=5.06, p=.026)$ and self-control

$$
(F(1,111)=4.55, p=
$$


.035; Kisiel et al., 2006).

According to Heyward's (2010) instructional paper on the use of applied theatre and role-play to assist in student learning, applied theatre and role plays allows students to acquire new knowledge and skills through practice, application, and further enhancement of new information. Role-plays improve students' understanding and engagement. The use of role-play in schools leads to greater emotional engagement by the students in the subject which further assists learning, as well as more accurate and readily remembered experiences (Heyward, 2010). Heyward also asserts that engaging students through theatre allows for a more educative experience when exploring social issues (2010). Students are provided with opportunities to work through and explore emotionally charged situations in the safe confines of a fictional world that results in little consequences in the real world. Students are then able to practice, refine, and (sometimes) fail during rehearsal, allowing for a deeper understanding of the complexities of the issues and effective strategies for change (Heyward, 2010). This literature suggests that principles of applied theatre can serve as an effective learning modality. The literature also shows support for interventions which use applied theatre as an effective method of disseminating knowledge and promoting behavior change.

\section{Forum Theatre}

Forum Theatre allows participants to define and explore problems based on their own experience (Boal, 1999). Forum Theatre has been especially useful in addressing a range of issues in the developing world, especially health-related concerns (Stuttaford et al., 2006). Interventions involving Forum Theatre have shown 
significant results, particularly in Africa, empowering rural villagers and the urban poor to recognize and address issues relevant to them, including poverty, war, AIDS, and political and social injustice (Nogueira, 2002). Forum Theatre typically involves a group of actors who perform a short play around a community or universal issue, as described to them by members of the audience. The actors then play through the action several times, allowing members of the audience to pause the action and step into the scene as 'spect-actors' (Boal, 1979) and take the place as the oppressed protagonist, trying out different solutions to try and change or improve the oppressive situation. The improvised scene continues until the oppression is counteracted, or the solution provided fails, or the scene becomes unrealistic (e.g., the protagonist gains superhero powers). A lead facilitator conducts an ongoing discussion. The facilitator is also able to change the scene or offer alternative suggestions (Burton \& O'Toole, 2009).

Although research involving formal evaluations is limited, Forum Theatre has been shown to be a successful technique to use in bullying prevention (Gourd \& Gourd, 2011; Burton, 2009; Dennis, 2009; Burton \& O’Toole, 2009). In a study of 148 eighth-graders in a Northwest middle school, Gourd and Gourd (2011) evaluated the impact of using Forum Theatre in a social studies classroom setting, in order to address issues of bullying using qualitative data. Results showed that students were able to develop effective strategies to confront bullying and make a commitment to end bullying in their school community following three class sessions of a Forum Theatre intervention (Gourd \& Gourd, 2011). In a study of 2,440 middle and high school students, Graves, Frabutt and Vigliano (2007), found decreased levels of 
relational bullying after participation in a Forum Theatre bullying intervention. Additionally, there was a decrease in levels of physical bullying in high school students. High school students also reported an increase in levels of effective communication. Middle and high school students demonstrated an increase in knowledge of positive conflict resolution strategies (middle school students: $t(610)=$ 13.47, $p<.001$; high school students: $\mathrm{t}(926)=6.95, \mathrm{p}<.001$; Graves, Frabutt \&Vigliano, 2007).

The power of applying Forum Theatre lies in the acknowledgement of students as "knowers- experts on their own experience of bullying... able to analyze and understand the complexity of their personal and social interactions" (Gourd \& Gourd, 2011, p.404). Based on a review of the literature, Forum Theatre has shown promise as a successful framework for bullying prevention in the schools, and would benefit from further evaluation of programming, such as CHOICES, which employs such techniques.

\section{Summary and Restatement of Research Questions}

Prior to this study, there had been no formal evaluation of the effectiveness of CHOICES. In formal evaluations, the literature supports measuring fidelity of implementation, in order to accurately interpret the outcomes of a prevention program like CHOICES (Durlak \& Dupre, 2008). Although the research on fidelity of implementation of prevention programs is limited, available research report that high levels of implementation are positively correlated with program effectiveness in many school-based prevention programs (Gottfredson \& Gottfredson, 2008; Fagen et al., 
2008; Durlak \& DuPre, 2008; Dusenbury et al., 2003; Dane \& Scneider, 1998). However, the research demonstrates that many of these programs are not implemented with high levels of fidelity (Gottfredson \& Gottfredson, 2008; Fagen et al., 2008; Durlak \& DuPre, 2008; Dusenbury et al., 2003). In the current study, measures of fidelity levels will help gauge if possible variations in fidelity impact the program's intended outcomes.

Outcome evaluations systematically document the impact or results of a program or intervention (Wall, 2000; McNamara, 2006; Orsini et al., 2012) and determine the impact of the intervention on its participants. Outcomes can be measured in terms of knowledge and skills acquired, as well as behavior and attitude change (McNamara, 2006). Results are viewed in terms of the relationship between the predetermined goals of the program and what was actually achieved (McNamara, 2006). It is currently unknown if CHOICES effectively achieves its intended effects related to cyberbullying and suicide knowledge, as well as willingness and confidence to apply knowledge; thus, a formal measurement of these outcomes is needed.

According to the literature, cyberbullying and suicide remain significant health problems for children and adolescents (CDC, 2012). Literature that identifies effective strategies and effective prevention programs that address cyberbullying and suicide has only begun to emerge, and what research that does exist has produced mixed results (McCuiston, 2008; Isaac et al., 2011; Quinnett, 2007; Issac et al., 2009; Wyman et al., 2008; Brown et al., 2007). Due to time constraints, schools often provide brief interventions; however, the empirical support for these interventions is limited (Will \& Sabo, 2010). Similarly limited is empirical support for applied theatre 
interventions Gourd \& Gourd, 2011; Burton \& O’Toole, 2009; Graves, Frabutt \&Vigliano, 2007). CHOICES is a brief applied theatre intervention that seeks to increase student knowledge of effective strategies that address cyberbullying and suicide and positively affect student's attitudes and behavior towards using these strategies. Anecdotal evidence, including my own background developing and facilitating Theatre of the Oppressed interventions, suggests that brief applied theatre programs can have a lasting emotional impact on its audience. What is not known is whether that impact consistently translates to changes in attitudes, knowledge and behavior. Currently, formal evaluations of interventions with similar designs are scarce; therefore an evaluation of CHOICES will determine its effectiveness and provide valuable information about the feasibility of similar programs.

The present study determined if CHOICES was implemented with high levels of fidelity within and across deliveries. This study also determined if CHOICES produced significant changes in student knowledge, willingness, and confidence related to effective strategies that address cyberbullying and suicide. 


\section{CHAPTER III}

\section{METHODOLOGY}

The purpose of this study was to evaluate the effectiveness of

CHOICES, a brief, applied theatre intervention aimed at addressing cyberbullying and suicide in middle school and high school students.

\section{Research Hypotheses}

The following hypotheses were developed in response to the research questions proposed in Chapter I:

In terms of overall fidelity of implementation:

Hypothesis 1: CHOICES is implemented with overall fidelity at .80 or greater.

In terms of program outcomes:

Hypothesis 2: Student exposure to CHOICES will be associated with gains in knowledge of effective strategies for addressing cyberbullying when it occurs.

Hypothesis 3: Student exposure to CHOICES will be associated with gains in knowledge of the warning signs of suicide in peers. 
Hypothesis 4: Student exposure to CHOICES will be associated with gains in knowledge of how to get help for peers if warning signs of suicide are present.

Hypothesis 5: Student exposure to CHOICES will be associated with confidence in their ability to apply knowledge of effective strategies when faced with a scenario involving cyberbullying.

Hypothesis 6: Student exposure to CHOICES will be associated with willingness to apply knowledge of effective strategies when faced with a scenario involving cyberbullying.

Hypothesis 7: Student exposure to CHOICES will be associated with confidence in their ability to apply knowledge of effective strategies when faced with a scenario involving a peer's suicidal behavior.

Hypothesis 8: Student exposure to CHOICES will be associated with willingness to apply knowledge of effective strategies when faced with a scenario involving a peer's suicidal behavior.

\section{Sample and Setting}

The participants involved in this study were a convenience sample from the population of adolescent students enrolled in middle or high school in a large urban school district in a mid-southern state. There are a total of 19 middle and 21 high schools in the district. Three schools participated in the study; 2 middle schools-

Schools A ( $6^{\text {th }}$ grade $)$ and B ( $8^{\text {th }}$ grade), and one high school- School C ( $9^{\text {th }}$ grade). A 
total of 697 students attended the interventions, across the three schools. Participant data were collected from students $(n=68$, including 21 males and 47 females) who attended the intervention at these schools ( $9.75 \%$ of the total students in attendance). Reported ethnicity included 59\% Non-Minority and $41 \%$ Minority. At the request of the school district, students' ethnicity was not defined further, in order to protect the confidentiality of the participants. Table 3 provides descriptive data of the participants.

\section{Table 2}

Gender, Ethnicity and Grade Level of students who participated in the pre and post assessments

\begin{tabular}{|c|c|c|c|}
\hline Characteristics & $\begin{array}{c}\text { School A }\left(6^{\text {th }}\right. \\
\text { grade }) \\
(n=17) \\
\%\end{array}$ & $\begin{array}{c}\text { School B }\left(8^{\text {th }}\right. \\
\text { grade }) \\
(n=27) \\
\%\end{array}$ & $\begin{array}{c}\text { School C }\left(9^{\text {th }}\right. \\
\text { grade }) \\
(n=24) \\
\%\end{array}$ \\
\hline \multicolumn{4}{|l|}{ Gender } \\
\hline Male & 29 & 26 & 38 \\
\hline Female & 71 & 74 & 62 \\
\hline \multicolumn{4}{|l|}{ Ethnicity } \\
\hline Non-Minority & 59 & 74 & 42 \\
\hline Minority & 41 & 26 & 58 \\
\hline
\end{tabular}

A total of six deliveries of the intervention were observed and data was collected from participants. I initially requested that all students attending the 
intervention participate in the study. However, the teachers at each school reported that collecting data from all of the students would be too time consuming and difficult to organize. Therefore, the teachers from each school chose one class of students, per delivery, to participate in the study. All six deliveries were provided in November of 2013. There was one delivery (A.1) of the intervention at School A, with 360 students in attendance and 17 students participating in the pre and post assessment portion of

the study. There were two deliveries of the intervention at School B, delivered on two consecutive days (Deliveries B.1 and B.2), with 130 and 110 students in attendance. Delivery B.1 had 14 student participants and Delivery B.2 had 13 student participants. There were three deliveries at School C, delivered back to back on the same day (Deliveries C.1, C.2, and C.3). Delivery C.1 had 7 students participate in the study, Delivery C.2 had 6 student participants and Delivery C.3 had 11 student participants. Teacher and parental consent for participation in the study, as well as student assent, were obtained through letters sent home by the each school. Student confidentiality was maintained. Teachers created an ID for each student participating, in order to match their pre and post assessments and so that the identity of the participants would be unknown to others and myself. All digital audio recordings of the deliveries were deleted on school grounds on the same day of the delivery, following a review by the two coders observing the delivery.

\section{Overview of the Intervention}

In 2009, in response to legal responsibilities to provide middle and high school students with cyberbullying and suicide prevention education, the school district approached a local theatre company to create a brief, theatre-based 
intervention for middle and high school students, addressing both areas. The theatre company has a strong history of educational outreach programs, whose content empowers participants to actively engage in solution finding around issues that affect them. The theatre company teamed up with the school district to create CHOICES, which allows students to explore issues of cyberbullying and teen suicide by devising possible scenarios and solutions through discussion and role-plays.

\section{Fidelity of Implementation Measurement (Hypothesis 1)}

The fidelity of implementation was measured by addressing how much (i.e., dosage) of what (i.e., adherence) was delivered in what ways (i.e., quality of implementation) and how it was received (i.e., participant responsiveness) (Dane \& Schneider, 1998; Domitrovich \& Greenberg, 2000). Contamination from prior exposure to the content was also measured (i.e. program differentiation). In a review of studies assessing fidelity, Mowbray et al. (2008) found that the most common methods for measuring fidelity include ratings by experts based on observations, interviews and/or recorded sessions.

\section{Observer Implementation Checklist}

An Observer Implementation Checklist was used by trained coders to track and code the fidelity of implementation across six separate audio-recorded deliveries of the intervention. The primary role of the coders was to mark whether or not each of the targeted behaviors was implemented. Eleven items on the checklist required a number count of how many times a certain element was present (i.e. "How many students offered suggestions"). There were five total coders, including myself, with 
two coders observing each intervention. I trained the coders so that each target behavior was described, defined, and operationalized as unambiguously as possible. I trained the coders by providing an in-depth description of the intervention, using the checklist as a guide and carefully describing each element in terms of accurate delivery and fidelity. I met with each coder, individually, and operationalized each item on the checklist, so that each coder would know what to assess for.

Each delivery was coded live, by two coders. Audio recordings of the deliveries allowed the coders to assess for inter-rater agreement. Following live coding of the intervention by both coders, the two coders compared checklists, identified discrepancies between ratings, and then used the audio recording to review the areas in the intervention where discrepancies occurred, in order to reach $100 \%$ coding agreement.

An implementation checklist (Appendix 2) was used in order to create a fidelity measure with low inference, so that differences between coders' judgment on identical items were less likely to lead to lower inter-rater reliability than other forms of observation measures such as rating scales and rubrics (Medley, Coker and Soar, 1984). The checklist measured four of the five dimensions described by Dane and Schneider- program adherence, dosage, quality of delivery, and participant responsiveness (1998). Dane and Schneider's fifth dimension, program differentiation, was measured with items on the teacher and student pre-assessment measure related to student's prior exposure to cyberbullying and suicide awareness activities and programs. 
Program adherence was measured by comparing the essential elements of the intervention to what was actually delivered in each delivery. Adherence was measured by the coders with items such as "Facilitator introduces basic structure of the intervention" and "Facilitator defines cyberbullying." Following each intervention, the coders asked the facilitators whether the short play imbedded within the intervention was performed according to script, a further measure of adherence, and noted their answers on the checklist. Dosage was measured by the coders with items that address the length (e.g. minutes) of the overall intervention, as well as the length (e.g. minutes) of each section. Quality of implementation was measured with items related to how the coders perceived the effectiveness of the intervention (including the level of accuracy with which the core content was delivered), as well as the facilitator's apparent overall enthusiasm during the intervention. Quality of implementation items included "Facilitator defines cyberbullying accurately, as 'repeated and willful acts of harm through the internet or cellphone"" and "Facilitator explains why the strategies are ineffective, accurately." Participant responsiveness was measured with items related to the level of student participation (i.e. number of active participants, number of total participants). Participant responsiveness was measured with items related to whether or not common implementation problems were encountered (i.e. student misbehavior, lack of student responsiveness) (Ennett et al., 2011; Fagen et al., 2008). Participant responsiveness items included, "Total number of student suggestions offered" and "STOP strategy is suggested by a student." Coders were also ask to judge the level of attention given by the students as well as provide feedback about any possible issues that may have affected student 
responsiveness, such as outside noise distractions and low student/teacher ratio.

Developing and Piloting the Implementation Measure

The Observer Implementation Checklist was developed through a number of steps. The first step involved the developers of the intervention identifying the goals (in terms of outcomes) of the intervention, the core content components related to knowledge and skills, and the methods used to delivery these core components. In the second step, I observed two deliveries of the intervention to list the core components and methods of delivery observed in the intervention. During the third step, I reviewed the script of the 20-minute play that is imbedded in the intervention, and identified any core content components present in that particular section.

In order to pilot the fidelity measure, I observed a delivery of CHOICES, and completed the Observer Implementation Checklist during the delivery in order to identify any potential problems with the checklists. I met with the developers (who also facilitate the intervention) to read over the checklist and discuss the operational definitions and descriptors for each item on the measure as well as any questions the facilitators might have.

\section{Outcome Measures (Hypotheses 2-8)}

Participant self-report data were collected using pre and post assessments in order to determine the outcomes of CHOICES. These measures were developed by the researcher with guidance from several of the original dissertation committee members (see Appendices 4 and 5). Pre and post measures each delivery were 
collected after obtaining both school district and University of Louisville IRB approval.

Pre-assessment measure

This instrument was administered to participants one school day before the intervention. The measure identified:

1. Prior exposure to cyberbullying and/or suicide awareness information.

2. Prior knowledge of cyberbullying and suicide intervention strategies. (Hypotheses 3 and 5)

3. Prior knowledge of the warning signs of suicide in a peer. (Hypothesis 4)

4. Level of willingness and level of confidence in helping a classmate who is being cyberbullied. (Hypotheses 6 and 8 )

5. Level of willingness and level of confidence in helping a classmate who is showing the warning signs of suicide. (Hypotheses 7 and 9)

Items included in this instrument measured prior knowledge of strategies for cyberbullying intervention, prior knowledge of the warning signs of suicide, and the tactic of identifying three trusted adults the students can go to in order to report a peer's suicidal behavior. Items included in the instrument that measure prior exposure to information were devised using information from the possible cyberbullying and suicide awareness interventions provided to individual schools by the school district. 


\section{Post-assessment measure}

A post-intervention assessment measure was administered to participants two weeks following the delivery of CHOICES. The instrument covered the following areas:

1. Students' participation in the intervention.

2. Level of the student's enjoyment of the intervention.

3. Student perception of their knowledge gained from the intervention related to addressing cyberbullying.

4. Student perception of their knowledge gained from the intervention related to addressing suicide.

5. Knowledge of effective cyberbullying and suicide intervention strategies. (Hypotheses 3 and 5)

6. Knowledge of the warning signs of suicide in a peer. (Hypothesis 4)

7. Level of willingness and level of confidence in helping a classmate who is being cyberbullied. (Hypotheses 6 and 8)

8. Level of willingness and level of confidence in helping a classmate who is showing the warning signs of suicide. (Hypotheses 7 and 9)

9. Students' identification with the cyberbullying victim.

Items included in these measures identifying the student's knowledge of cyberbullying and suicide prevention strategies were based on the core content identified in the intervention. Although the items on the post-assessment parallel the content of those in the pre assessment, they are different, in terms of wording, than those used in the pre assessment measure, in order to protect against testing effects. 
Developing and Piloting the Outcome Measures

I created a pilot measure, which combined items from both the pre and post assessments. Items from the posttest were omitted that duplicated content on the pretest [See Appendix 3 for the Pilot Measure]. An example of duplicate content questions between pre and post is: (Pre) "You emailed a private picture to your boyfriend or girlfriend, and they forwarded it to the entire school. Which of the following would be the BEST strategy to deal with the situation?" and (Post) "An anonymous person posts on Instagram pictures of you in your bathing suit at a friend's pool party. In the posting, they say really mean things about your body. Which of the following would be the BEST strategy to deal with the situation?"

The measure was piloted with a group of 13 students from grade levels 6-12. I contacted personal friends who are teachers of these grade levels, and asked for their help recruiting students who would be interested in participating. The students who participated in the pilot did not participate in the intervention. Pilot participants were asked to complete the measure and comment on the readability and clarity of the measure's items. Feedback was provided through written comments that students wrote directly on the measure. I incorporated this feedback into the final drafts of the pre and post assessments used for the evaluation. See Appendices 4 and 5 for the Pre and Post Measures.

Hypothesis 3 was tested using a three-item cyberbullying scale on the pre and posttest measures. The items describe the Stop-Block-Tell strategies defined in the research as effective strategies for addressing cyberbullying (Lorenz and Laanpere, 
2012; Robinson, 2012; Mishna et al., 2011, Hinduja \& Patchin, 2011; Feinberg \& Robey, 2009). Each item required the student participant to identify the best strategy (out of five options including a Stop-Block-Tell strategy) to address a given cyberbullying scenario. The cyberbullying strategy items were coded 0 for incorrect responses and 1 for correct responses. The total cyberbullying score was determined by summing across the 3 items. Scores ranged from 0 to 3 , with 3 indicating perfect identification of appropriate use of the stop, block, and tell strategies.

Hypothesis 4 was tested with a seventeen-item scale measuring warning signs of suicide on the pre and posttest measures, as defined in the literature (Rudd et al., 2006). Students read a list of 17 scenarios and indicated whether they believed the scenario described a warning sign of suicide. Students could indicate "I don't know" if they were unclear whether the scenario described a warning sign. The warning signs of suicide items were coded 0 for an incorrect response and a 1 for a correct response. The total pre- and post-warning signs scores were determined by summing across the 17 items on each scale. Scores ranged from 0 to 17 , with 17 indicating perfect identification of warning signs of suicide.

Hypothesis 5 was tested with one item that asked students to identify the best strategy (out of six options) for intervening if they witnessed a peer is displaying the warning signs of suicide. The answer designated as the best strategy involved reporting a peer's suicidal behavior to a trusted adult, the strategy modeled after gatekeeper programs, which focus on identifying individuals who are at risk for suicide and referring them for help (Isaac et al., 2009; Wyman et al., 2008; Brown et al., 2007). The suicide strategy item was coded 0 for an incorrect response and a 1 for 
a correct response. A total score of 1 on the pre- or post-scale indicated correct identification of the best strategy to address the presence of warning signs of suicide in a peer.

The pre- and posttest measures also included an item that measured the level of the student's willingness to help a classmate who is being cyberbullied (Hypothesis 6), as well as an item that measured willingness to help a classmate displaying the warning signs of suicide (Hypothesis 8). Responses were coded 1, 2, 3 or 4 with 4 indicating the highest willingness to help. Two pre and posttest items measured student's confidence in their ability to help a classmate who is being cyberbullied (Hypothesis 7), as well as confidence in their ability to help a classmate who is exhibiting the warning signs of suicide (Hypothesis 9). Responses were coded 1, 2, 3 or 4 with 4 indicating the highest confidence in their ability to help.

Several design issues led to low reliability of the scales on the outcome measures. Analyses of the reliability of the cyberbullying and warning signs of suicide scales were conducted following collection of the pre and post data. The internal consistency Cronbach's alpha of the pretest cyberbullying scale score (3 items) was .52 and the posttest reliability was .50 , indicating that the scores had low reliability on both versions of the measure. The internal consistency Cronbach's alpha of the pretest warning signs of suicide scale scores was .63 and the posttest reliability was .67 , indicating that the scores had low reliability on both versions of the measure. 


\section{Data Analyses}

\section{Analyses of fidelity of implementation}

Borelli et al. (2005) suggested defining high fidelity of implementation as .80 or greater proportion adherence to the fidelity checklist across all aspects (adherence, dosage, quality of implementation, participant responsiveness). The data were analyzed to determine if the $80 \%$ or more of the entire intervention was implemented as originally intended (Hypothesis 1). Levels of fidelity within each aspect were determined based on the proportion of core content items evident in each delivery. Further analyses also determined the levels of fidelity within each section of the intervention.

\section{Analyses of outcome data}

Descriptive statistics for the student survey data included means and frequency distributions. Inferential statistical methods used included paired t-test analyses.

Students' pre and post test scores were analyzed using paired t-tests, to determine if significant positive gains were present in students' knowledge of cyberbullying strategies, the warning signs of suicide and suicide strategies (Hypotheses 2-4) occurred as a result of the intervention. Students' pre and post test scores were also analyzed using paired t-tests, to determine if significant positive gains were present in students' confidence and willingness to intervene in situations involving cyberbullying of a classmate, as well as if a classmate is exhibiting the 
warning signs of suicide (Hypotheses 5-8). A Bonferroni correction was used to control for Type 1 and the alpha level will be .007 . 


\section{CHAPTER IV}

RESULTS

\section{Fidelity of Implementation (Hypothesis 1)}

Fidelity of implementation data (Hypothesis 1) were gathered from two sources, the Observer Implementation Checklist and the student pretest. Two coders completed Observer Implementation Checklists for each of the six deliveries of the intervention.

Total levels of fidelity within each dimension were determined based on the proportion of core content items evident across each entire delivery of CHOICES. Further analyses also determined the levels of fidelity within each section of the intervention. A fidelity ratio was computed for each section, as well as for the entire delivery (number of observed core content items/total number of core content items). This ratio captured the level at which the intervention, comprising core content items, was delivered as it was initially designed. Table 3 shows the fidelity ratio scores within each section, as well as the total fidelity ratio scores for each of the six deliveries, using data from the fidelity of implementation checklists. 


\section{Table 3}

Fidelity of Implementation Total Ratio Scores and Within Section Ratio Scores

\begin{tabular}{lllllll}
\hline Delivery & $\begin{array}{l}\text { Total } \\
\text { Ratio }\end{array}$ & Section 1 & Section 2 & Section 3 & Section 4 & Section 5 \\
\hline A.1 & 0.70 & $1.00^{*}$ & $1.00^{*}$ & $1.00^{*}$ & 0.78 & 0.30 \\
B.1 & 0.78 & $1.00^{*}$ & $1.00^{*}$ & $0.82^{*}$ & 0.74 & 0.70 \\
B.2 & $0.80^{*}$ & $1.00^{*}$ & $1.00^{*}$ & $1.00^{*}$ & 0.78 & 0.60 \\
C.1 & 0.77 & $1.00^{*}$ & $1.00^{*}$ & $0.82^{*}$ & $0.87 *$ & 0.50 \\
C.2 & 0.67 & $1.00^{*}$ & $1.00^{*}$ & $0.82^{*}$ & $0.83^{*}$ & 0.25 \\
C.3 & 0.78 & $1.00^{*}$ & $1.00 *$ & $1.00^{*}$ & 0.74 & 0.60 \\
Mean & $\mathbf{0 . 7 5}$ & & & & & \\
\hline
\end{tabular}

$*$ High fidelity $\geq .80$

Across all six deliveries the mean total fidelity ratio was $0.75(S D=0.05)$.

Although the total fidelity ratio is moderate, the total fidelity ratio does not meet the .80 threshold of high fidelity suggested by Borelli et al (2008). Therefore, Hypothesis 2 was not supported.

In terms of individual deliveries, Delivery B.2 was the only delivery to meet the .80 threshold. However, it should be noted that the first three sections of the intervention, across all six deliveries, met the threshold of high fidelity. Lowest levels of fidelity were found in Sections 4 and 5.

In addition to measuring fidelity within and across the intervention, the checklist also measured four of the five dimensions described by Dane and Schneider- program adherence, dosage, quality of delivery, and participant 
responsiveness (1998). Every core content item on the checklist fell into one or more of these dimension categories (see the Appendix 2: Observer Implementation Checklist). Dane and Schneider's fifth dimension, program differentiation, was measured with items on the pretest measure related to student's prior exposure to cyberbullying and suicide awareness activities and programs. Table 4 shows the program adherence, quality of delivery, and participant responsiveness fidelity ratios (number of observed core content items per dimension/total number of core content items per dimension).

\section{Table 4}

Program Adherence, Quality of Delivery, and Participant Responsiveness Fidelity Ratios per Delivery

\begin{tabular}{llll}
\hline Delivery & $\begin{array}{l}\text { Program } \\
\text { Adherence }\end{array}$ & $\begin{array}{l}\text { Quality of } \\
\text { Delivery }\end{array}$ & $\begin{array}{l}\text { Participant } \\
\text { Responsiveness }\end{array}$ \\
\hline A.1 & 0.66 & $0.89^{*}$ & $0.85^{*}$ \\
B.1 & 0.74 & 0.78 & $0.92^{*}$ \\
B.2 & 0.77 & $0.89^{*}$ & $0.85^{*}$ \\
C.1 & 0.72 & 0.78 & $0.92^{*}$ \\
C.2 & 0.64 & 0.56 & $0.85^{*}$ \\
C.3 & 0.77 & $0.89 *$ & $0.85^{*}$ \\
& & & \\
\hline
\end{tabular}

*High fidelity $\geq .80$ 
Across all six deliveries, high program adherence fidelity was not achieved. Across all deliveries of the intervention, the facilitator failed to explicitly teach and reinforce the true warning signs of suicide. In Deliveries B.1, B.2, C.1, C.2, and C.3, the facilitator asked the students to list the warning signs of suicide they witnessed in the play, but then failed to reinforce to the students which signs were true warning signs. For example, in several deliveries, students suggested that a warning sign of suicide included Hannah (the character in the play) offering her prized X-Box to her brother. This example is not a warning sign of suicide, based on what is defined in the literature (Rudd et al., 2006). Nevertheless, when this was suggested, the facilitators did not correct the student. However, in these five deliveries, the facilitator did provide the effective suicide strategy of seeking help from a trusted adult.

High fidelity was reached in Deliveries A.1, B.2 and C.3 in the quality of delivery dimension. High fidelity was reached across all deliveries in the participant responsiveness dimension.

The dimensions of dosage and program differentiation can provide valuable information that informs the outcomes of the intervention. The developers of the intervention developed CHOICES to be approximately 90 minutes in length. Dosage was measured by tracking the time spent on each of the six deliveries of the intervention. Table 5 shows the total time in minutes of each delivery, as well as the total time spent on each section of each delivery. 


\section{Table 5}

Dosage: Total Time Spent in Minutes per Delivery and Time Spent per Section

\begin{tabular}{lllllll}
\hline Delivery & $\begin{array}{l}\text { Total } \\
\text { Time }\end{array}$ & Section 1 & Section 2 & Section 3 & Section 4 & Section 5 \\
\hline A.1 & 88 & 8 & 21 & 11 & 44 & 4 \\
B.1 & 72 & 5 & 20 & 7 & 32 & 8 \\
B.2 & 86 & 4 & 20 & 8 & 34 & 20 \\
C.1 & 50 & 4 & 18 & 5 & 20 & 3 \\
C.2 & 53 & 4 & 18 & 5 & 22 & 4 \\
C.3 & 59 & 6 & 18 & 5 & 25 & 5 \\
\hline
\end{tabular}

The coders for Delivery A.1 noted that due to the size of the audience (360 students), the role-playing portion of the intervention (Section 4) took much longer (44 minutes) than the time allotted by the developers (20-30 minutes). Due to so much time being spent in Section 4, only four minutes was spent in Section 5. Consequently, nearly all of the content related to the warning signs of suicide was left unaddressed, with one exception: The facilitator did ask the students, "Think of three adults you trust, three people you can go to if you or a friend are thinking of hurting or killing themselves."

Program differentiation was measured with items on student pre assessment measures related to their exposure to cyberbullying and suicide awareness activities and programs before participating in CHOICES. In a survey completed prior to the CHOICES delivery, Teacher 3 from School C reported that she had provided her students with information about cyberbullying within the current school year, in the form of classroom lessons, a video and speakers. Teacher 1 from School A and 
Teacher 2 from School B both reported that they had not provided such information. In terms of suicide awareness materials, all three teachers reported that they had provided their students with suicide awareness materials, using a state required curriculum that included a classroom lesson, video and a pamphlet. Out of the 68 student participants, 38 students $(55.9 \%)$ reported having received written materials about cyberbullying and 54 students (79.4\%) reported having received classroom lessons about cyberbullying in the past school year. In terms of suicide awareness, 46 students $(67.6 \%)$ reported having received written materials and 59 students $(86.8 \%)$ reported having received classroom lessons in the past school year. Sixteen students (23.5\%) reported having seen an interactive play about bullying at some point in their school career. Table 6 provides a description of the percentage of student exposure to cyberbullying and suicide awareness materials, per grade level.

\section{Table 6}

Prior exposure to cyberbullying and suicide materials by grade level

\begin{tabular}{lccc}
\hline Exposure & Grade 6 (n=17) & Grade 8 (n=27) & Grade 9 (n=24) \\
\hline $\begin{array}{l}\text { Cyberbullying } \\
\text { written materials }\end{array}$ & $35.3 \%$ & $29.6 \%$ & $100.0 \%$ \\
$\begin{array}{l}\text { Cyberbullying } \\
\text { class-room lessons }\end{array}$ & $76.4 \%$ & $70.3 \%$ & $91.7 \%$ \\
$\begin{array}{l}\text { Suicide written } \\
\text { materials }\end{array}$ & $41.2 \%$ & $55.6 \%$ & $100.0 \%$ \\
$\begin{array}{l}\text { Suicide classroom } \\
\text { lessons }\end{array}$ & $64.7 \%$ & $92.6 \%$ & $95.8 \%$ \\
$\begin{array}{l}\text { Interactive play } \\
\text { about } \\
\text { cyberbullying }\end{array}$ & $35.3 \%$ & $16.7 \%$ & $25.0 \%$ \\
\hline
\end{tabular}




\section{Student Outcomes (Hypotheses 2-8)}

Descriptive statistics and paired sample t-tests were conducted to address research hypotheses 2-8. Table 7 shows descriptive statistics and t-test results for Cyberbullying Strategies (Hypothesis 2), Warning Signs of Suicide (Hypothesis 3), and Suicide Strategies (Hypothesis 4).

\section{Table 7}

Descriptive Statistics and t-test Results for Knowledge of Cyberbullying Strategies, Warning Signs, and Suicide Strategies

\begin{tabular}{|c|c|c|c|c|c|c|c|c|}
\hline \multirow[b]{2}{*}{ Outcome } & \multicolumn{2}{|c|}{ Pretest } & \multicolumn{2}{|c|}{ Posttest } & \multirow[b]{2}{*}{$n$} & \multirow[b]{2}{*}{$\begin{array}{c}p- \\
\text { value }\end{array}$} & \multirow[b]{2}{*}{ t-value } & \multirow[b]{2}{*}{$d f$} \\
\hline & $M$ & $S D$ & $M$ & $S D$ & & & & \\
\hline Cyberbullying & 2.31 & 0.87 & 2.43 & 0.83 & 68 & 0.38 & 0.88 & 67 \\
\hline Warning Signs & 11.44 & 2.48 & 12.00 & 2.82 & 68 & 0.07 & 1.87 & 67 \\
\hline Suicide & 0.71 & 0.46 & 0.71 & 0.46 & 68 & 1.0 & 0.00 & 67 \\
\hline
\end{tabular}

Examination of means at both time points revealed that student Cyberbullying scores (Hypothesis 2) were high before the intervention, indicating that students had previous knowledge of effective strategies to address cyberbullying as measured by the pretest. Examination of means on the Warning Signs of Suicide scale (Hypothesis 3) also indicated that students recognized many of the warning signs of suicide before being exposed to the intervention. Paired-sample t-tests comparing pre and post scores were not significant for both cyberbullying strategies $(t(67)=0.88, p=0.38)$, 
and the warning signs of suicide $(t(67)=1.87, p=0.07)$. Therefore, Hypotheses 2 and 3 were not supported.

Examination of the Suicide Strategy scores (Hypothesis 4) demonstrated that the means remained unchanged from pretest to posttest and the paired samples t-test comparing the pre and post Suicide Strategy scores were not significant $(t(67)=0.00, p=1.0)$. Therefore, Hypothesis 4 was not supported.

Table 8 shows descriptive statistics and t-test results for Confidence in Addressing Cyberbullying (Hypothesis 5), Willingness to Address Cyberbullying (Hypothesis 6), Confidence in Addressing Suicide (Hypothesis 7), and Willingness to Address Suicide (Hypothesis 8).

\section{Table 8}

Descriptive Statistics and t-test Results for Confidence in Addressing Cyberbullying, Willingness to Address Cyberbullying, Confidence in Addressing Suicide, and Willingness to Address Suicide

\begin{tabular}{|c|c|c|c|c|c|c|c|c|}
\hline \multirow[b]{2}{*}{ Outcome } & \multicolumn{2}{|c|}{ Pretest } & \multicolumn{2}{|c|}{ Posttest } & \multirow[b]{2}{*}{$n$} & \multirow[b]{2}{*}{$\begin{array}{c}p- \\
\text { value }\end{array}$} & \multirow[b]{2}{*}{$\begin{array}{c}t- \\
\text { value }\end{array}$} & \multirow[b]{2}{*}{$d f$} \\
\hline & $M$ & $S D$ & $M$ & $S D$ & & & & \\
\hline Cyber & & & & & & & & \\
\hline Confidence & 3.34 & 0.77 & 3.43 & 0.73 & 68 & 0.43 & 0.80 & 67 \\
\hline $\begin{array}{l}\text { Cyber } \\
\text { Willingness }\end{array}$ & 3.63 & 0.73 & 3.50 & 0.89 & 68 & 0.34 & -0.96 & 67 \\
\hline $\begin{array}{l}\text { Suicide } \\
\text { Confidence }\end{array}$ & 3.35 & 0.82 & 3.38 & 0.81 & 68 & .80 & 0.26 & 67 \\
\hline $\begin{array}{l}\text { Suicide } \\
\text { Willingness }\end{array}$ & 3.77 & 0.52 & 3.56 & 0.78 & 68 & 0.05 & -1.98 & 67 \\
\hline
\end{tabular}


Examination of means at both time points revealed that Cyber and Suicide Confidence scores (Hypotheses 5 and 7) were high before the intervention. Paired sample t-tests comparing the pre and post Confidence scores on both cyberbullying strategies $(t(67)=0.80, p=0.43)$, and the warning signs of suicide $(t(67)=0.26, p=0.80)$, were not significant. Therefore, Hypotheses 5 and 7 were not supported.

Examination of means at both time points revealed that Cyber and Suicide Willingness scores (Hypotheses 6 and 8) were high before the intervention. A pairedsample t-test comparing the pre and post student Willingness scores on the cyberbullying strategies $(t(67)=-0.96, p=0.34)$ were not significant. A pairedsample t-test comparing the pre and post student Willingness scores on the warning signs of suicide $(t(67)=\quad-1.98, p=0.05)$ was also not statistically significant. Therefore, Hypotheses 6 and 8 were not supported. 


\section{CHAPTER V}

\section{DISCUSSION}

\section{Summary of Findings}

In the present study, the effectiveness of CHOICES, a brief, applied-theatre intervention that addresses cyberbullying and suicide was evaluated. Investigation of the fidelity of implementation revealed that CHOICES was not implemented with high levels of fidelity. The analyses of the outcomes found no significant changes in student knowledge of effective strategies that address cyberbullying and suicide. No significant change was found in student confidence or willingness to intervene on behalf of a peer in a cyberbullying situation. No significant change was found in student confidence or willingness to intervene on behalf of a peer exhibiting the warning signs of suicide. Along with the lack of significant findings, it is difficult to draw conclusions about the effects of CHOICES because of issues of fidelity and instrumentation. Following is a discussion of these findings, including supportive data and theory, limitations and implications of the study, and recommendations for future research.

\section{Fidelity of Implementation}

As indicated in the review of the literature, research on fidelity of implementation and the implications for high and low levels of fidelity are still 
emerging. Fidelity checks can guide evaluators to identify areas of interventions that are not being implemented as originally intended. In many school-based prevention programs, high levels of fidelity are positively correlated with program effectiveness (Gottfredson \& Gottfredson, 2008; Fagen et al., 2008; Durlak \& DuPre, 2008; Dusenbury et al., 2003; Dane \& Schneider, 1998). However, even the most empirically sound interventions will lack effectiveness if delivered with poor fidelity. It remains to be seen whether improving fidelity in CHOICES would improve program effectiveness.

The dimensions of adherence and dosage particularly impacted the total fidelity of implementation across the deliveries. Results of the fidelity check showed that program adherence had the lowest total fidelity ratios across all deliveries (.64.77). This demonstrated that facilitators did not deliver, to a high degree, the intervention as it was intended. For example, it is possible that CHOICES produced no significant changes in knowledge of the suicide warning signs because clear explanation of empirically-supported signs of suicide did not occur. The fidelity check revealed that across all deliveries of the intervention, the facilitator failed to explicitly teach and reinforce the warning signs of suicide. This failure of implementation could call into question any change in students' learning of this content being attributed to CHOICES.

As previously reported, Section 5 (including the suicide content) was most susceptible to the effects of dosage. Dosage can impact outcomes because less time spent teaching content will result in less learning. Teacher 1 from School A addressed this issue on a survey she completed following the intervention, "The play was great! 
Needs to be longer than 1 hour. Possibly have some audience participation, but that part took up a lot of time. The suicide part is an issue I wish we had gotten to address. Possibly have a time limit that allows for a certain amount of time for each portion of the play and discussion afterwards." Time constraints affect the facilitator's ability to deliver the intervention with high levels of adherence and quality. Similarly, participant's response levels are sacrificed when time is limited. CHOICES was designed to encourage interaction between the facilitators and the students, through brainstorming and role-plays. When time constraints limited these interactions, it was difficult measure the impact of this design element. Similarly, when the facilitators ran out of time the core content provided in Section 5 was sacrificed, and thus learning could not occur. Thus, the program as designed on paper is not what was delivered, so there cannot be an expectation that any change can be due to intervention.

Results involving program differentiation also impacted the lack of significant findings in this study. In addition to CHOICES, cyberbullying interventions provided to the students in the district include iSafe, NetSmartz, iKeepSafe, and CyberSmart. The primary suicide awareness information provided to the middle and high schools is an information brochure. The high percentage of students who were previously exposed to cyberbullying and suicide awareness materials probably accounts for the high pre-test scores in these areas. CHOICES use of applied theatre interventions could allow opportunities for students to put their previously acquired knowledge into practice through role-plays. The evaluation revealed that students were not provided with adequate time to do this. 
Measurement of fidelity of implementation is necessary in order to accurately interpret the outcomes of a program (O'Donnel, 2008; Dusenbury, et al., 2003). Measuring the fidelity of a theatre-based program, which is inherently adaptable and changing in form, allowed for a unique challenge and provided valuable information about how to evaluate programs that are fluid and flexible in nature, yet still have concrete learning objectives. Understanding where facilitators made adaptations, along with the appropriateness and reasons behind the changes, can help developers and facilitators make more informed decisions, prior to and during the intervention, to insure higher levels of fidelity and avoid the possible repercussions of low levels.

\section{Outcomes}

The majority of states have legislation to address both cyberbullying and suicide in schools (Stanton, S., 2012; Snakenbourg, et al., 2011). The schools involved in this study were already addressing this mandate prior to the delivery of CHOICES. The schools involved in this study provide cyberbullying curriculum to their students that include the Stop-Block-Tell strategies. Mishna et al. (2011) found evidence that some Internet safety programs using the Stop-Block-Tell approach reported significant increases in students' knowledge of Internet safety. The suicide awareness materials provided by the state (which the majority of the participants reported having received prior to the intervention) employed the Gatekeeper model by providing a list of the warning signs of suicide, as well as providing a help-seeking strategy. Gatekeeper programs are increasingly used as the suicide prevention approach in schools (Issac, et al., 2009; Brown, et al., 2007) and have been shown to positively increase self-evaluated knowledge, as well as perceived willingness and 
confidence in participants' ability to intervene in situations involving suicidal students (Wyman, et al., 2008). In the current study, in addition to knowledge, students reported confidence and willingness to intervene in situations involving cyberbullying and the warning signs of suicide, both before and after the intervention. This suggests that students are benefitting from the cyberbullying and suicide content provided to them prior to CHOICES. No significant gains in knowledge, confidence, or willingness were found after participation in CHOICES.

In addition to issues of fidelity of implementation, along with prior exposure to the core content, the conclusions about the effects of CHOICES cannot be determined due to issues with poor instrumentation. It is probable that the instruments did not reliably measure the intended outcomes of the intervention. The reliability of the pre and post measures were low and would have benefitted from a more rigorous piloting process. High pretest scores may have been attributed to students' prior knowledge, willingness and confidence. In addition, the pre- and post-test items related to students' perceived confidence and willingness were possibly too general in nature to adequately capture students' attitudes.

It is also possible that pre-assessment results were inflated as a result of an overestimation of the participants' willingness and confidence to intervene in suicide and cyberbullying situations. Upon involvement in the intervention, participants may have discovered that their understanding of the constructs shifted. Use of a retrospective pre-test would possibly control for this response-shift bias (Pratt, McGuigan, and Katzev, 2001). 


\section{Implications for Future Direction}

Programming

A comprehensive approach to addressing cyberbullying at the school-level is the most recommended approach found in cyberbullying prevention literature (Couvillon \& Ilieva, 2011; Beale \& Hall, 2010; Kowalski et al., 2008). This is in line with the research on effective prevention programming strategies for youth at risk, recommending a comprehensive approach, which targets not only the youth themselves, but the community, school and families of the youth (Nation et al., 2003; Hawkins \& Catalano, 1992). Comprehensive programs address risk factors across multiple domains (e.g. family, school, community), which "influence the development and perpetuation of the behaviors to be prevented" (Nation et al., 2003, p. 452). In their review of cyberbullying prevention programs, Couvillon and Ilieva (2011) found that, when compared to other less inclusive forms of programing, comprehensive programs that involve multiple participants (i.e., administrators, teachers, students, and parents) using a variety of resources, such as school-wide surveys, in-class curricula, and professional development were most effective, as they involve all the stakeholders concerned with the safety and well-being of students, and most effectively send a message that cyberbullying is unacceptable. Kowalski, Limber, and Agastan (2008) suggest that comprehensive prevention efforts should begin with a school-wide assessment of cyberbullying amongst the school population, in order to capture the scope of the problem within the school. Additionally, researchers suggest that teachers and administrators should receive ongoing professional development regarding cyberbullying, including associated risk factors 
and repercussions, as well as prevention and intervention measures (Couvillon \& Ilieva, 2011; Beale \& Hall, 2010; Kowalski et al., 2008).

Despite pressures of time and money, if schools want to invest in programming and curriculum that is cost-effective and impacts learning and behavioral change, they should seek programming that is more comprehensive, delivered repeatedly across time, and uses a variety of methods. The theatre company that developed CHOICES would likely benefit by directing their program development efforts toward interventions that enhance students' previous knowledge through active skill development, such as role-play and other forms of applied theatre. In an effort to intervene with multiple systems, a future adaptation of the intervention could engage students with teachers and parents in role-plays of the cyberbullying and suicide strategies, which could help promote positive relationships, and increase help-seeking behaviors. Additionally, the facilitators could return to provide followup booster sessions that allow for further practice of the skills developed in the intervention.

In order to insure the program is more appropriately timed, the intervention might be more effective if adapted for a younger audience. Considering both the middle and high school student participants reported having prior exposure to cyberbullying and suicide awareness materials, future adaptations of the intervention could involve older students facilitating the intervention in order to make it more effective for younger audiences. Perhaps the current alternative version of the intervention, which employs student actors from the same school district, would be a viable option. 


\section{Improved Fidelity}

Of the six deliveries, no two deliveries were the same, as evidenced by the variability of implementation, particularly in terms of adherence and dosage. Although there cannot be definitive conclusions drawn about the impact of varying levels of fidelity on the outcomes of CHOICES, the measures of fidelity can still be used to guide practical change. The evaluation of implementation highlights areas of the intervention that can be changed to allow for higher adherence in future deliveries. Similarly, the specific identification of the essential content and design elements provides valuable information to the facilitators to help them make more informed choices when adaptations to the interventions are necessary (i.e. due to time restraints; Foster, 2011; Dane \& Schneider, Dusenbury et al., 2003; Mowbray, 2003).

Research remains scarce (Dusenbury et al., 2003) on fidelity of implementation that includes evaluating a program across all five dimensions, as proposed by Dane and Schneider (1998). This study suggests that continued investigation of fidelity of implementation in prevention programs is warranted. Considered with the characteristics described by Nation et al. (2003), attention to fidelity of implementation will help the developers gain a greater understanding of the content and design elements that are critical to delivering effective programming.

\section{Limitations}

\section{Outcome Measures}

As previously discussed, the reliability of the measures makes it difficult to draw conclusions about the effects of CHOICES on student outcomes related to 
knowledge, confidence, and willingness, which is a limitation of this study. In addition, social desirability (Crowne \& Marlowe, 1960) may have been a threat to the reliability and validity of these self-report measures, as participants may have been motivated to answer in ways that would promote a positive self-image as ready and willing to intervene on behalf of a friend.

If this study were to be replicated, additional information needs to be obtained in a pilot study before full implementation of the evaluation. Piloting would be helpful to determine if different grade levels require different measures, as well as if the reading levels need to be adjusted. Piloting would also determine whether measures are equivalent pre and post, whether reliable scales can be created, and would determine if the factor structure is there and consistent across grade levels.

\section{Observer Implementation Checklist}

Critical content items on the Observer Implementation Checklist were not weighted in the calculation of the fidelity ratios, which creates another measurement issue. For example, in terms of adherence, whether the facilitator introduced the theatre company was given just as much weight (1 point) as whether the warning signs of suicide were discussed (also 1 point). This is an obvious limitation of the measure and must be considered when interpreting the data. Future versions of the Observer Implementation Checklist should include weighted critical content items. Available research on fidelity of implementation does not give a clear answer as to how to consider or weight certain key elements over other less essential elements (Dusenbury et al., 2003; Dane \& Schneider, 1998). In future evaluations, weighting certain items, specifically adherence items linked to the critical content of the 
intervention, would likely change the fidelity ratios and provide a more accurate depiction of fidelity of implementation.

\section{Sample Limitations}

Data collection for this study was restricted to a one-month period in the fall of 2013. Due to diminishing numbers of deliveries, as well as concern that collecting data across multiple school years would affect the validity of the study, only six deliveries were included in the evaluation. Ideally, I would have collected data from more deliveries, allowing for a greater sample size, as well as providing a broader snapshot of the fidelity of implementation. The sample was a convenience sample from three schools (two middle and one high school) from a large urban school district in a mid-southern state, with a total of 68 students participating in the pre and post assessments. The small response percentage of students (9.75\%) who participated in the pre and post assessment makes it difficult to draw conclusions about the effects of the intervention on the larger group of students who participated in the intervention. The small sample size also made it impossible to examine between group differences because of the decreased sample size at each level. Although the sample size does not affect the analyses of the fidelity of implementation of the deliveries, small sample size, low response rate, restricted demographics, and lack of random assignment do not allow for generalizability.

The present study included both middle and high school deliveries. Evaluating these two age groups together confounds the results of the study, because the interventions existed in different places for different amounts of time with students of 
different cognitive complexity. All three high school deliveries were given on the same day, at the same school, in the same grade, making it difficult to generalize the findings to a broader high school population. Similarly, this study was limited in that only two middle schools participated (3 deliveries total), making it difficult to generalize the findings to that population.

\section{Recommendations for Future Research}

Given the results, as well as the limitations of this study, several recommendations for future research emerged. Time and budgetary constraints will continue to support the use of brief, one-shot interventions in schools, despite the strong evidence that more comprehensive programs delivered over time, across settings are more effective (Nation, et al, 2003). Future research should investigate the effectiveness of brief interventions imbedded within comprehensive programs, rather than as a stand-alone approach. Schools will continue to be enticed by interventions that are interactive and enjoyable for students, such as theatre and other arts-based interventions. Therefore, further research on effective arts- based programs would be an important contribution to the literature.

Research on fidelity of implementation is in its infancy. Future research that not only addresses the impact of fidelity on outcomes, but also investigates the impact and relative strength of the five dimensions of fidelity, would help inform the field of comprehensive program evaluation. Future research should look more closely at how to identify "critical components" of an intervention to allow for the development of fidelity measures that more accurately assess implementation. 
Students' reports of knowledge, willingness, and confidence to intervene do not necessarily predict behavioral change (Portzky \& Heeringen, 2006; Katz, et al, 2013). Future research might look at the long-term effects on behaviors. Longitudinal data collection, for example a 6-month follow-up, would allow the evaluation of whether students were able to put theory into practice. Research on cyberbullying and effective intervention and prevention is nascent (Hinduja \& Patchin, 2013). As technology changes rapidly, it is a challenge for researchers and interventionists to stay ahead of the curve in providing effective programming for youth that is salient and accurate. Future research on effective cyberbullying prevention that remains socioculturally relevant would address this challenge.

Research that investigates the relationship between cyberbullying and suicide in youth is also scarce (Hinduja \& Patchin, 2009) and there is little evidence of how cyberbullying prevention and suicide prevention can be used in tandem (Baumann, et al., 2013). Further research in these areas would allow for more effective development of evidenced-based prevention programs, including possible future adaptations of CHOICES. Also, future research that identifies the underlying mechanisms that support cultures of bullying can help inform future iterations of the intervention, by identifying effective ways to prevent cyberbullying before it occurs, rather than intervene afterwards.

\section{Conclusion}

Cyberbullying and suicide remain critical issues facing adolescents and their communities. Although the outcomes of CHOICES produced non-significant results, 
the study did provide evidence that students are gaining knowledge on effective strategies to address both cyberbullying and suicide, through curricula and materials provided to them. Although students may have the knowledge to address these issues, what remains to be seen is if this knowledge is leading to lasting changes in their behavior. Applied theatre interventions which focus on active skill development may help students put knowledge into action. Comprehensive approaches that involve active participation of youth, schools, families, and communities, provided repeatedly over time, will likely prove most effective. 


\section{REFERENCES}

Andsager, J.L., Austin, E.W., \& Pinkleton, B.E. (2001). Questioning the value of realism: Young adults' processing of messages in alcohol-related public service announcements and advertising. Journal of Communication, 51, 121142.

Ang, R. P., \& Goh, D.H. (2010). Cyberbullying among adolescents: The role of affective and cognitive empathy, and gender. Child Psychiatry and Human Development, 41, 387-397.

Baer, A. L., \& Glasgow, J. N. (2008). Take the bullies to task: Using process drama to make a stand. English Journal, 97, 79-86.

Bandura, Albert (1963). Social learning and personality development. New York: Holt, Rinehart, and Winston.

Breitenbecher, K., \& Scarce, M. (1999). A Longitudinal Evaluation of the Effectiveness of a Sexual Assault Education Program. Journal of Interpersonal Violence, 14, 459-78.

Bridge, J.A., Goldstein, T.R., \& Brent, D.A. (2006). Adolescent suicide and suicidal behavior. Journal of Child Psychology and Psychiatry,47, 372-394.

Bronfenbrenner, U. (1979). The Ecology of Human Development: Experiments by Nature and Design. Cambridge, MA: Harvard University Press.

Boal, A. (1979). Theatre of the oppressed. New York: Theatre Communications 
Group.

Broadband Data Improvement Act, 110th Congress, 2007-2009. Text as of Oct 01, 2008 (Passed Congress/Enrolled Bill).

Brown, C.H., Wyman, P.A., Brinales, J.M., \& Gibbons, R.D. (2007). The role of randomized trials in testing interventions for the prevention of youth suicide. International Review of Psychiatry, 19, 1-15.

Burton, B. (2010). Dramatising the hidden hurt: Acting against covert bullying by adolescent girls. Research in Drama Education, 15, 255-270.

Centers for Disease Control and Prevention. Injury Center: Violence Prevention. Suicide Prevention, Youth Suicide. 2012. Retrieved September 11, 2012, from Centers for Disease Control and Prevention, National Center for Injury and Prevention Control website:

www.cdc.gov/ViolencePrevention/suicide/index.html

Centers for Disease Control and Prevention. Adolescent and School Health: Youth Risk Behavior Surveillance System (YRBSS). 2012. Retrieved September 11, 2012, from Centers for Disease Control and Prevention, Adolescent and School Health website: www.cdc.gov/healthyyouth/yrbs/index.htm

Cheadle A., Cahill C., Schwartz P.M., Edmiston, J., Johnson, S., Davis, L., \& Robbins, C. (2012). Engaging youth in learning about healthful eating and active living: an evaluation of educational theater programs. Journal of Nutrition Education and Behavior, 44,160-165.

Chernoff, R. A., \& Davison, G. C. (2005). An evaluation of a brief HIV/AIDS prevention intervention for college students using normative feedback and 
goal setting. AIDS Education and Prevention, 17, 91-104.

Couvillon, M., \& Ilieva, V. (2011). Recommended practices: A review of schoolwide preventative programs and strategies on cyberbullying. Preventing School Failure, 55, 96-101.

Cross, W. F., Seaburn, D., Gibbs, D., Schmeelk-Cone, K., White, A., \& Caine, E. D. (2011). Does practice make perfect? A randomized control trial of behavioral rehearsal on suicide prevention gatekeeper skills. Journal of Primary Prevention, 32, 195-211.

Crowne, D. P., \& Marlowe, D. (1960). A new scale of social desirability independent of psychopathology. Journal of Consulting Psychology, 24, 349-354.

Dane, A.V. \& Schneider, B.H. (1998). Program integrity in primary and early secondary prevention: are implementation effects out of control? Clinical Psychology Review, 18, 23-4.

Diamanduros, T., Downs, E., \& Jenkins, S. J. (2008). The role of school psychologists in the assessment, prevention, and intervention of cyberbullying. Psychology in the Schools, 45(8), 693-704.

Demyan, A., \& Anderson, T. (2012). Effects of a brief media intervention on expectations, attitudes, and intentions of mental health seeking. Journal of Counseling Psychology, 59(2), 222-229.

Dennis, K. (2009) Acting up: Theatre of the oppressed as critical ethnography. International Journal of Qualitative Methods. 8(2), 65-96.

Devine, P., \& Lloyd, K (2012). Internet use and psychological well-being among 10year-old and 11-year-old children. Child Care in Practice, 18(1), 5-22. 
Diamanduros, T., Downs, E., \& Jenkins, S. J. (2008). The Role of School Psychologists in the Assessment, Prevention, and Intervention of Cyberbullying. Psychology in the Schools, 45(8), 693-704.

Dillard, J. P., \& Peck, E. (2000). Affect and persuasion: Emotional responses to public service announcements. Communication Research, 27, 461-495.

Durden, E., \& Tomaselli, K. (2012). Theory meets theatre practice: Making a difference to public health programmes in southern Africa. Professor Lynn Dalrymple: South African scholar, activist, educator. Curriculum Inquiry, 42(1), 80-102.

Dusenbury, L., Brannigan, R., Falco, M., and Hansen, W. (2003). A review of research on fidelity of implementation: implications for drug abuse prevention in school settings. Health and Education Research: Theory and Practice, 18(2), 237-256.

Foster, L. H. (2011). Fidelity: Snapshots of implementation of a curricular intervention. (Order No. 3485327, University of Virginia). ProQuest Dissertations and Theses, 215.

Gervais, M. (2006). Exploring moral values with young adolescents through process drama. International Journal of Education \& the Arts, 7(2) 33-47.

Goldstein, T. R., \& Winner, E. (2012). Enhancing empathy and theory of mind. Journal of Cognition And Development, 13(1), 19-37.

Gourd, K. M., \& Gourd, T. Y. (2011). Enacting Democracy: Using Forum Theatre to confront bullying. Equity \& Excellence In Education, 44(3), 403-419.

Graves,K., Frabutt, J., \& Vigliano, D. (2007). Teaching conflict resolution skills to 
middle and high school students through applied theatre and role play. Journal of School Violence, 6(4), 59-79.

Greenhow, C., Walker, J., \& Kim, S. (2009). Millennial learners and net-savvy teens? Examining Internet use among low-income students. Journal of Computing in Teacher Education, 26(2), 63-68.

Harvey, B., Stuart, J., \& Swan, T. (2000). Evaluation of a drama-in-education programme to increase AIDS awareness in South African high schools: A randomized community intervention trial. International Journal of STD and AIDS, 11(2), 105-111.

Hawkins, J. David; Catalano, Richard F.; Miller, Janet Y. (1992). Risk and protective factors for alcohol and other drug problems in adolescence and early adulthood: Implications for substance abuse prevention. Psychological Bulletin, 112(1),64- 105.

Heyward, P. (2010). Emotional Engagement through Drama: Strategies to Assist Learning through Role-Play. International Journal of Teaching and Learning in Higher Education, 22(2), 197-204.

Hinduja, S., \& Patchin, J. W. (2008). Cyberbullying: An exploratory analysis of factors related to offending and victimization. Deviant Behavior, 29(2), 1-29.

Hinduja, S., \& Patchin, J. (2009). Bullying Beyond the Schoolyard. Thousand Oaks, CA: Corwin.

Hinduja, S., \& Patchin, J. (2010). Cyberbullying fact sheet: Identification, Prevention, and Response. Cyberbullying Research Center. Retrieved 
September 4, 2012, from

http:/www.cyberbullying.us/Cyberbullying_Identification_

Prevention_Response_Fact_Sheet.pdf

Hinduja, S., \& Patchin, J.W. (2010). Bullying, cyberbullying, and suicide. Archives of Suicide Research, 14, 206-221.

Hinduja, S., \& Patchin, J.W. (2010). Cyberbullying research summary: Cyberbullying and suicide. Cyberbullying Research Center. Retrieved September 4, 2012, from

http://www.cyberbullying.us/cyberbullying_and_suicide_research_fact sheet.pdf

Hinyard, L., \& Kreuter, M. (2007). Using narrative communication as a tool for health behavior change: A conceptual, theoretical, and empirical overview. Health Education \& Behavior, 34(5), 777-792.

Howard, L. (2004). Speaking theatre/doing pedagogy: Re-visiting Theatre of the Oppressed. Communication Education, 53(3), 217-233.

Isaac, M., Elias, B., Katz, L.Y., Belik, S., Deane, F.P., Enns, M.W., \& Sareen, J. (2009). Gatekeeper training as a preventative intervention for suicide: A systematic review. Canadian Journal of Psychiatry-Revue Canadiennede Psychiatrie, 54 (4), 260-268.

i-SAFE. (1998). I-SAFE: e-Safety curriculum (Grades K-12). Carlsbad, CA: Author.

Katz, C., Bolton, S., Katz, L.Y., Isaak, C., Tilston-Jones, T., \& Sareen, J. (2013). A 
systematic review of school-based suicide prevention programs. Depression and Anxiety, 30(10), 1030-1045.

Kisiel, C., Blaustein, M., Spinazzola, J., Schmidt, C. S., Zucker, M., \& van der Kolk, B. (2006). Evaluation of a theater-based youth violence prevention program for elementary school children. Journal of School Violence, 5(2), 19-36.

Kowalski, R.M., \& Limber, S.P. (2007). Electronic bullying among middle school students. Journal of Adolescent Health, 41, S22-S30.

Kowalski, R.M., Limber, S.P., \& Agaston, P.W. (2008) Cyber Bullying: The new moral frontier. Blackwell Publishing Ltd, Oxford, UK.

Lenhart, A., Madden, M., Smith, A., Purcell, K., Zickuhr, K, \& Rainie, L. (2011). Teens, kindness and cruelty on social network sites. How American teens navigate the new world of "digital citizenship". Washington, DC: Pew Internet \& American Life Project.

Lenhart, A., Ling, R., Campbell, S., \& Purcell, K. (2010). Teens and Mobile Phones. Text messaging explodes as teens embrace it as the centerpiece of their communication strategies with friends. Washington, DC: Pew Internet \& American Life Project.

Lonsway, K. A. (1996). Preventing acquaintance rape through education: What do we know? Psychology of Women Quarterly, 20, 229-265.

Lorenz, B., Kikkas, K., \& Laanpere, M. (2012). Comparing children's e-safety strategies with guidelines offered by adults. The Electronic Journal or eLearning, 10(3), 326-338.

Marsella, S., Johnson, W.L., \& LaBore, C. (2003). Interactive pedagogical drama for 
health interventions. Presentation for the International Conference on Artificial Intelligence in Education, Australia.

Martiniuk, A.C., Secco, M., Yake, L., \& Speechley, K.N. (2010). Evaluating the effect of a television public service announcement about epilepsy. Health Education Research, 25(6), 1050-1060.

McCuiston, K. (2008). Cyber-bullying: The silent tormentor. Retrieved from Kentucky Center for School Safety. www.kysafeschools.org

Milhausen, R. R., McBride, K. R., \& Jun, M. (2006). Evaluating a peer-led, theatrical sexual assault prevention program: How do we measure success?. College Student Journal, 40(2), 316-328.

Mustacchi, J. (2009). R U safe? Educational Leadership, 66, 78-82.

Nansel TR, Overpeck M, Pilla RS, Ruan W, Simons-Morton B, Scheidt P. (2001). Bullying behaviors among US youth: Prevalence and association with psychosocial adjustment. JAMA. 285(16), 2094-2100.

Nation, M., Crusto, C., Wandersman, A., Kumpfer, K.L., Seybolt, D., Morrussey-Kane, E., \& Davino, K. (2003). What works in prevention: Principles of effective prevention programs. American Psychologist, 58, 449456.

Olweus, D. (1999). Sweden. In Smith, P.K., Morita, Y., Junger-Tas, J., Olweus, D., Catalano, R. \& Slee, P. (Eds). The nature of school bullying: A crossnational perspective (pp.7-27). London \& New York: Routledge.

Olweus, D. (1993). Bullying at school: What we know and what we can do. Oxford: Blackwell Publishers. 
Patchin, J.W. \& Hinduja, S. (2010). Cyberbullying and self-esteem. Journal of School Health, 80(12), 614-621.

Pratt, C. C., McGuigan, W. M., \& Katsev, A. R. (2000). Measuring Program Outcomes: Using Retrospective Pretest Methodology. American Journal Of Evaluation, 21(3), 341-49.

Robinson, D., \& Meyer, M. (2012) Health education and applied theatre; Findings from a service learning project. Health Education Journal, 71(2), 219-228.

Rudd, M., Mandrusiak, M., Joiner, T. r., Berman, A. L., Van Orden, K. A., \& Hollar, D. (2006). The emotional impact and ease of recall of warning signs for suicide: A controlled study. Suicide and Life-Threatening Behavior, 36(3), 288-295.

Sharp, W., Hargrove, D. S., Johnson, L., \& Deal, W. P. (2006). Mental health education: An evaluation of a classroom based strategy to modify help seeking for mental health problems. Journal of College Student Development, 47(4), 419-438.

Shen, L. (2010). Mitigating psychological reactance: The role of message-induced empathy in persuasion. Human Communication Research, 36(3), 397-422.

Slovak, K., \& Singer, J. B. (2011). School social workers' perceptions of cyberbullying. Children \& Schools, 33(1), 5-16.

Smith, P.K., Mahdavi, J., Carvalho, M., Fisher, S., Russell, S., \& Tippett, N. (2008). Cyberbullying: its nature and impact in secondary school pupils. The Journal of Child Psychology and Psychiatry, 49(4), 376-385.

Snakenborg, J., Van Acker, R., Gable, R. (2011). Cyberbullying: Prevention and 
intervention to protect our children and youth. Preventing School Failure, $55(2), 88-95$.

Solberg, M.E., Olweus, D., \& Endresen, I.M. (2007). Bullies and victims at school: Are they the same pupils?. British Journal Of Educational Psychology, 77(2), $441-464$.

Sourander, A., Klomek, A. B., Ikonen, M., Lindroos, J., Luntamo, T., Koskelainen, M., Ristkari, T., \& Helenius, H. (2010). Psychosocial risk factors associated with cyberbullying among adolescents: A population-based study. Archives of General Psychiatry, 67(7), 720 - 728.

Stanton, S., personal communication, (March 12, 2012).

Thompson, J. \& A. Jackson, "Applied Theatre/Drama: An e-debate in 2004:

Viewpoints.” RIDE:Research in Drama and Education, 11(1), 90-95.

Turner, H. A., Finkelhor, D., Hamby, S.L., Shattuck, A., \& Ormrod, R.K. (2011). Specifying type and location of peer victimization in a national sample of children and youth. Journal of Youth And Adolescence, 40(8), 1052-1067.

U.S. Department of Justice, Bureau of Justice Statistics, School Crime Supplement (SCS) to the National Crime Victimization Survey (NCVS), 2009.

van Geel, M., Vedder. P., \& Tanilon, J. (2014) Relationship between peer victimization, cyberbullying, and suicide in children and adolescents: A metaanalysis. JAMA Pediatics. 168(5), 435-442.

van Orden, K.A., Joiner, T.R., Hollar, D., Rudd, M., Mandrusiak, M., \& Silverman, M. (2006). A test of the effectiveness of a list of suicide warning signs for the public. Suicide And Life-Threatening Behavior, 36(3), 272-287. 
Vieno A, Gini G, \& Santinello M. (2011). Different forms of bullying and their association to smoking and drinking behavior in Italian adolescents. Journal Of School Health [serial online]. 81(7), 393-399.

Wang, J., Ianotti, R.J., Nansel, T.R. (2009). School bullying among adolescents in the United States: physical, verbal, relational, and cyber. Journal of Adolescent Health, 45, 368-375.

Will, K., \& Sabo, C. (2010). Reinforcing Alcohol Prevention (RAP) Program: A secondary school curriculum to combat underage drinking and impaired driving. Journal of Alcohol And Drug Education, 54(1), 14-36.

Wyman, P. A., Brown, C., Inman, J., Cross, W., Schmeelk-Cone, K., Guo, J., \& Pena, J. B. (2008). Randomized trial of a gatekeeper program for suicide prevention: 1-year impact on secondary school staff. Journal of Consulting and Clinical Psychology, 76(1), 104-115.

Ybarra, M.L., Mitchell, K. J., Finkelhor, D., \& Wolak, J. (2007). Internet prevention messages: Targeting the right online behaviors. Archives of Pediatric Adolescent Medicine, 161, 138-145.

Ybarra, M.L., Diener-West, M., \& Leaf, P.J. (2007). Examining the overlap in Internet harassment and school bullying: Implications for school intervention. Journal of Adolescent Health, 41, S42-S50. 
Appendix 1

\section{CHOICES play script}

\section{Choices \\ SC 1--Like To Be Me Intro \\ SCENE 1}

Hannah is pouring coffee for her mom. Mom walks in sleepily.

Mom

Good morning sweetie.

Hannah hands coffee to Mom

Hannah

Morning Mom! Here's your coffee

Mom

Thank you, Hannah

Mom sits with coffee. Hannah pours herself a cup and begins putting LOTS of sugar in it

Mom

You're having coffee?

\section{Hannah}

You said I could start to have coffee. I'm fifteen and you said that...

\section{Mom}

I know. I know. You're just growing up fast. (Sternly) That is a lot of sugar.

Hannah puts spoon down and closes sugar. Goes to the fridge to get milk.

\section{Mom}

Did you sleep all right?

\section{Hannah}


No. I was up late chatting. (Sarcastically) Can I have some milk in it?

\title{
Mom
}

Yeees. Milk does the body good. May I ask who you were on the phone until the wee hours?

Hannah pours milk in coffee and puts milk back in fridge.

\section{Hannah}

Not the phone Mom, chatting online

\section{Mom}

Ooohh. With whom?

\author{
Hannah \\ Just Abby... \\ Mom \\ Uh huh. \\ Hannah \\ and some friends \\ Mom \\ You have field hockey tonight right? \\ Hannah goes and sits down at the table
}

Hannah

Uh huh.

Mom

Would you like me to pick you up?

Hannah

Abby was going to drive me home.

The following dialogue is overlapping and quick.

Mom

How long has she had her license?

\section{Hannah}

Just like a month but she had her permit for like six months and...

Mom 
Alright.

Hannah

...she practiced driving with her parents like every day.

\title{
Mom
}

Alright! Are you going to be home around five?

\section{Hannah}

We wanted to know if we could stop by the Starbucks to hang out...

\section{Mom}

You spend a lot of time at that coffee shop.

\section{Hannah}

Well, there's this cute guy...

\section{Mom}

I thought as much

\section{Hannah}

Who works there...

\section{Mom}

He works there? How old is he?

\author{
Hannah \\ Just seventeen. \\ Mom gets up from chair and goes over to kiss Hannah. \\ Mom \\ All right. Tell Abby I said good morning. \\ Hannah \\ Ok. \\ Mom \\ Have a good one! \\ Hannah \\ Thanks mom! Love you! \\ Mom exits. Hannah sips her coffee \\ Mom
}


Love you!

SC 2--"Just Dance"

\title{
SCENE 2
}

Abby changes into hoodie. Hannah sets up car and peels away to enter. Abby sits in driver's seat.

Abby is picking Hannah up for school. She unlocks door for Hannah as she approaches the car.

\author{
Abby \\ Hey girl! \\ Hannah \\ Hey! \\ Hannah gets in car and put on seat belt
}

\author{
Abby \\ You look really cute! \\ Hannah \\ Really? \\ Abby \\ Most definitely! \\ Hannah \\ Mom said we could go to Starbucks.

\begin{abstract}
Abby
Yes! He is so gonna be checking you out!

Hannah pulls down visor to check her hair in mirror

\section{Hannah}

I hope so.
\end{abstract}

\begin{abstract}
Abby
If he isn't, he is not worth your time. You're a dime!

Their favorite song comes on the radio. They sing along.
\end{abstract}




\section{SCENE 3}

Abby changes into teacher, Hannah moves the SR car chair DS into classroom position.

Hannah is in class. She is working at her desk. The teacher is standing in the back of the room

\section{Teacher}

Alright, class. As you work on this assignment, I'm going to be handing out last week's essays.

Teacher mimes passing papers back to students in the room

\section{Teacher}

Nice job, Abby

Teacher comes to Hannah

\section{Teacher}

I'm really impressed with this work Hannah.

Hannah

Thanks

Teacher

Have you thought of taking some AP classes next year?

\section{Hannah}

Maybe.

\section{Teacher}

I think you should. You've really got a brain for it.

Hannah

Thanks.

Teacher moves on. Hannah looks at Abby and smiles.

Teacher changes back into Abby, Hannah moves her class chair back into car position.

SC 3-"Just Wanted to See You So Bad"

\section{SCENE 4}


It is after school. Abby and Hannah enter, put their bags in the back seat and get in Abby's car.

Abby
Are you ready to go see your man candy?

Hannah

I guess so. Do I look okay?

\begin{abstract}
Abby
You look awesome! He was so flirting with you at lunch today.

Hannah pulls down visor and checks her hair and makeup.
\end{abstract}

\title{
Hannah
}

Really? I thought maybe he was just being nice.

Abby

Oh no, that was flirting. You know how I know? You know Kelsey?

\section{Hannah}

Kelsey his ex?

\section{Abby}

Yah. She did not look happy when he was joking with you.

Hannah puts visor back up.

\section{Hannah}

Well if she's jealous she doesn't have much right to be. I mean, they broke up, like what, four month ago?

\author{
Abby \\ Right! \\ Hannah \\ And she broke up with him.
}

\begin{abstract}
Abby
Right. And when you were leaving, he was totally checking you out. And not in a gross way.
\end{abstract}

Hannah is excited. They laugh. Hannah receives a text message.

\section{Abby}

Is that him? 


\title{
Hannah
}

I hope not.

Hannah shows text to Abby.

Abby
Oh my God! You are most definitely not a slut. Do you think that's from Kelsey?

\section{Hannah}

I don't know the number. Maybe it's just a prank or wrong number.

\begin{abstract}
Abby
Right. Well, whoever it is, is totally immature so just ignore it. You're going to go flirt with Evan. Ignore it. Drop it.

Hannah

Yeah, I'm so not a slut anyway.

Abby

Not a slut.

SC 4--Destiny's Darling

\section{SCENE 5}

Abby changes into Mom. Hannah moves her car chair into kitchen position, then crosses US to the kitchen door. Mom is chopping veggies at the kitchen counter.

Hannah comes home and gets a soda from the fridge.
\end{abstract}

\section{Hannah}

Hey mom. I'm home.

\section{Mom}

Hey sweetie. How was coffee?

Hannah laughs

Hannah

Good. I'm going to go work on some homework.

\section{Mom}

All right. Dinner will be ready in half an hour.

\section{Hannah}


Okay.

Hannah goes up stairs to her room and sits down at her computer. There is a bing of an instant message. The voice of the bully is heard.

Cyberbully

U better watch ur back u little ho!!

Hannah types

Hannah

Who is this? Is this Kelsey?

Cyberbully

Who's Kelsey? I'm ur worst nightmare!!

SC 5- Radiohead-Amnesiac, Disc 1, Push Pull Revolving Doors

SCENE 6

Scene begins with sound and projection montage of texts, emails, IM's, etc. that increase in numbers, Hannah moves through montage showing different times and places. These messages are not read outload by the Bully.

Mom changes to teacher, moves SR chair into class position, then goes to write on board. Hannah is seated in the classroom. She pulls phone out of her pocket and looks at it when text message chime goes off

Text Message

$\mathrm{u}$ think $\mathrm{u}$ know all the answers in class, but I know wht ur really like u little slut!

Teacher exits SR. Hannah is at her locker

\section{Text Message}

Hannah is a big fat pig

Hannah is in her room at her computer

IM

Idk y u even try to look cute??

IM

idk y any1 wld go out w/ a fatso like u??? 


\title{
IM
}

must be cuz they know u'll bang em!!!!

Teacher becomes Abby and sets chair as car. Hannah puts on her hoodie, and crosses to the car. Hannah is in the car with Abby. When she gets the message Abby tries to look at it. Hannah pulls phone away.

\section{Text Message}

No 1 wants 2 hang out w/ such a skanky hoe like $u$.

Abby exits SR. Hannah is on her bed. After the second message she goes to her computer

\author{
IM \\ ur an F...ing whore!!
}

IM

I'm sure u have every STD in the book.

\section{IM}

No guy in his rite mind wld touch $\mathrm{u} \mathrm{w} / \mathrm{a} 10 \mathrm{ft}$ pole!!!

Hannah zips up her hoodie as she crosses to the car. Hannah is in the car with Abby. Hannah is looking out the window ignoring Abby. Abby looks concerned and confused.

Hannah pulls her hair back. Abby becomes Mom, sets the chairs in the kitchen and sits $S R$, sipping coffee. Hannah is approaching her house when she receives the next message

\section{Text Message}

This school would $\mathrm{b}$ a better place if $\mathrm{u}$ just ended ur miserable little life.

Montage ends with her coming home having skipped field hockey. Mom is sitting at kitchen table and is surprised to see Hannah home.

\section{Mom}

Hannah?

the door slams

\section{Mom}

I thought you had field hockey?

\section{Hannah}

I'm not going today. 


\author{
Mom \\ Are you okay? \\ Hannah \\ (Angry not wanting to talk about it) \\ I just don't feel like going! \\ Mom \\ (concerned) \\ Do you feel alright? \\ Hannah \\ I'm fine. I'm gonna go work on my homework.
}

Mom removes scarf, exits SR to become bully. Hannah exits to her room. She sits on her bed. She hears several IM's bing in. She tries to ignore them.

Bully/IM

2 busy screwin the football tm 2 go 2 field hocky practice???

Bully/IM

b careful, skippin practice will only make u fatter!!

Bully/IM

Who wld wnt 2 date a fat skanky ho like $u$ ?

Finally Hannah goes over to the computer and responds to the IMS

Hannah

Leave me the $\mathrm{F}$ alone!

Bully/IM

I'll never leave u alone.

Hannah

Why $\mathrm{r}$ u doing this?

Bully/IM

cuz I wnt the WHOLE world 2 know ur a FILTHY DIRTY HO BAG!!!

Hannah

Who do u think u r u f...ing bitch? 


\section{Bully becomes Mom, enters}

Mom

Hannah are you on the myspace again? I thought you were doing homework? (seeing what's in the computer screen) Did you just send that?

Hannah

Yes

\section{Mom}

Hannah, that is not the way I raised you to speak to your friends.

\section{Hannah}

Well, you should see what they're saying. And they're not my friends.

\section{Mom}

Well, that makes no difference. You need to be the bigger person here. No matter what other people say to you, you are responsible for your own actions. And that is not appropriate.

\section{Hannah}

But they were...

\section{Mom}

You're going to have to learn to ignore them Hannah. Log off and shut down.

\section{Hannah}

Fine

Mom leaves. Hannah looks over her shoulder to see if mom is gone. She goes back to IM.

\section{Hannah}

y r u doing this? I'm not a slut!

\section{Bully/IM}

u say ur not a slut? Let's let the school decide. www.is hannah a ho.com

$$
\text { Voting site comes up. }
$$

\section{Bully}

Is Hannah a slut? You decide

$$
\text { Rate Hannah 1-10. One - Not Slutty. } 10 \text { - a big fat ho }
$$


Share Hannah's Sluttinees on You Tube, Facebook, Twitter, and Myspace

Hannah looks horrified at the screen.

SC 6 - Nomads

\title{
SCENE 7
}

Bully becomes Abby, sets car chairs. Abby is in the car in front of Hannah's house. Enter enters and gets in the car.

\author{
Abby \\ Hey Girl! \\ Hannah \\ Hey \\ Abby \\ What's up? Are you okay? \\ Hannah \\ You mean you don't know?

Abby
Know what?
Hannah
Nothing, nothing, just forget about it

Abby

Okaaay. Listen, I called you like three times last night. And you didn't call me back? What's up with that?

\section{Hannah}

I know. I'm sorry. I meant too. I was just... I was just really busy. 


\begin{abstract}
Abby
(Teasing her)

Yeah, the busy life of a sex kitten!
\end{abstract}

\title{
Hannah
}

I'm not a sex kitten.

\section{Abby}

I know. It was a joke.

\section{Hannah}

Well. It's not funny.

\begin{abstract}
Abby
What is going on Hannah? You have been weird for days. You've been, forgive me, but bitchy for like a week. What's going on?
\end{abstract}

\section{Hannah}

I just... I had a really hard night, okay. I just... My mom and I had a fight about the computer

\section{Abby}

Oh my God. I totally get that. My mother drives me crazy. But listen, I've known you for a long time. You can talk to me okay. So what happened?

\author{
Hannah \\ It's just that... \\ Pause while Hannah decided if she should tell her \\ Abby (Frustrated) \\ WHAT HANNAH??? \\ Hannah \\ Never mind. You'll know soon enough anyway? \\ Abby \\ (Confused and starting to get pissed) \\ What does that mean?

\section{Hannah} \\ Nothing. Abby, I don't want to talk about it!
}

\section{Abby}


(Angry)

Whatever!

\section{SC 7-Which Will? IF we need anything}

\section{$\underline{\text { SCENE } 8}$}

Abby becomes teacher. Later that day at school, Hannah is at her locker. Her teacher walks by. Hannah looks nervous when she sees her.

\section{Teacher}

Hannah? I'm glad I ran into you. I was surprised you didn't turn in your essay yesterday. I've never known you to not turn something in.

\section{Hannah}

I know. I'm sorry. Um. I'll... I'll give it to you on Monday, okay.

\section{Teacher}

Is everything okay Hannah?

\section{Hannah}

Yea. Umm. I just have a lot going on right now. I'm just really tired. I'm fine.

Teacher

Okay. Well I'm be looking for your essay on Monday.

SC 8-Freedom--cutting off after "sadness finds its way into me"

\section{SCENE 9}

Teacher becomes Sam and stands US. Hannah is in her bedroom. Listening to her ipod. She hears her cell phone vibrate and she tenses up. When she sees it is her brother she is relieved and answers the phone. Sam moves SR chair DS and out as he crosses into the scene.

\section{Hannah}

Hey. I'm glad you called

\section{Brother}

Really? Cuz I've been trying to get a hold of you sis, but your phone goes strait to voicemail.

\section{Hannah}

I know. I'm sorry. There's just been a lot going on. I've had my phone on silent. But I am really glad you called, I've been meaning to call you back. Umm I was 
thinking... I know how you love my Guitar Hero and like you always play it when you're in town. So I wanted you to have it. I was gonna send it to you.

\section{Brother}

No way! Your guitar hero? You play that all the time.

\section{Hannah}

I just wanted you to have it.

\section{Brother}

Dude, you sound like a zombie. Is something going on?

\section{Hannah}

No. Well...just some kids at school are being jerks.

\section{Brother}

Yeah. That happens. You know when you get to college it's a totally different story. Only three more years, right?

\section{Hannah}

Yeah

\section{Brother}

If you were my little brother I would say beat 'em up but. You're my little sister so I guess just ignore them or what ever you do. Ya know. Sticks and stones and all that.

\section{Hannah}

Sure. Right. Ignore 'em. Stick and stones. Listen, I gotta go. I have an essay to write. So you want me to send you Guitar Hero? (pause) Sam, you're a great big brother. I love you.

\section{Brother}

Yeah! Love you too Hannah bear.

Sam exits, resets his chair in the kitchen, becomes bully. There is an IM bing on Hannah's computer. Hannah looks at computer terrified. She hesitates and then goes over to the computer. She sees this IM come up.

\section{Bully/IM}

Check out ur new facebook page Hannah. Now everyone will know the truth about you.

Hannah clicks on link. Facebook page comes up. Bully reads facebook page. 


\title{
SCENE 10
}

Bully becomes Abby, crosses DS. The next day at school, Hannah is surprised to see Abby at her locker. She goes up to her.

\section{Hannah}

Hey Abby, I thought you were sick. Why didn't you pick me up for school today? Is everything okay.

\section{Abby}

Why would I pick you up for school?

\section{Hannah}

Because that's what we have been doing every day for the last few weeks.

overlapping

Abby

After the things you said about me last night...

\section{Hannah}

Last night?...

Abby

...Why would I pick you up?

\section{Hannah}

...I didn't talk to anyone last night. Believe me.

\begin{abstract}
Abby
Did you think I wasn't going to find out Hannah? Your little message to your new friend about how fat I am. About how ugly I am. About how you can't get with guys when you're with me. I heard about your NEW facebook page Hannah. I didn't even know you had a new page. You didn't even friend me.
\end{abstract}

\section{Hannah}

That page isn't...

\author{
Abby \\ Whatever, Hannah.
}

\section{Hannah}


Who sent you that message?

Abby
They wouldn't say because they were afraid you would turn your bitchiness on
them. But they're a better friend than you because they thought I ought to know
the truth.

\title{
Hannah
}

You think I'm a bitch! I thought you were my best friend.

\begin{abstract}
Abby
Do you think I can trust anything you say? I thought you were my best friend Hannah.
\end{abstract}

\section{Hannah}

I am.

\begin{abstract}
Abby
Whatever. This friendship is over.
\end{abstract}

Abby storms off.

Hannah

Abby please...wait!

\section{SC 10--Radiohead "Packt Like Sardines"}

\section{SCENE 11}

Hannah walks home. As she walks home the bully faces her, and follows her around the stage, saying the following lines, and setting the SL chair CS in front of the projector.

\section{Bully}

You're a slut.

No one want to hang out w/ a skanky ho like you.

No guy in his right mind would touch you with a 10 foot pole.

You better watch you back.

When she arrives home, Hannah goes into medicine cabinet and gets bottle of pills. She brings into kitchen and stands behind the chair USC with the bottle of pills in her hand. Other actor comes behind her moving around her in a semicircle 
as she becomes each character. She has a pose that goes with each character as she says the following lines. These characters are the in Hannah's head.

\title{
Teacher
}

I'll be looking for your essay on Monday.

\section{Hannah sits}

\section{Hannah}

I'm probably just going to fail out of school anyway.

Sam

Sticks and Stones, right?

Hannah

Why can't I just ignore it?

\section{Mom}

This isn't the way I raised you to speak to your friends

\section{Hannah}

Maybe I am a bitch!

\author{
Abby \\ This friendship is over! \\ Hannah \\ My best friend hates me.
}

As the bully, other actor comes behind Hannah and mimes pushing down on her hands elbows up.

\section{Bully}

This world would be better off without you.

Hannah and Bully say the following lines simultaneously.

Hannah has her hands up under Bully's

\section{Bully}

Maybe you should just put yourself out of your misery.

\section{Hannah}

Maybe I should just put myself out of my misery 
Bully exits, becomes Mom. Her mom comes home. Hannah puts pills in her pocket. Crosses to other chair and sits when Mom comes in.

\section{Mom}

Hi sweety. Why are you sitting her in the dark?

\section{Hannah}

I...um... just got home. I um...

\section{Mom}

Is everything okay?

\section{Hannah}

Umm yea. I um have a lot of homework to do so I'm going to, um, go upstairs.

\section{Mom}

Okay. Dinner in half and hour.

Mom starts to fix dinner with her back to Hannah.

\section{Hannah}

Yah.

Starts to go up stairs

Mom...I love you...Thanks for everything...um goodbye.

\section{Mom \\ (confused)}

Okay. I love you too. I'll see you in half and hour.

\section{Hannah}

Yah.

\section{SC 11-Waltz Across TX Tonight}

Hannah goes upstairs and sits down at her computer desk. She gets out the pills and dumps them into her hand. Scene ends with her looking at pills. 


\section{APPENDIX 2}

\section{CHOICES Observation Implementation Checklist}

\section{Date of Observation}

School

Grade level

Total in Attendance

Start time:

End time:

\begin{tabular}{|c|c|c|c|c|c|c|c|}
\hline \multicolumn{8}{|l|}{ Cast: } \\
\hline & $\begin{array}{l}\text { CHOICES } \\
\text { COMPONENT }\end{array}$ & YES & NO & COMMENTS & $\begin{array}{l}\text { CORE } \\
\text { CONTENT } \\
\text { (if } \\
\text { applicable) }\end{array}$ & $\begin{array}{l}\text { METHOD (if } \\
\text { applicable) }\end{array}$ & $\begin{array}{l}\text { FIDELITY } \\
\text { TYPE }\end{array}$ \\
\hline \multicolumn{8}{|l|}{$\begin{array}{l}\text { SECTION } \\
1\end{array}$} \\
\hline $\begin{array}{l}\text { Start } \\
\text { Time: }\end{array}$ & & & & & & & Dosage \\
\hline 1 & $\begin{array}{l}\text { Facilitator(F.) } \\
\text { introduces } \\
\text { herself and } \\
\text { the other two } \\
\text { actors }\end{array}$ & & & & & $\begin{array}{l}\text { Direct } \\
\text { instruction }\end{array}$ & Adherence \\
\hline 2 & $\begin{array}{l}\text { F. introduces } \\
\text { theatre } \\
\text { company }\end{array}$ & & & & & $\begin{array}{l}\text { Direct } \\
\text { instruction }\end{array}$ & Adherence \\
\hline 3 & $\begin{array}{l}\text { F. talks about } \\
\text { play's } \\
\text { development }\end{array}$ & & & & & $\begin{array}{l}\text { Direct } \\
\text { instruction }\end{array}$ & Adherence \\
\hline 4 & $\begin{array}{l}\text { F. introduces } \\
\text { play's } \\
\text { characters }\end{array}$ & & & & & $\begin{array}{l}\text { Direct } \\
\text { instruction }\end{array}$ & Adherence \\
\hline 5 & $\begin{array}{l}\text { F. introduces } \\
\text { basic } \\
\text { structure of } \\
\text { the } \\
\text { intervention }\end{array}$ & & & & & $\begin{array}{l}\text { Direct } \\
\text { instruction }\end{array}$ & Adherence \\
\hline 6 & $\begin{array}{l}\text { F. talks about } \\
\text { use of strong } \\
\text { language }\end{array}$ & & & & & $\begin{array}{l}\text { Direct } \\
\text { instruction }\end{array}$ & Adherence \\
\hline \multicolumn{8}{|l|}{$\begin{array}{l}\text { Major } \\
\text { Deviations }\end{array}$} \\
\hline Additional & & & & & & & \\
\hline
\end{tabular}




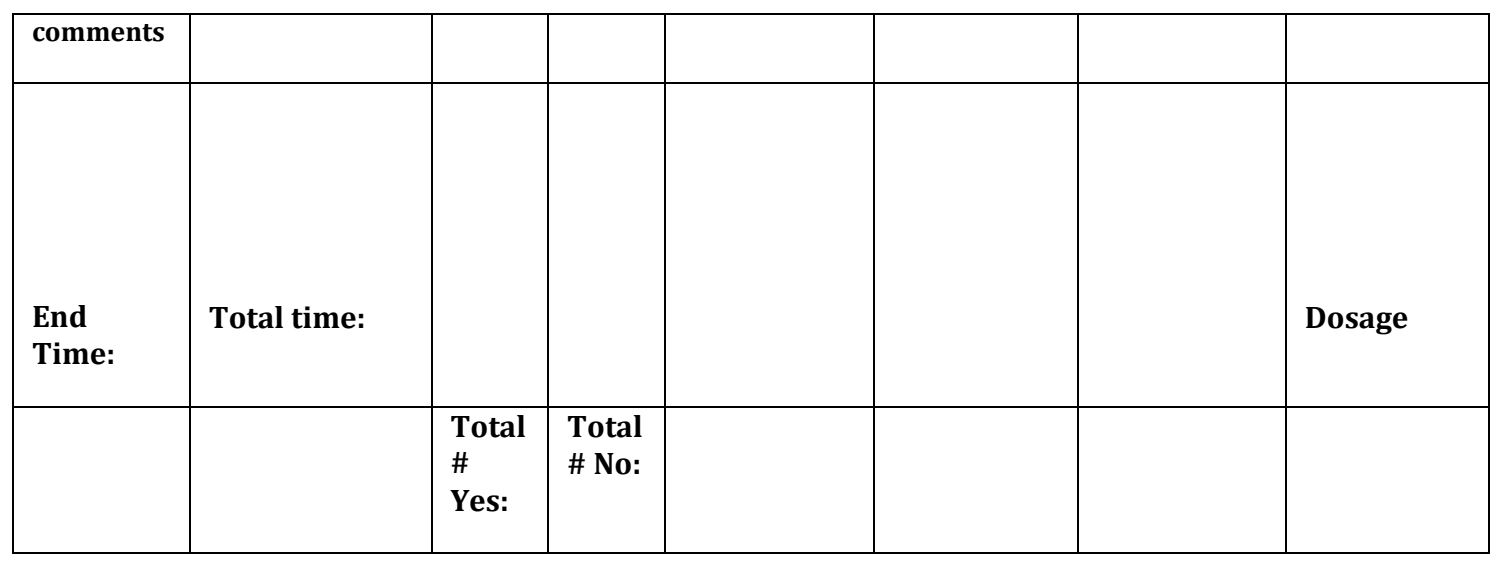

\begin{tabular}{|c|c|c|c|c|c|c|c|}
\hline & $\begin{array}{l}\text { CHOICES } \\
\text { COMPONEN } \\
T\end{array}$ & YES & NO & $\begin{array}{l}\text { COMMENT } \\
\mathrm{S}\end{array}$ & $\begin{array}{l}\text { CORE } \\
\text { CONTENT } \\
\text { (if } \\
\text { applicable } \\
\text { ) }\end{array}$ & $\begin{array}{l}\text { METHOD (if } \\
\text { applicable) }\end{array}$ & $\begin{array}{l}\text { FIDELITY } \\
\text { TYPE }\end{array}$ \\
\hline $\begin{array}{l}\text { SECTION } \\
2\end{array}$ & & & & & & & \\
\hline $\begin{array}{l}\text { Start } \\
\text { Time: }\end{array}$ & & & & & & & Dosage \\
\hline 1 & $\begin{array}{l}\text { Play is } \\
\text { performed } \\
\text { exactly } \\
\text { according } \\
\text { to script } \\
\text { (read along } \\
\text { with script) }\end{array}$ & & & & $\begin{array}{l}\text { Warning } \\
\text { signs }\end{array}$ & $\begin{array}{l}\text { Demonstratio } \\
\text { n }\end{array}$ & Adherence \\
\hline 2 & $\begin{array}{l}\text { All slides } \\
\text { are shown, } \\
\text { according } \\
\text { to script }\end{array}$ & & & & & $\begin{array}{l}\text { Demonstratio } \\
\text { n }\end{array}$ & Adherence \\
\hline 3 & $\begin{array}{l}\text { Majority } \\
(90 \%) \text { of } \\
\text { audience } \\
\text { are paying } \\
\text { attention }\end{array}$ & & & & & & $\begin{array}{l}\text { Participant } \\
\text { responsivene } \\
\text { ss }\end{array}$ \\
\hline 4 & $\begin{array}{l}\text { Actors are } \\
\text { believable } \\
\text { in their } \\
\text { roles }\end{array}$ & & & & & $\begin{array}{l}\text { Demonstratio } \\
\mathrm{n}\end{array}$ & Quality \\
\hline $\begin{array}{l}\text { Major } \\
\text { Deviation } \\
s\end{array}$ & & & & & & & \\
\hline Additiona & & & & & & & \\
\hline
\end{tabular}




\begin{tabular}{|l|l|l|l|l|l|l|l|}
\hline $\begin{array}{l}\text { comment } \\
\text { s }\end{array}$ & & & & & & & \\
\hline $\begin{array}{l}\text { End } \\
\text { Time: }\end{array}$ & Total Time: & & & & & & Dosage \\
\hline & & $\begin{array}{l}\text { Tota } \\
\text { Yes: } \\
\text { Yota } \\
\text { 1 No: }\end{array}$ & & & & & \\
\hline
\end{tabular}

\begin{tabular}{|c|c|c|c|c|c|c|c|}
\hline & $\begin{array}{l}\text { CHOICES } \\
\text { COMPONENT }\end{array}$ & YES & NO & COMMENTS & $\begin{array}{l}\text { CORE } \\
\text { CONTENT } \\
\text { (if } \\
\text { applicable) }\end{array}$ & $\begin{array}{l}\text { METHOD (if } \\
\text { applicable) }\end{array}$ & FIDELITY TYPE \\
\hline \multicolumn{8}{|c|}{ SECTION 3} \\
\hline $\begin{array}{l}\text { Start } \\
\text { Time: }\end{array}$ & & & & & & & Dosage \\
\hline 1 & $\begin{array}{l}\text { F. explains } \\
\text { that students } \\
\text { will now be } \\
\text { allowed to } \\
\text { offer and try } \\
\text { out } \\
\text { suggestions } \\
\text { that will } \\
\text { change the } \\
\text { outcome of } \\
\text { the play, by } \\
\text { stopping the } \\
\text { action of the } \\
\text { play }\end{array}$ & & & & & $\begin{array}{l}\text { Direct } \\
\text { instruction }\end{array}$ & Adherence \\
\hline 2 & $\begin{array}{l}\text { F. asks what } \\
\text { is learned } \\
\text { about H. in } \\
\text { the early } \\
\text { scenes of the } \\
\text { play }\end{array}$ & & & & & $\begin{array}{l}\text { Guided } \\
\text { discussion }\end{array}$ & Adherence \\
\hline 3 & $\begin{array}{l}\text { Students } \\
\text { describe } \\
\text { Hannah }\end{array}$ & & & & & $\begin{array}{l}\text { Guided } \\
\text { discussion }\end{array}$ & $\begin{array}{l}\text { Participant } \\
\text { responsiveness }\end{array}$ \\
\hline 4 & $\begin{array}{l}\text { F adds } \\
\text { additional } \\
\text { descriptors } \\
\text { not } \\
\text { mentioned }\end{array}$ & & & & & $\begin{array}{l}\text { Direct } \\
\text { instruction }\end{array}$ & Adherence \\
\hline 5 & $\begin{array}{l}\text { F asks what } \\
\text { Hannah could } \\
\text { have done } \\
\text { differently }\end{array}$ & & & & & $\begin{array}{l}\text { Guided } \\
\text { discussion }\end{array}$ & Adherence \\
\hline 6 & Students give & & & & & Guided & Participant \\
\hline
\end{tabular}




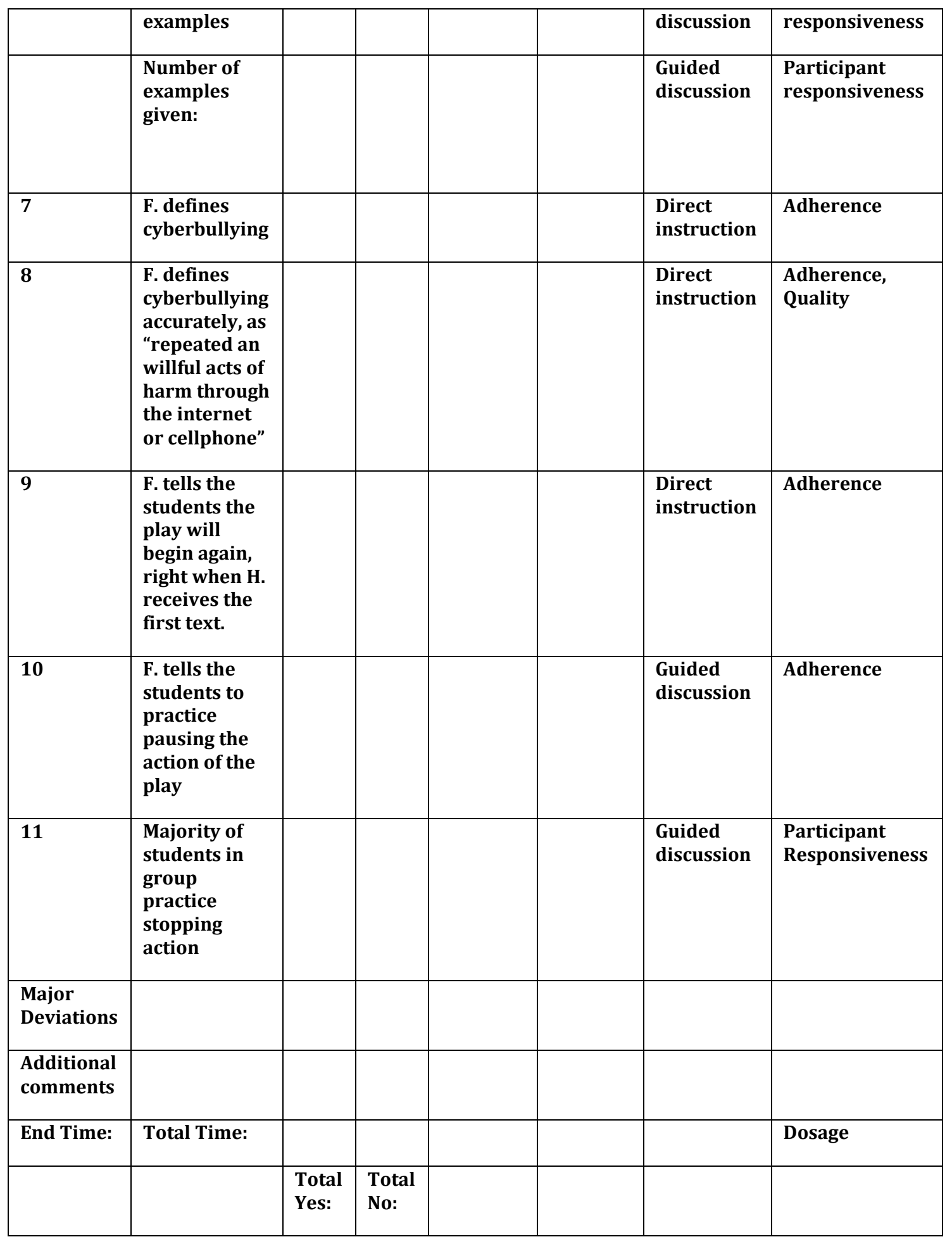

\begin{tabular}{|l|l|l|l|l|l|l|l|}
\hline & $\begin{array}{l}\text { CHOICES } \\
\text { COMPONENT }\end{array}$ & YES & NO & COMMENTS & $\begin{array}{l}\text { CORE } \\
\text { CONTENT } \\
\text { (if } \\
\text { applicable) }\end{array}$ & $\begin{array}{l}\text { METHOD (if } \\
\text { applicable) }\end{array}$ & FIDELITY TYPE \\
\hline
\end{tabular}




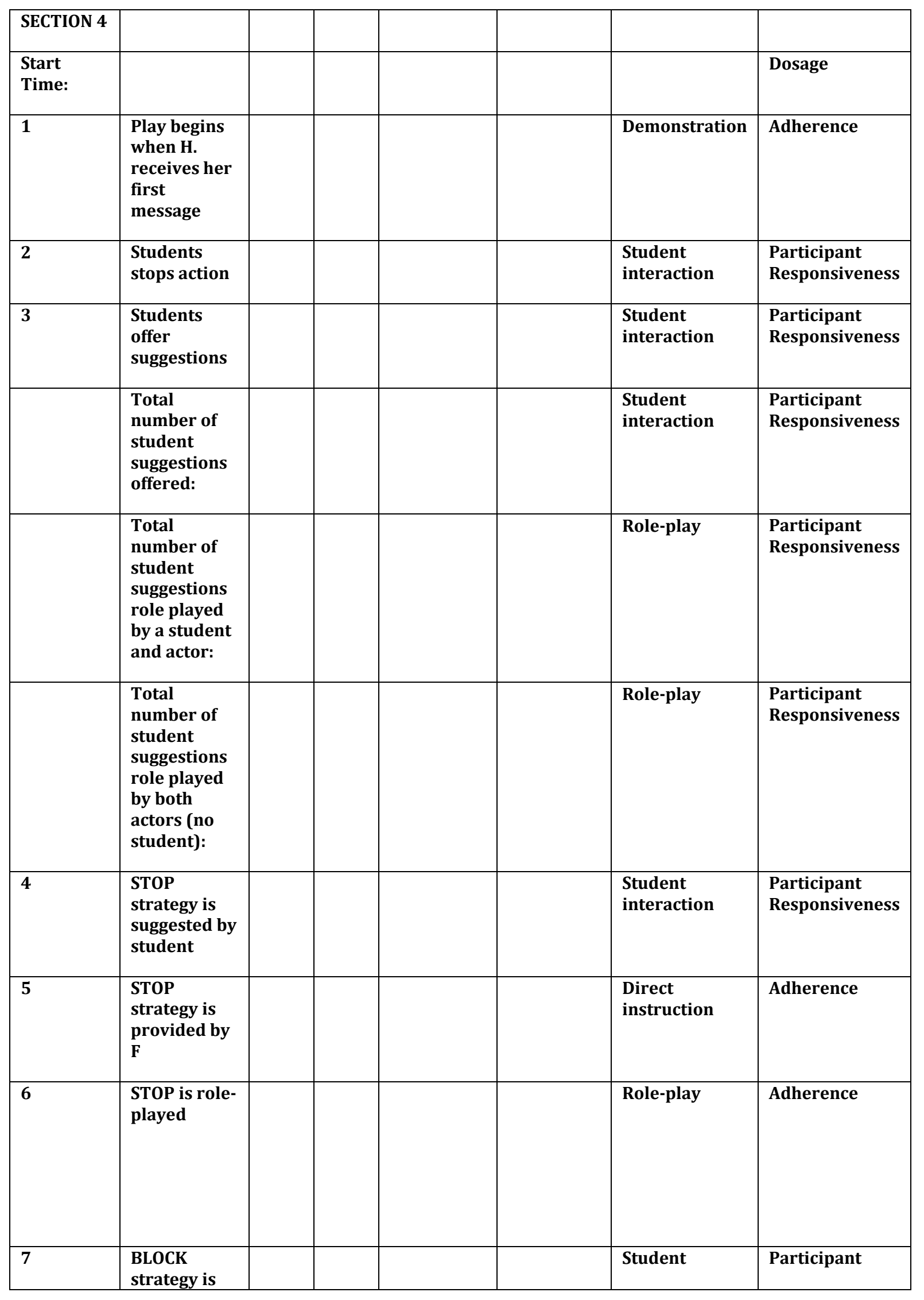




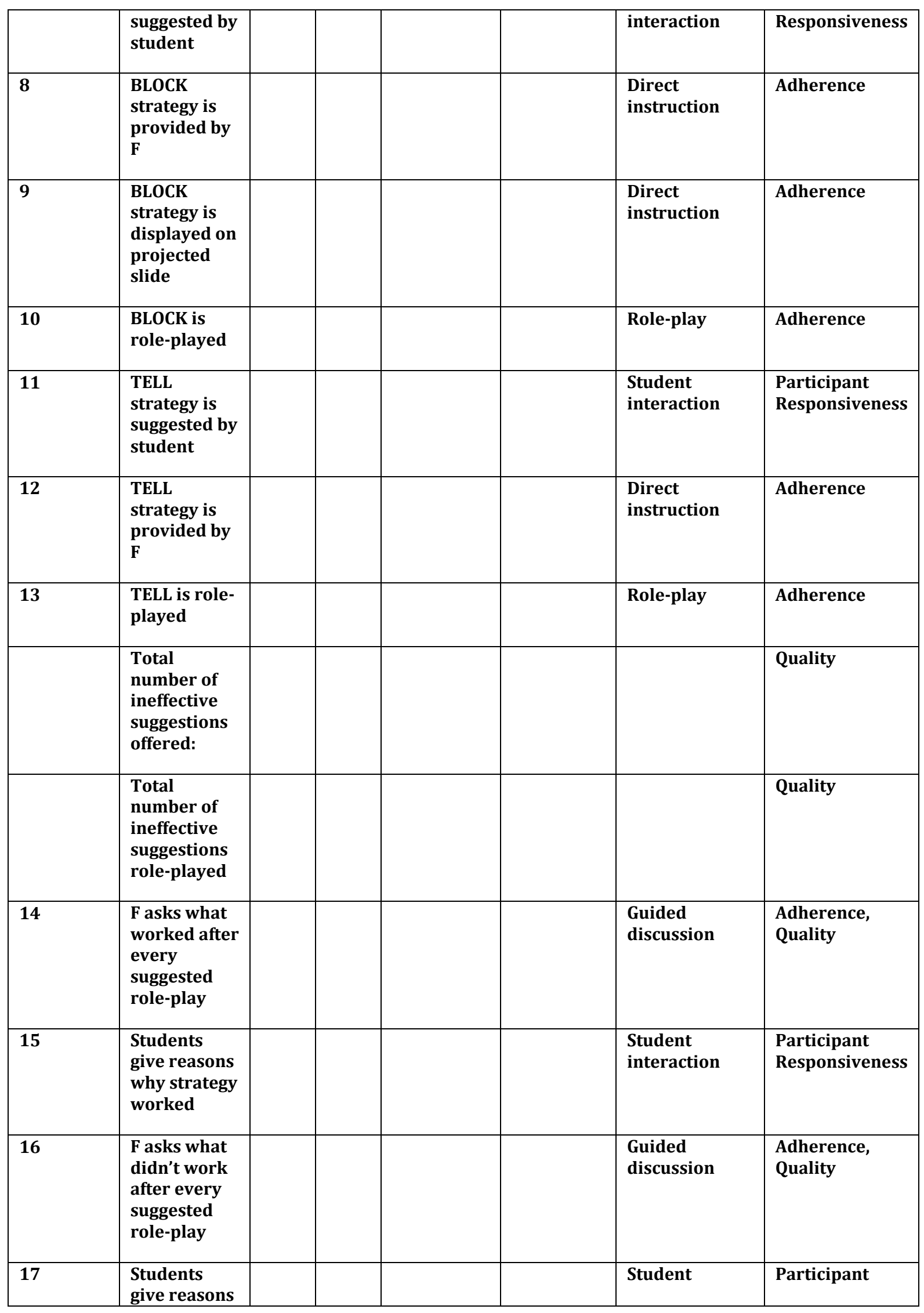




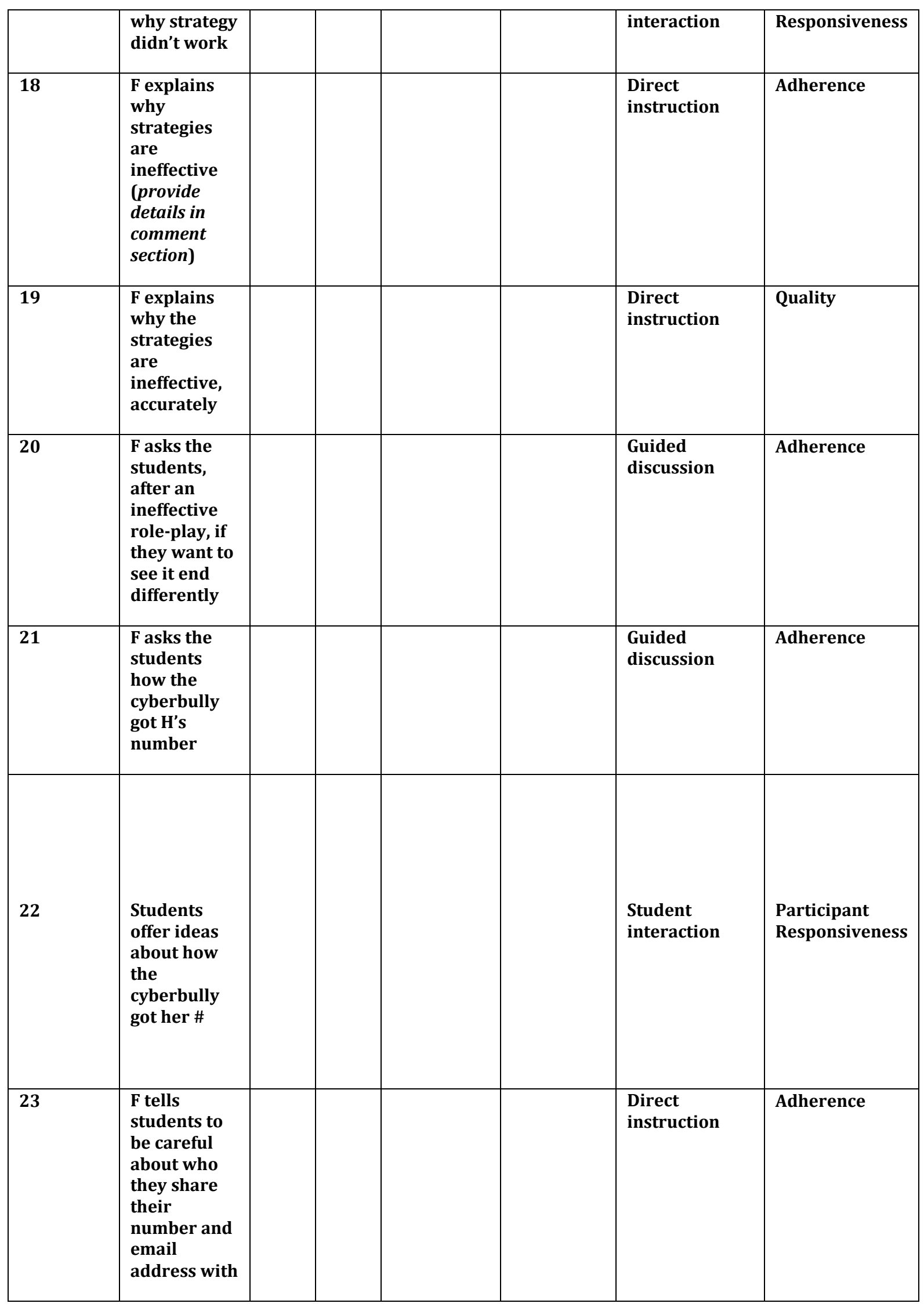




\begin{tabular}{|l|l|l|l|l|l|l|l|}
\hline $\begin{array}{l}\text { Major } \\
\text { Deviations }\end{array}$ & & & & & & & \\
\hline $\begin{array}{l}\text { Additional } \\
\text { comments }\end{array}$ & & & & & & & \\
\hline End Time: & Total Time: & & & & & & Dosage \\
\hline & & $\begin{array}{l}\text { Total } \\
\text { Yes: }\end{array}$ & $\begin{array}{l}\text { Total } \\
\text { No: }\end{array}$ & & & & \\
\hline
\end{tabular}

\begin{tabular}{|c|c|c|c|c|c|c|c|}
\hline & $\begin{array}{l}\text { CHOICES } \\
\text { COMPONENT }\end{array}$ & YES & NO & COMMENTS & $\begin{array}{l}\text { CORE CONTENT (if } \\
\text { applicable) }\end{array}$ & $\begin{array}{l}\text { METHOD } \\
\text { (if } \\
\text { applicable) }\end{array}$ & $\begin{array}{l}\text { FIDELITY } \\
\text { TYPE }\end{array}$ \\
\hline \multicolumn{8}{|c|}{ SECTION 5} \\
\hline $\begin{array}{l}\text { Start } \\
\text { Time: }\end{array}$ & & & & & & & Dosage \\
\hline \multirow[t]{4}{*}{1} & $\begin{array}{l}\text { F asks the students } \\
\text { to remember what } \\
\text { happened to } \mathrm{H} \text {. } \\
\text { towards the end of } \\
\text { the play. She asks } \\
\text { them to list the } \\
\text { warning signs of } \\
\text { suicide that they } \\
\text { witnessed in } H\end{array}$ & & & & Warning signs & $\begin{array}{l}\text { Guided } \\
\text { discussion }\end{array}$ & Adher. \\
\hline & $\begin{array}{l}\text { \# of students who } \\
\text { offer suggestions }\end{array}$ & & & & Warning signs & $\begin{array}{l}\text { Student } \\
\text { interaction }\end{array}$ & $\begin{array}{l}\text { Part. } \\
\text { Resp. }\end{array}$ \\
\hline & $\begin{array}{l}\text { \# of correct signs } \\
\text { named* }\end{array}$ & & & & Warning signs & $\begin{array}{l}\text { Student } \\
\text { interaction }\end{array}$ & Quality \\
\hline & $\begin{array}{l}\text { \# of incorrect } \\
\text { signs named }\end{array}$ & & & & Warning signs & $\begin{array}{l}\text { Student } \\
\text { interaction }\end{array}$ & \\
\hline 2 & $\begin{array}{l}\text { F clarifies which } \\
\text { are signs are which } \\
\text { are not signs of } \\
\text { suicide }\end{array}$ & & & & Warning signs & $\begin{array}{l}\text { Direct } \\
\text { instruction }\end{array}$ & Quality \\
\hline 3 & $\begin{array}{l}\text { F adds warning } \\
\text { signs not suggested } \\
\text { by students }\end{array}$ & & & & Warning signs & $\begin{array}{l}\text { Direct } \\
\text { instruction }\end{array}$ & Adher. \\
\hline 4 & $\begin{array}{l}\text { F relists the } \\
\text { warning signs* }\end{array}$ & & & & Warning signs & $\begin{array}{l}\text { Direct } \\
\text { instruction }\end{array}$ & Adher. \\
\hline
\end{tabular}




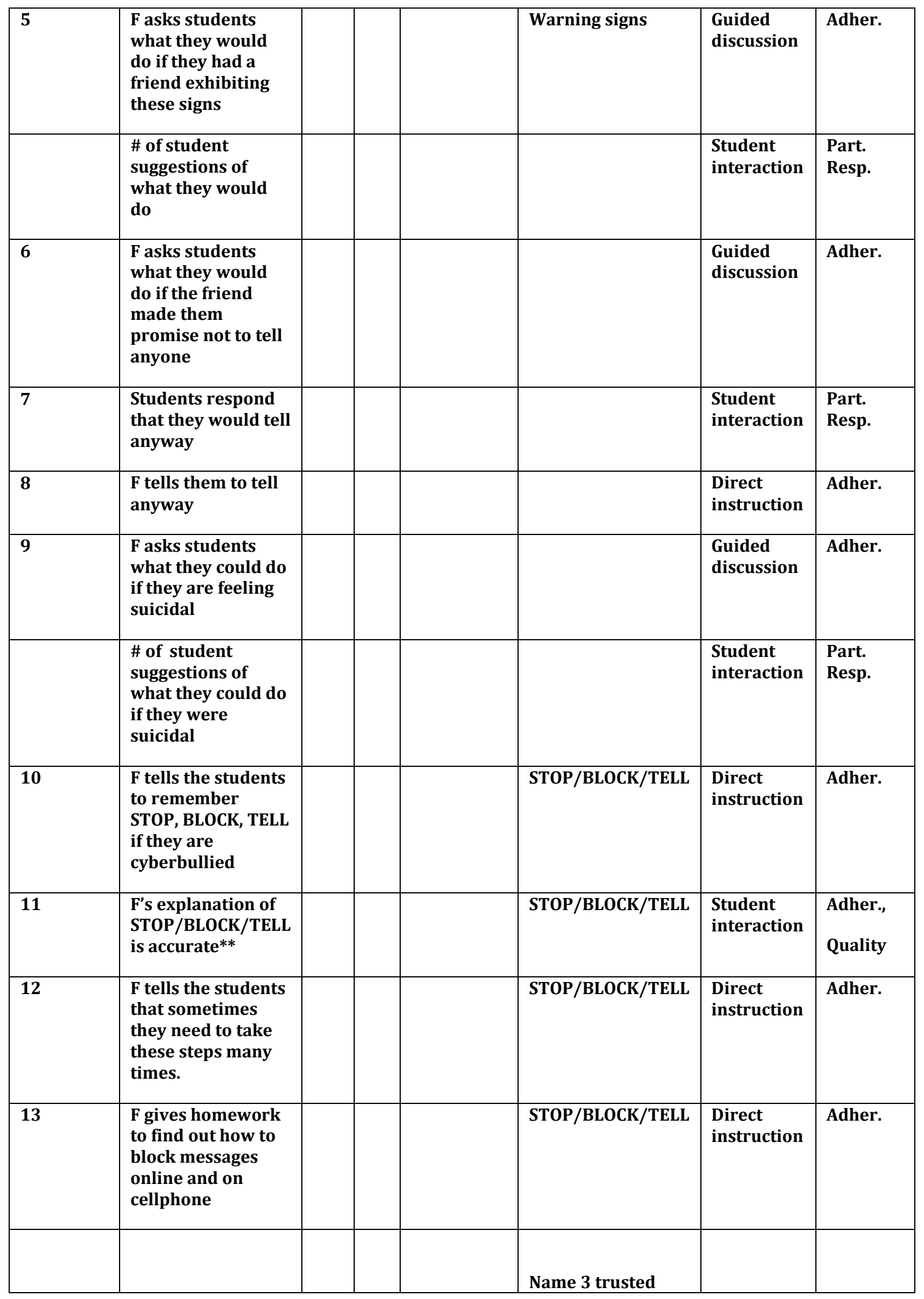




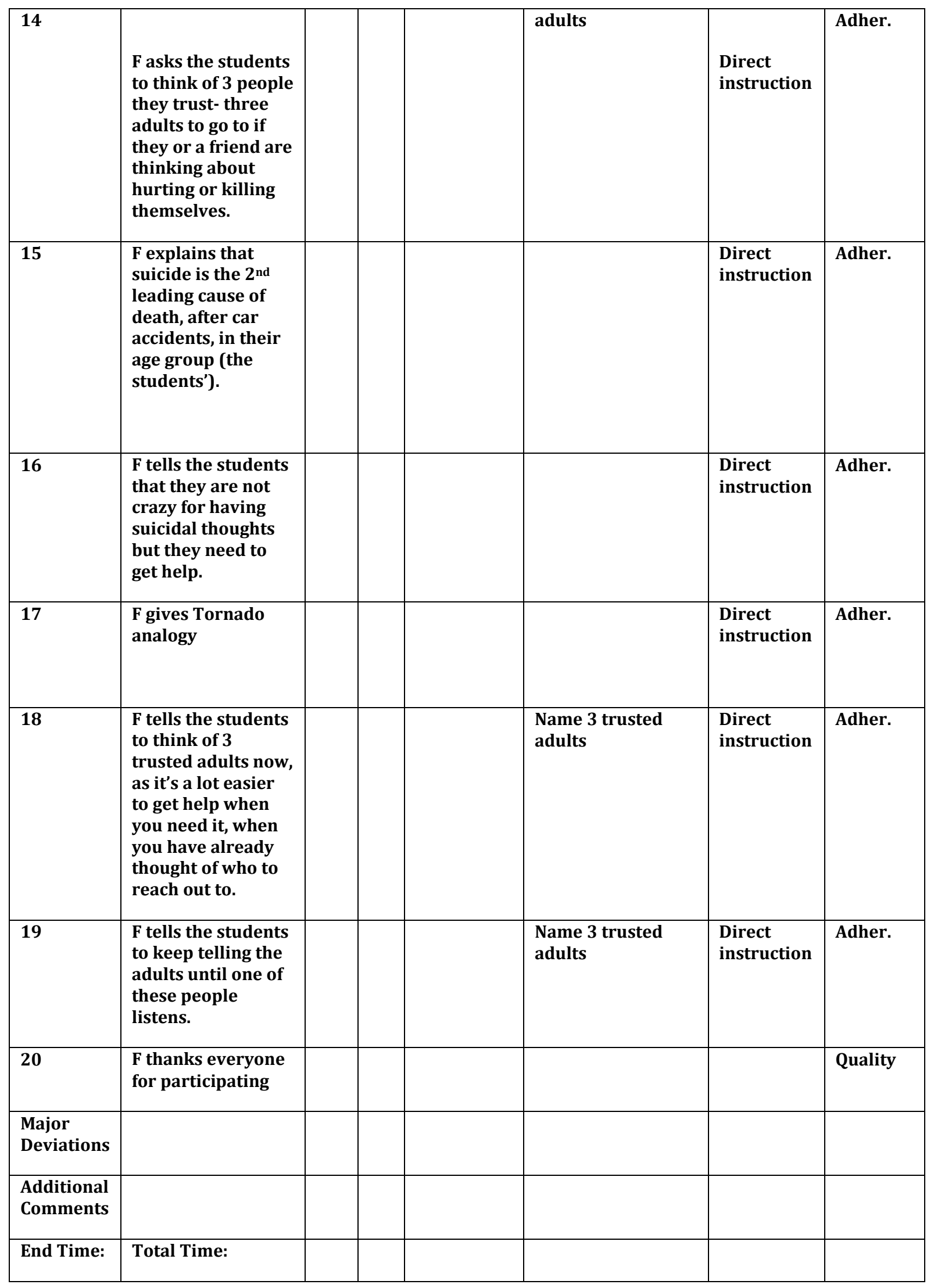




\begin{tabular}{|l|l|l|l|l|l|l|l|}
\hline Total Yes: & Total No: & & & & & & \\
\hline
\end{tabular}

*Warning Signs of Suicide: Missing field hockey practice (stopping activities), not interacting with Mom and Abby (stopping interaction with friends and family), her appearance declined (Change in appearance), her mood changed from happy to depressed (Change in mood), she stopped doing her homework (Decline in schoolwork)

**Accurate description of STOP/BLOCK/TELL- STOP engaging with the bully and don't respond. BLOCK messages from that sender. TELL an adult you trust.

Additional comments regarding the implementation of intervention: 
APPENDIX 3

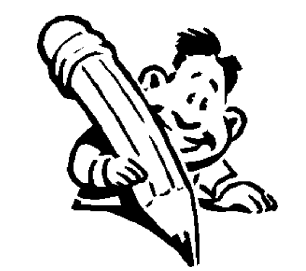

\section{PILOT}

Knowledge of Cyberbullying and Suicide Awareness

These questions are about YOU and safety in YOUR SCHOOL. Answer each item as best you can. Please be honest with your answers.

Your answers will not be shared with anyone at your school. Thank you for your help!

\section{Part I}

In the past school year, have you received:

1. Written materials about cyberbullying?

$\square$ Yes $\square$ No

2. Classroom lessons about cyberbullying?

$\square$ Yes $\square$ No

3. Written materials about suicide awareness?

$\square$ Yes $\square$ No 
4. Classroom lessons about suicide awareness?

$\square$ Yes $\square$ No

At any point during your school career (current or past school years), have you:

5. Seen an interactive play about cyberbullying?

$\square$ Yes $\square$ No

\section{Part II}

\section{Please choose the BEST answer to each question below:}

6. If an anonymous person sent you text threatening to beat you up after school, which of the following would be the BEST strategy to deal with the situation:

$\square$ Try and find out who the person is and confront them in person

$\square$ Stay home from school for the next week

$\square$ Contact your cell phone provider to block the person from sending you

more messages

$\square$ Forward the message to a friend

$\square$ Write them back a nasty message

7. You emailed a private picture to your boyfriend or girlfriend, and they forwarded it to the entire school. Which of the following would be the BEST strategy to deal with the situation:

$\square$ Report the incident to a trusted adult

$\square$ Ask a friend what to do

$\square$ Transfer to another school

$\square$ Share private photos of them to get even

$\square$ Change your phone number 
8. Someone you don't know keeps texting you, saying that they saw you in the shower in the school locker room. They make comments about your body that make you uncomfortable. Which of the following would be the BEST strategy to deal with the situation: alone

$\square$ Text the person back and tell them they are disgusting and to leave you

$\square$ Forward it to all of your friends and see what they think you should do $\square$ Ignore the texts

$\square$ Stop using the school locker room to shower

$\square$ Try and find out who the person is

\section{Below is a list of scenarios. Please check}

YES, if you think it is a possible warning sign of suicide

$N O$, if you think it is not a possible warning sign

\section{DON"T KNOW, if you're not sure}

9.

Jose goes out and spends his entire paycheck at the mall.

口YES a NO IIDON'T KNOW

10.

Jenny talks to you about how excited she is to go to college next year.

$\square$ YES $\square$ NO $\square$ IDON'T KNOW

11. Sunil, a varsity player, stops going to soccer practice and stops hanging out with his friends on the weekends.

$\square$ YES $\square$ NO $\square$ IDON'T KNOW

12. Kasi used to laugh and smile all the time, but now she seems angry a lot and cries easily over little things.

$\square$ YES $\square$ NO $\square$ IDON'T KNOW 
13. Dana quits cheerleading and joins the debate team.

口YES a NO aIDON'T KNOW

14. Jake plays video games all the time and never goes outside.

$\square$ YES $\square$ NO $\square$ IDON'T KNOW

15. Jairon is eating a lot more than usual.

aYES a NO $\square$ IDON'T KNOW

16. Rosie is on Twitter and Instagram almost all the time and seems to have more "virtual" friends than "real" ones.

$\square$ YES $\square$ NO $\square$ IDON'T KNOW

17. Jordan stops eating dinner with his family and spending time with them on the weekends like he used to do.

$\square$ YES $\square$ NO $\square$ IDON'T KNOW

18.

Mercedes starts spending all of her time training for a

marathon.

$\square$ YES $\square$ NO $\square$ IDON'T KNOW

$19 . \quad$ Tanisha, a straight A student, stops studying and turning her homework.

$\square$ YES $\square$ NO $\square$ IDON'T KNOW

20. Mason starts wearing all black.

口YES a NO IIDON'T KNOW

21. Candace talks about using her dad's gun to kill herself.

$\square$ YES $\square$ NO $\square$ I DON'T KNOW

22. Stephanie stops dressing nicely for school and doesn't look like she brushes her hair.

$\square$ YES $\square$ NO $\square$ I DON'T KNOW 
23. Julian tells you that he doesn't see the point in doing anything anymore.

$\square$ YES $\square$ NO $\square$ IDON'T KNOW

24. Sami stops eating lunch and has lost a lot of weight.

$\square$ YES $\square$ NO $\square$ IDON'T KNOW

25. Charlie starts listening to a lot music with violent and scary lyrics.

口YES a NO $\square$ IDON'T KNOW

26.

Which of the following is the BEST strategy to use if you are concerned because a classmate is showing warning signs of suicide? Choose only ONE answer.

$\square$ Drive them to the hospital

Never leave them alone

$\square$ Tell a trusted adult

Try and talk them out of it

$\square$ Promise not to tell anyone

$\checkmark$ Remind them of everything they have to live for

$\square$ Ignore them

\section{Part III}

27. How willing are you to help a classmate who is being cyberbullied?

$\square$ Very unwilling $\square$ Unwilling $\square$ Willing $\square$ Very willing

28. How confident do you feel in your ability to help a classmate who is being cyberbullied?

$\square$ Very unsure $\square$ Not confident $\square$ Confident $\square$ Very confident

29. How willing are you to help a classmate who is showing the warning signs of suicide? 
$\square$ Very unwilling $\square$ Unwilling $\square$ Willing $\square$ Very willing

30. How confident do you feel in your ability to help a classmate who showing the warning signs of suicide?

$\square$ Very unsure $\square$ Not confident $\square$ Confident $\square$ Very confident

\section{Part IV}

The following questions have to do with your opinion of Hannah, the girl in the play who was cyberbullied

31. I saw parts of myself in Hannah

$\square$ Strongly Agree $\square$ Agree $\square \quad$ Disagree $\square$ Strongly Disagree

32. I can imagine myself being in the same situation Hannah was in

$\square$ Strongly Agree $\square$ Agree $\square \quad$ Disagree $\square$ Strongly Disagree

33. I can imagine myself doing the same things Hannah did, in reaction to being cyberbullied

$\square$ Strongly Agree $\square$ Agree $\square \quad$ Disagree $\square$ Strongly Disagree

34. I understood the way Hannah felt

$\square$ Strongly Agree $\square$ Agree $\square$ Disagree $\square$ Strongly Disagree

35. I would have handled being cyberbullied differently than how Hannah handles it

$\square$ Strongly Agree $\square$ Agree $\square \quad$ Disagree $\square$ Strongly Disagree

36. I would never react the way Hannah did

$\square$ Strongly Agree $\square$ Agree $\square$ Disagree $\square$ Strongly Disagree

\section{Part V}

These questions tell us something about you. Please check the box next to your answer. 
37. Are you a

$\square \quad$ Male

口 Female

38. What grade are you in?
$\square 5^{\text {th }}$ grade $\square 6^{\text {th }}$ grade $\square 7^{\text {th }}$ grade $\square 8^{\text {th }}$ grade
$\square 9^{\text {th }}$ grade $\square 10$ th grade $\square 11^{\text {th }}$ grade $\square 12^{\text {th }}$ grade

39. Are you

$\square$ A Non-Minority (white)
$\square$ A Minority

The End

Thank you! 
$\underline{\text { Pre Assessment Measure }}$

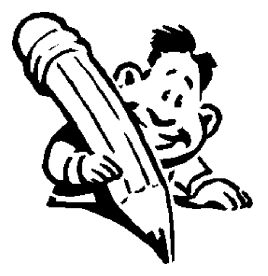

\section{CHOICES}

Knowledge of Cyberbullying and Suicide Awareness

Form I

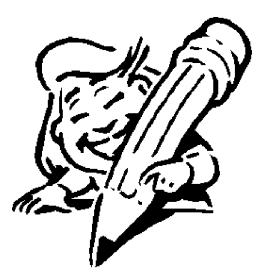

These questions are about YOU and safety in YOUR SCHOOL.

Answer each item as best you can. Please be honest with your answers.

Your answers will not be shared with anyone at your school. Thank you for your help!

Part I

In the past school year, have you received:

40. Written materials about cyberbullying?

$\square$ Yes $\square$ No

41. Classroom lessons about cyberbullying?

$\square$ Yes $\square$ No 
42. Written materials about suicide awareness?

$\square$ Yes $\square$ No

43. Classroom lessons about suicide awareness?

$\square$ Yes $\square$ No

At any point during your school career (current or past school years), have you:

44. Seen an interactive play about cyberbullying?

$\square$ Yes $\square$ No

\section{Part II}

Please choose the BEST answer to each question below:

45. If an anonymous person sent you text threatening to beat you up after school, which of the following would be the BEST strategy to deal with the situation:

$\square$ Try and find out who the person is and confront them in person

Stay home from school for the next week

$\square$ Contact your cell phone provider to block the person from sending you

more messages

$\square$ Forward the message to a friend

$\square$ Write them back a nasty message

46. You emailed a private picture to your boyfriend or girlfriend, and they forwarded it to the entire school. Which of the following would be the BEST strategy to deal with the situation:

$\square$ Report the incident to a trusted adult

Ask a friend what to do

$\square$ Transfer to another school

$\square$ Share private photos of them to get even

$\square$ Change your phone number 
47. Someone you don't know keeps texting you, saying that they saw you in the shower in the school locker room. They make comments about your body that make you uncomfortable. Which of the following would be the BEST strategy to deal with the situation:

alone

Text the person back and tell them they are disgusting and to leave you

$\square$ Forward it to all of your friends and see what they think you should do

Ignore the texts

$\square$ Stop using the school locker room to shower

$\square$ Try and find out who the person is

Below is a list of scenarios. Please check

YES, if you think it is a possible warning sign of suicide

$N O$, if you think it is not a possible warning sign

I DON"T KNOW, if you're not sure

48. Jose goes out and spends his entire paycheck at the mall.

aYES $\square$ NO $\square$ IDON'T KNOW

49. Jenny talks to you about how excited she is to go to college next year.

口YES $\square$ NO $\square$ IDON'T KNOW

50. Sunil, a varsity player, stops going to soccer practice and stops hanging out with his friends on the weekends.

$\square$ YES $\square$ NO $\square$ IDON'T KNOW

51. Kasi used to laugh and smile all the time, but now she seems angry a lot and cries easily over little things.

$\square$ YES $\square$ NO $\square$ IDON'T KNOW

52. Dana quits cheerleading and joins the debate team.

$\square$ YES $\square$ NO $\square$ IDON'T KNOW 
53. Jake plays video games all the time and never goes outside.

$\square$ YES $\square$ NO $\square$ I DON'T KNOW

54. Jairon is eating a lot more than usual.

$\square$ YES $\square$ NO $\square$ IDON'T KNOW

55. Rosie is on Twitter and Instagram almost all the time and seems to have more "virtual" friends than "real" ones.

$\square$ YES $\square$ NO $\square$ IDON'T KNOW

56. Jordan stops eating dinner with his family and spending time with them on the weekends like he used to do.

$\square$ YES $\square$ NO $\square$ IDON'T KNOW

57. Mercedes starts spending all of her time training for a marathon.

口YES $\square$ NO $\square$ IDON'T KNOW

58. Tanisha, a straight A student, stops studying and turning her homework.

$\square$ YES $\square$ NO $\square$ IDON'T KNOW

59. Mason starts wearing all black.

$\square$ YES $\square$ NO $\square$ IDON'T KNOW

60. Candace talks about using her dad's gun to kill herself.

口YES a NO IIDON'T KNOW

61. Stephanie stops dressing nicely for school and doesn't look like she brushes her hair.

$\square$ YES $\square$ NO $\square$ I DON'T KNOW

62. Julian tells you that he doesn't see the point in doing anything anymore. 
63. Sami stops eating lunch and has lost a lot of weight.

$\square$ YES $\square$ NO $\square$ IDON'T KNOw

64. Charlie starts listening to a lot music with violent and scary lyrics.

$\square$ YES $\square$ NO $\square I D O N ’ T$ KNOW

65. Which of the following is the BEST strategy to use if you are concerned because a classmate is showing warning signs of suicide? Choose only ONE answer.

$\square$ Drive them to the hospital

$\square$ Never leave them alone

$\square$ Tell a trusted adult

$\square$ Try and talk them out of it

$\square$ Promise not to tell anyone

$\square$ Remind them of everything they have to live for

$\square$ Ignore them

\section{Part III}

66. How willing are you to help a classmate who is being cyberbullied?

$\square$ Very unwilling $\square$ Unwilling $\square$ Willing $\square$ Very willing

67. How confident do you feel in your ability to help a classmate who is being cyberbullied?

$\square$ Very unsure $\square$ Unsure $\square$ Confident $\square$ Very confident

68. How willing are you to help a classmate who is showing the warning signs of suicide?

$\square$ Very unwilling $\square$ Unwilling $\square$ Willing $\square$ Very willing 
69. How confident do you feel in your ability to help a classmate who showing the warning signs of suicide?

$\square$ Very unsure $\square$ Unsure $\square$ Confident $\square$ Very confident

\section{Part IV}

These questions tell us something about you. Please check the box next to your answer.

70. Are you a $\square$ Male $\square$ Female

71. What grade are you in?

$\square 5^{\text {th }}$ grade $\square 6^{\text {th }}$ grade $\square 7^{\text {th }}$ grade $\square 8^{\text {th }}$ grade

$\square 9^{\text {th }}$ grade $\square 10$ th grade $\square 11^{\text {th }}$ grade $\square 12^{\text {th }}$ grade

72. Are you

$\square$ A Non-Minority (white)
$\square$ A Minority

The End

Thank you! 
Post Assessment

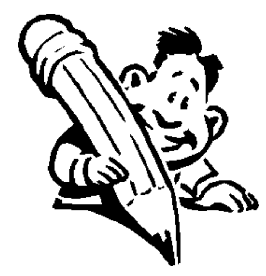

\section{CHOICES}

Knowledge of cyberbullying and suicide awareness

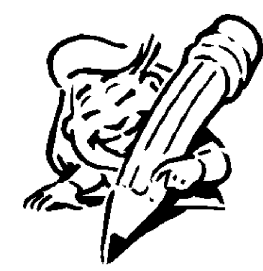

\section{Form II}

These questions are about YOU and safety in YOUR SCHOOL. Answer each item as best you can. Please be honest with your answers.

Your answers will not be shared with anyone at your school. Thank you for your help!

\section{Part I}

During today's program,

1.

Did you raise your hand to volunteer?

$\square \mathrm{YES} \square \mathrm{NO}$

2. Were you called on to share your ideas?

$\square$ YES $\square$ NO

3. Did you get up and try out your ideas?

$\square$ YES $\square$ NO 
4. What was the number one thing you learned today? (Write in the space below)

5. I liked the short play about cyberbullying and suicide, shown at the beginning of today's program
$\square$ Strongly Agree
$\square$ Agree
Disagree $\square$ Strongly Disagree

6. I liked the section of today's program when students could get up and try out their solutions to Hannah's problem
$\square$ Strongly Agree
$\square$ Agree
Disagree $\square$ Strongly Disagree

7. During the section when students could get up and try out their solutions to Hannah's problem, I learned about what to do if about what to do if I am cyberbullied

$\square$ Strongly Agree $\square$ Agree $\square \quad$ Disagree $\square$ Strongly Disagree

8. During the section when students could get up and try out their solutions to Hannah's problem, I learned about what to do if a classmate is showing the warning signs of suicide

$\square$ Strongly Agree $\square$ Agree $\square$ Disagree $\square$ Strongly Disagree

9. I learned what to do if I am cyberbullied directly from the information the women from the theatre company told us

$\square$ Strongly Agree $\square$ Agree $\square \quad$ Disagree $\square$ Strongly Disagree

10. I learned how to recognize the warning signs of suicide directly from the information the women from the theatre company told us

$\square$ Strongly Agree $\square$ Agree $\square$ Disagree $\square$ Strongly Disagree

11. I learned what to do if a classmate is showing the warning signs of suicide directly from the information the women from the theatre company told us

$\square$ Strongly Agree $\square$ Agree $\square \quad$ Disagree $\square$ Strongly Disagree 
12. Which of the following helped you learn DIRECT INFORMATION about suicide and cyberbullying?

$\square$ The short play

$\square$ The student brainstorming and role-playing

$\square$ Direct instruction by the theatre company members

In terms of today's program, when it comes to cyberbullying.

13. I knew everything that was taught already

$\square$ YES $\square$ NO

14. I knew some things already and learned some new things

$\square$ YES $\square$ NO

15. Everything I learned today was new

$\square$ YES $\square$ NO

In terms of today's program, when it comes to suicide awareness,

16. I knew everything that was taught already

$\square$ YES $\square$ NO

17. I knew some things already and learned some new things

$\square$ YES $\square$ NO

18. $\quad$ Everything I learned today was new

$\square$ YES $\square$ NO

19. Overall, rate how much you enjoyed today's program

$\square$ Didn't enjoy it at all

$\square$ Enjoyed it a little bit

$\square$ Neutral

$\square$ Mostly enjoyed it

$\square$ Extremely enjoyed it

\section{Part II}




\section{Please choose the BEST answer to each question below:}

20. Someone keeps tweeting on Twitter that you hooked up with a much older classmate at a party. Which of following would be the BEST strategy to deal with the situation?

$\square$ Send out a tweet denying the rumors

$\square$ Have all of your friends tweet mean things about the person

$\square$ Don't respond to the tweets at all

$\square$ Call the police

$\square$ Don't go to school until you're sure its blown over

21. Someone who won't say who they are keeps sending you G-chat messages telling you that everyone thinks you are stupid and ugly. They also are threatening to jump you at homecoming game. Which of the following would be the best strategy to deal with the situation

Remove that user from your list of friends on G-chat and prevent them

from being added in the future

$\square$ Stop using your computer

$\square$ Have one of your parents send them an email asking them to stop $\square$ Ask them questions until you find out who they are, so you can report them

$\square$ Have all of your friends send the person mean messages

22. An anonymous person posts on Instagram pictures of you in your bathing suit at a friend's pool party. In the posting, they say really mean things about your body. Which of the following would be the best strategy to deal with the situation

$\square$ Call the police

Post a bunch of disgusting pictures and tag the person in all of them

$\square$ Tell a trusted to adult who can help you figure out what to do

Ignore the posting

$\square$ Take a great picture of yourself and post it, so people will know how good you really look 
Below is a list of scenarios. Please check YES, if you think it is a possible warning sign of suicide, NO, if you think it is not a possible warning sign, and I DON"T KNOW, if you're not sure

23. Jack pays for all of his friends to go to the movies and says, "What's the point in saving my money anyway?"

$\square$ YES $\square$ NO $\square$ IDON'T KNOW

24. Ann is really looking forward to her family's trip to Gatlinburg during spring break

$\square$ YES $\square$ NO $\square$ IDON'T KNOW

25. Suchita is a senior point guard on the basketball team and suddenly stops going to practice and doesn't show up for the team's homecoming game

口YES a DO IDON'T KNOW

26. Jason used to love goofing around and cracking jokes, but now he seems to get angry over little things and hardly talks at school anymore

$\square$ YES $\square$ NO $\square$ I DON'T KNOW

27. Lana quits the dance team so she can take a poetry class after school

$\square$ YES $\square$ NO $\square$ IDON'T KNOW

28. Max sits in front of his computer in his room all day long $\square$ YES $\square$ NO $\square$ IDON'T KNOW

29. Ben ate an entire half gallon of ice cream in one sitting $\square$ YES $\square$ NO $\square$ IDON'T KNOW

30. Raia talks more and more to the other people on X-box than she does other people at school

$\square$ YES $\square$ NO $\square$ IDON'T KNOW 
31. Jon stops going to the library and park with his friends after school, which he used to do every day. Now, he just sits in his room by himself

口YES $\square$ NO $\square$ IDON'T KNOW

32. Kayla starts collecting pain pills from her mother's cabinet and tells you she has thought about taking them all at one time

口YES $\square$ NO $\square$ IDON'T KNOW

33. Miller begins getting up at 5 a.m. so that he can swim 2 miles before school

$\square$ YES $\square$ NO $\square$ IDON'T KNOW

34. Malik has been talking about going to college all year and has been studying for the college entry exam. Then, all of a sudden, he stops studying and blows off the test

$\square$ YES $\square$ NO $\square$ IDON'T KNOW

35.

Cam starts wearing a trench coat to school every day

$\square$ YES $\square$ NO $\square$ I DON'T KNOW

36. Jen talks a lot about going to sleep and never waking up

$\square$ YES $\square$ NO $\square$ IDON'T KNOW

37. Jayden seems to have stopped showering and doesn't seem to care whether his clothes are dirty or his hair is washed

$\square$ YES $\square$ NO $\square$ IDON'T KNOW

38. Matt visits his brother's gravesite every day after school. Sometimes, he even skips school to eat lunch there

$\square$ YES $\square$ NO $\square$ IDON'T KNOW

39. April exercises 3 hours a day and seems to be really concerned about how much she weighs 
口YES aNO $\square$ IDON'T KNOW

40. Based on what you've learned from today's program, which of the following is the BEST strategy to use if you see a friend showing the warning signs of suicide

$\square$ Don't let them stay by themselves

$\square$ Tell them how many people will miss them

$\square$ Swear to them that you'll keep it a secret

$\square$ Let your parents know what is going on

$\square$ Write encouraging messages on Facebook to cheer them up

$\square$ Try and decide if they're doing it for attention

\section{Part III}

The following questions have to do with your opinion of Hannah, the girl in the play who was cyberbullied

41. I saw parts of myself in Hannah

$\square$ Strongly Agree $\square$ Agree $\square$ Disagree $\square$ Strongly Disagree

42. I can imagine myself being in the same situation Hannah was in

$\square$ Strongly Agree $\square$ Agree $\square$ Disagree $\square$ Strongly Disagree

43. I can imagine myself doing the same things Hannah did, in reaction to being cyberbullied

$\square$ Strongly Agree $\square$ Agree $\square \quad$ Disagree $\square$ Strongly Disagree

44. I understood the way Hannah felt

$\square$ Strongly Agree $\square$ Agree $\square$ Disagree $\square$ Strongly Disagree

45. I would have handled being cyberbullied differently than how Hannah handles it
$\square$ Strongly Agree
$\square$ Agree
Disagree $\square$ Strongly Disagree 
46. I would never react the way Hannah did $\square$ Strongly Agree $\square$ Agree $\square \quad$ Disagree $\square$ Strongly Disagree

\section{Part IV}

After participating in today's program,

47. How willing are you to help a classmate who is being cyberbullied?

$\square$ Very unwilling $\square$ Unwilling $\square$ Willing $\square$ Very willing

48. How confident do you feel in your ability to help a classmate who is being cyberbullied?

$\square$ Very unsure $\square$ Unsure $\square$ Confident $\square$ Very confident

49. How willing are you to help a classmate who is showing the warning signs of suicide?

$\square$ Very unwilling $\square$ Unwilling $\square$ Willing $\square$ Very willing

50. How confident do you feel in your ability to help a classmate who showing the warning signs of suicide?

$\square$ Very unsure $\square$ Unsure $\square$ Confident $\square$ Very confident

\section{Part V}

These questions tell us something about you. Please check the box next to your answer.

51. Are you a $\square$ Male $\square$ Female

52. What grade are you in?

$\square 5^{\text {th }}$ grade $\square 6^{\text {th }}$ grade $\square 7^{\text {th }}$ grade $\square 8^{\text {th }}$ grade

$\square 9^{\text {th }}$ grade $\square 10$ th grade $\square 11^{\text {th }}$ grade $\square 12^{\text {th }}$ grade 
53. Are you

$\square$ A Non-Minority (white)
$\square$ A Minority

The End

Thank you! 


\title{
CURRICULUM VITAE
}

\section{Kathryn Hopkins}

\author{
134 Fenley Avenue
}

Louisville, KY 40206

513-646-7297

Email: katy.hopkins@ louisville.edu

\section{$\underline{\text { Educational History }}$}

\section{University of Louisville, Louisville, Kentucky, APA Accredited August 2009- present \\ Ph. D. Candidate in Counseling Psychology (degree anticipated December 2014) \\ Dissertation Title- A program evaluation of a brief theatre-based cyberbullying and suicide prevention program for middle and high school students.}

\section{New York University, New York, NY}

BFA with Honors, 2004

Major: Theatre-Acting and Directing

\section{Professional Experience}

\section{Clinical Coordinator, Instructor}

Department of Counseling, Counseling Psychology and College Student Personnel, University of Louisville

Louisville, KY

August 2014present

- Courses taught: ECPY 648 Intelligence Assessment, ECPY 621 Differential Diagnosis, ECPY 619 Theories and Techniques of Counseling 
- Clinical coordination of 50+ practica placements per semester for counseling psychology and clinical mental health masters and doctoral students

- Postdoctoral intern for the Cardinal Success Program @ Shawnee

Pre Doctoral Intern, Child and Family Psychology Emphasis Southern Arizona Psychology Internship Consortium, La Frontera, Inc. APA Accredited

Tucson, AZ

2013-present

July

- Provide individual, family, and group therapy in a community mental health center setting for children and adolescents.

- Administer psychological, neuropsychological, and intellectual testing batteries for children and adults and integrate results in comprehensive written reports

- Provide supervision and consultation for clinical treatment teams.

- Provide professional development trainings for agency and local mental health providers in the following areas: Strengths-based assessment and treatment; Trauma informed care; Resiliency and Empathy; Changes in the DSM-5; Integrated behavioral health; Domestic violence assessment; Bullying prevention.

- Design and implement outcome evaluations for clinical services

- 6 month minor rotation in equine assisted psychotherapy for adults with SMI in a residential treatment setting

- 6 month minor rotation in training and program development

Counselor/Graduate Assistant

University of Louisville College Counseling Center

Louisville, KY

January 2013-

May 2013

- Provided individual, couples and group therapy in a public university counseling center setting.

- Administered psychological and intellectual testing batteries and integrated results in comprehensive written reports.

\section{Adjunct Professor}

Department of Teaching and Learning, University of Louisville, Louisville, KY

August 2012-

December 2012

- Course taught: EDTL 107 Human Development for Future Educators 
Assessment and Counseling Intern

Weisskopf Child Evaluation Center, University of Louisville School of

Medicine, Department of Pediatrics

Louisville, KY

May 2012-

December 2012

- Administered psychological, neuropsychological and intellectual testing batteries to children, adolescents and adults as part of a multidisciplinary team which included psychologists, pediatricians, nutritionists, occupational therapist and speech and language pathologists.

- Participated in multidisciplinary feeding evaluations of children and adolescents.

- Provided mental status exams for patients receiving genetic counseling.

- Provided counseling interventions to children with developmental, learning and behavioral disorders who have co-morbid medical conditions.

\section{Counseling Intern}

Communicare, Inc. Elizabethtown, KY

September 2011-

April 2012

- Provided individual, group and family therapy to children and adults in a rural community mental health setting.

- Served as a member of the early childhood treatment team, focusing on behavioral and family interventions for children ages 0-5.

Counseling and Assessment Intern

Maryhurst, Inc. Louisville, KY

May 2010-

August 2011

- Provided individual, family, and group therapy to adolescent girls in a residential treatment setting.

- Administered psychological and intellectual testing batteries and integrate results in comprehensive written reports

- Focused on trauma-focused treatment with developmentally delayed and sexually reactive populations.

Graduate Assistant

Office of Educator Development and Clinical Placement, University of Louisville, Louisville, KY

2009-2012 
- Coordinated student placements in local elementary, middle, and high schools for teacher observation.

- Communicated with $\mathrm{U}$ of L students to prepare and assist them through placements as needed.

- Communicated with local school officials to coordinate student placements and maintain university-school relationships.

\section{Trainer/Coach}

2008-2009 LifestreamSupport, LLC Cincinnati, OH

- Parenting coach for online website.

- Trained counselors and coaches in web-based technology.

\section{Education Director}

2007- 2008 Women In Safe Homes, Ketchikan, Alaska

- Provided oversight and development of educational outreach program in rural Southeast Alaska for victims and survivors of domestic violence, sexual assault and other violent crimes.

- Transitioned agency from intervention-based reactive model to proactive prevention-based approach in developing a continuum of safety.

- Developed, facilitated and evaluated behaviorally-based skills training for children, adolescents and adults

- Supervised staff in providing prevention and child advocacy services.

- Taught key interventions for clients including establishment of safety, trauma-processing, self-care, and cognitive-behavioral skill-building

- Enhanced multicultural competencies for mental-health providers in Alaska regarding victim advocacy, dynamics of violent crimes, artsbased approaches to primary prevention education, and mandated reporting

- Devlopped and implemented outcome evaluation of curricula to assure program efficacy for a culturally diverse population

- Administered school-wide survey on bullying; presented statistical analysis of findings to school administration, resulting in adoption of Bullying Prevention Program

- Facilitated strategic planning sessions to benefit community agencies throughout Alaska

- Provided comprehensive quarterly and annual reports for state funding agency

- Wrote grants to secure private, state and federal funding for the agency

\section{Children's Program Director}

2006- 2007

Women In Safe Homes, Ketchikan, AK

- Coordinated services to children and their families residing in an emergency shelter setting and in the community at large.

- Supervised child advocacy team.

- Implemented Evidenced-Based educational and support groups for child and teen survivors of domestic violence, sexual assault and child abuse

- Educated and supported parents while working on rebuilding family and community values

- Provided psycho-education to children and adolescents on personal safety, conflict resolution skills and problem solving techniques 
- Organized and expanded data base and library of materials regarding violent crime prevention for community-wide use

- Provide primary prevention education and program evaluation to area preschool and elementary schools

- Provided comprehensive quarterly and annual reports for state funding agency

\section{Program Administrator}

2004-2005

University of Cincinnati/Peace Village India/ TTS Schools, Uttar Pradesh, India

- Established a sustainable program focusing on improving relations between Hindu and Muslim communities, as well as between genders in rural northern India, through artistic and cultural exchange in two schools.

- Taught classes with an emphasis on cultural communication to children ages 2 yrs-18yrs

- Coordinated individualized schedules and curriculum for families and children

- Partnered with administration and teachers, implementing alternative methods of teaching and learning

- Conducted arts and cultural workshops with schools and community including writing, directing and producing a bi-lingual play, performed for audience of over 4000 and televised nationally

- Organized social, school and community events

- Curriculum development

- Multi-media programming- audio-visual tools, editing software

Luekopp Arts Therapy Program Director

University of Witswatersandl Leukopp Correctional Facility,

Johannesburg, South Africa

- Designed and implemented an arts-based therapeutic program in a men's juvenile prison ward for violent offenders, successfully creating a sustainable program and a continuing relationship between local university and near-by prison.

- Developped programming for bi-weekly group sessions for 10- 12 offenders/inmates

- Conducted sessions focusing on anger management, effective modes of communication, conflict resolution, personal responsibility, and AIDS awareness

- Offered opportunity for participants to express issues related to prevention of cycle of violence, cultural identity and acceptance of alternative values

Teaching Artist

University of Cincinnati/ Art In The Market, Cincinnati, $\mathrm{OH}$

- Established and facilitated a university-sponsored street theatre program in an urban, low-income neighborhood.

- Taught "at-risk" youth fundamentals of street theatre and poetry performance aimed at community pride and personal empowerment

- Created, facilitated and directed community-based theatre projects that reflected both the needs and the assets of the community 
- Focused on community healing after fall-out from race riots of 2001

Student Administrator

$2001-$

2003 New York University, TSOA Office of Community Connection, New York, New York

- Facilitated and supported collaborative programming among New York University students, faculty and New York area artists.

- Created, supported and expanded initiatives that engaged students in community-based arts projects;

- Identify and develop programming aimed at healing a post 9/11 New York

\section{$\underline{\text { Publications }}$}

Cunningham, N., Dewell, J., and Hopkins, K. (in progress). Early indicators of sexual harassment in early adolescent. Manuscript in preparation for submission for publication in several peer-reviewed journals.

Hopkins, K (2012). Fostering tolerance: Ways parents and kids can stand up to bullying. Children's Craniofacial Association Quarterly Newsletter.

Hopkins, K. (2010). Microfinance and women in the developing world: Implications for psychologists and counselors. International Association for Applied Psychologists Spring Newsletter.

Hopkins, K. (May, 2008). Bullying: correlations and trends in a southern southeast Alaskan Catholic elementary school. Report used by Holy Name School for use in seeking funding for purchase of violence prevention curriculum. Ketchikan, Alaska.

\section{$\underline{\text { Professional Presentations and Trainings }}$}

Hopkins, K. (March 2014) Trauma Informed Care. Presentation as part of Best Practices Series for local mental health providers at La Frontera, Inc., Tucson, Arizona.

Hopkins, K. (February 2014) Addressing bullying: Treatment strategies for both the bully and the bullied. CE training at Challenges in Psychological Practice conference. Tucson, Arizona. 
Hopkins, K. (February 2014) Assessment and diagnostic changes in the DSM 5. Presentation for local mental health providers at La Frontera, Inc., Tucson, Arizona.

Hopkins, K. (December 2013) Promoting empathy and resiliency in clients and ourselves. Training for local mental health providers at La Frontera, Inc., Tucson, Arizona.

Cunningham, N., Hopkins, K., Neinhuis, J. (August, 2011) Indicators of sexual harassment in early adolescence. Poster presentation at the 2011 annual conference of the American Psychological Association, Washington, D.C.

Cunningham, N., Hopkins, K., Neinhuis, J., Hessler, B. (August, 2010) Using social network analysis to examine victims of bullying. Poster presentation at the 2010 annual conference of the American Psychological Association, San Diego, California.

Cunningham, N., Hopkins, K., Neinhuis, J., Hessler, B. (August, 2010) Examining participant roles in early adolescent bullying. Poster presentation at the 2010 annual conference of the American Psychological Association, San Diego, California.

Cunningham, N., Hopkins, K., Neinhuis, J., Hessler, B. (May, 2010) Using social network analysis to examine victims of bullying. Poster presentation at the 2010 annual conference of the Kentucky Psychological Association, San Diego, California.

Hopkins, K. \& Irwin, J. (June, 2008). Alaskan's Speak Up! Prevention and Intervention of Vulnerable Adult Abuse. Advocacy training for people with disabilities, Southeast Alaska Independent Living, Ketchikan, Alaska.

Hopkins, K., Irwin, J. White, N. (June, 2008). Legal Advocacy for People with Disabilities. Training for people with disabilities, Southeast Alaska Independent Living, Ketchikan, Alaska.

Hopkins, K. (June, 2008). Child Abuse Indicators. Presented to advocates, Women In Safe Homes, Ketchikan, Alaska.

Hopkins, K. (June, 2008). Mandated Reporting. Presented to advocates, Women In Safe Homes, Ketchikan, Alaska.

Grassgreen, L., Hopkins, K. \& Nasiah, A. (May, 2008). Primary Prevention Strategies in Rural Southeast Alaska. Presented at the Alaska Council on Domestic Violence and Sexual Assault Tribal State Forum, Juneau, Alaska.

Hopkins, K. (May, 2008). Community Approaches to Serving Rural and Alaska 
Native Victim/Survivors of Domestic Violence. Facilitated strategic planning session at the Alaska Council on Domestic Violence and Sexual Assault Tribal State Forum, Juneau, Alaska.

Hopkins, K. (May, 2008). DVSA Resources. Presented at the Community Partnerships Conference, Ted Ferry Civic Center, Ketchikan, Alaska.

Hopkins, K. (April, 2008). Steps to Respect. Train-the- trainer workshop, Ketchikan High School, Ketchikan, Alaska.

Hopkins, K. (April 2008). Bullying Intervention and Prevention for Educators, Presented to Holy Name Elementary staff, WISH, Ketchikan, Alaska.

Hopkins, K. (March, 2008). Domestic Violence Indicators and Interventions for Medical Professionals and First Responders. Presented to US Coast Guard medical staff, United States Coast Guard Base, Ketchikan, Alaska.

Hopkins, K. \& Michalsen, N. (February, 2008). Mandated Reporting for Educator. Staff training, Ketchikan High School, Ketchikan, Alaska.

Hopkins, K. \& Michalsen, N. (February, 2008). Domestic Violence and Child Abuse. Staff training, Ketchikan High School, Ketchikan, Alaska.

Hopkins, K. (January, 2008). Safe Dates. Train-the-trainer workshop for primary prevention specialists, Craig Public Health, Craig, Alaska.

Hopkins, K. (January, 2008). Talking About Touching. Train-the-trainer workshop for primary prevention specialists, Craig Public Health, Craig, Alaska.

Hopkins, K. (January, 2008). Child Abuse Indicators. Presented to primary prevention specialists, Craig Public Health, Craig, Alaska.

Hopkins, K. (January, 2008). Dynamics of Power and Control. Presented to primary prevention specialists, Craig Public Health, Craig, Alaska.

Hopkins, K. (January, 2008). Advocating for Victim/Survivors of Domestic Violence and Sexual Assault. Presented to primary prevention specialists, Craig Public Health, Craig, Alaska.

Hopkins, K. (January, 2008). Building Effective Partnerships with Schools. Presented to primary prevention specialists, Craig Public Health, Craig, Alaska.

Hopkins, K. (January, 2008). Arts-Based Approaches to Violence Prevention Education. Presented to primary prevention specialists, Craig Public Health, Craig, Alaska. 
Hopkins, K. (January, 2008). Engaging Men and Boys in Ending Men's Violence Towards Women. Presented to primary prevention specialists, Craig Public Health, Craig, Alaska.

Hopkins, K. \& Michalsen, N. (October, 2007). Rural Advocacy for Victim/Survivors of Domestic Violence and Sexual Assault. Volunteer advocate training, Petersburg Mental Health, Petersburg, Alaska.

Hopkins, K. \& Michalsen, N. (May, 2007). Dynamics of Power and Control in Intimate Partner Violence. Presentation for parents and teachers, Metlakatla Head Start, Metlakatla Indian Reservation, Metlakatla, Alaska.

Hopkins, K. (April, 2007). Arts-Based Approaches to Violence Prevention Education. Workshop presented at the Alaska Network on Domestic Violence and Sexual Assault Biennial Conference, Anchorage, Alaska.

\section{$\underline{\text { School-Based Presentations and Trainings }}$}

Hopkins, K., Neinhuis, J. (September 2010) Bullying Prevention. 10 week intervention for $5^{\text {th }}$ graders, St. Aloysius Catholic School, Pee Wee Valley, KY.

Hopkins, K. (March 2010) Bullying Prevention. 10 week intervention for $6^{\text {th }}$ graders, St. Agnes Catholic School, Louisville, KY

Cunningham, N., Delaney, N., Hopkins, K. (October 2009) Bullying Prevention. 10 week intervention for $5^{\text {th }} \quad$ graders, St. Aloysius Catholic School, Pee Wee Valley, KY.

Cunningham, N., Delaney, N., Hopkins, K. (September 2009) Bullying Prevention. 10 week intervention for $9^{\text {th }} \quad$ graders, Liberty High School, Louisville, KY

Hopkins, K. (June 2008). Peer Advocacy. Training for teen residents, Ketchikan Regional Youth Facility, Ketchikan, Alaska.

Custer, J. \& Hopkins, K. (May, 2008). Fetal Alcohol Spectrum Disorder. Classroom presentations for $9^{\text {th }}$ grade health classes, Ketchikan High School, Ketchikan, Alaska.

Hopkins, K. (May, 2008). Dating Violence and Healthy Relationships. Classroom 
presentations for $9^{\text {th }}$ grade students, Petersburg Middle and High School, Petersburg, Alaska.

Hopkins, K. (May, 2008). Bullying Prevention. 2-day workshop for $7^{\text {th }}$ and 8 th grade students, Petersburg Middle and High School, Petersburg, Alaska.

Hopkins, K. (April, 2008). Empathy Training. 4-day classroom workshops for 1st grade students, Houghtaling Elementary, Ketchikan, Alaska.

Hopkins, K. (March, 2008). Dating Violence and Healthy Relationships. Classroom presentations for $9^{\text {th }}$ grade health classes, Ketchikan High School, Ketchikan, Alaska.

Hopkins, K. (February, 2008). Personal Safety. 4-day classroom workshops for kindergarten students, Houghtaling Elementary, Ketchikan, Alaska.

Hopkins, K. (January, 2008). Personal Safety. One-week classroom workshops for grades pre-K through 6, Holy Name Elementary, Ketchikan, Alaska.

Hopkins, K. (January, 2008). Bullying Prevention. One week classroom workshops for grades 2 through 6, Holy Name Elementary, Ketchikan, Alaska.

Hopkins, K. (January, 2008). Empathy Training. One week classroom workshops for grades pre-K through 1, Holy Name Elementary, Ketchikan, Alaska.

Hopkins, K. (January, 2008). Fetal Alcohol Spectrum Disorder. Classroom presentations for $9^{\text {th }}$ grade health classes, Ketchikan High School, Ketchikan, Alaska.

Hopkins, K. \& Michalsen, N. (October, 2007). Dating Violence and Healthy Relationships. Classroom presentations for $7,8,9^{\text {th }}$ grade students, Petersburg Middle and High School, Petersburg, Alaska.

Hopkins, K. \& Michalsen, N. (May, 2007). Personal Safety. Classroom presentation for Metlakatla Head Start 3 and 4 year-olds, Metlakatla Indian Reservation, Metlakatla, Alaska.

Hopkins, K. (March, 2007). Solve It Baby! Problem Solving and Conflict Resolution. Three week classroom workshop with $3^{\text {rd }}$ grade, Houghtaling Elementary, Ketchikan, Alaska.

Hopkins, K. (March, 2007). Second Step. One week classroom workshop focusing on empathy building with 2nd grade, Houghtaling Elementary, Ketchikan, Alaska. 
Hopkins, K. (February, 2007). Problem Solving and Conflict Resolution. One week classroom workshop with 1st grade, Houghtaling Elementary, Ketchikan, Alaska.

\section{Curriculum and Program Development}

Hopkins, K. (May, 2007). Arts-Based Approaches to Violence Prevention Education. Curriculum for use by advocates and primary prevention staff. Alaska Network on Domestic Violence and Sexual Assault. Anchorage, Alaska.

Hopkins, K. (March, 2007). Solve It Baby! Problem Solving and Conflict Resolution. Curriculum for use in elementary classrooms. Ketchikan, Alaska.

Hopkins, K. (September, 2006). Female Adolescent Support Group. Curriculum for use by advocates for female survivors of domestic violence and sexual assault, ages 11-18, Women In Safe Homes. Ketchikan, Alaska.

Hopkins, K. (September, 2006). Female Adolescent Support Group. Curriculum for use by advocates for male survivors of domestic violence and sexual assault, ages 11-18, Women In Safe Homes. Ketchikan, Alaska.

Hopkins, K. (September, 2006). Children's Support Group. Curriculum for use by advocates for child survivors of domestic violence and sexual assault, ages 3-10, Women In Safe Homes. Ketchikan, Alaska.

Hopkins. A \& Hopkins, K. (July, 2004). Peace Village India. Program promoting cultural exchange, non-violent communication and alternative methods of teaching and learning. University of Cincinnati. Faizabad, India.

Hopkins, K., Moyo, S. \& Sharpe, J. (January, 2004). Theatre and Therapy.

Sustainable

program development of arts- based therapeutic group in juvenile ward of men's correctional facility. University of Witswatersrand. Johannesburg, South Africa.

Hopkins. K. (June, 2003). Street Theatre for Non-Actors. Program for inner-city youth. Art In The Market. University of Cincinnati. Cincinnati, Ohio.

\section{Professional Affiliations}

Kentucky Psychological Association 
American Psychological Association Graduate Student, Divisions 44, 35, 37

Alaska Network on Domestic Violence and Sexual Assault, Statewide Training Team 2006-present

Revilla Island Prevention Coalition

2006-2008

Alaska Network on Domestic Violence and Sexual Assault Biennial Conference Faculty Member

2007, 2008

Ketchikan Wellness Coalition, Strategic Planning Team Member 2007-2008

Ketchikan Domestic Violence Task Force Member 2006-2008

Southeast Alaska Office of Children's Services Continuous Quality Improvement Team Member

2007-2008

Alaska Network on Domestic Violence and Sexual Assault Youth Leadership Conference Planning Committee Member 2008

Ketchikan Women of Distinction Event Planning Committee Member 2008

weLEAD Saxman Photovoice Project Director 2006-2008

Big Brothers/Big Sisters Volunteer

2006-2008

Human Rights Commission Officer, Women in Safe Homes 2008

\section{$\underline{\text { Awards and Honors }}$}

Graduate Student Spotlight Award, University of Louisville

College of Education and Human Development Doctoral Student Scholarship, University of Louisville 
Founder's Day Award, New York University 